\title{
An ecological study of Panax quinquefolius in central Appalachia: Seedling growth, harvest impacts and geographic variation in demography
}

\author{
Martha E. Van der Voort \\ West Virginia University
}

Follow this and additional works at: https://researchrepository.wvu.edu/etd

\author{
Recommended Citation \\ Van der Voort, Martha E., "An ecological study of Panax quinquefolius in central Appalachia: Seedling \\ growth, harvest impacts and geographic variation in demography" (2005). Graduate Theses, \\ Dissertations, and Problem Reports. 2343. \\ https://researchrepository.wvu.edu/etd/2343
}

This Dissertation is protected by copyright and/or related rights. It has been brought to you by the The Research Repository @ WVU with permission from the rights-holder(s). You are free to use this Dissertation in any way that is permitted by the copyright and related rights legislation that applies to your use. For other uses you must obtain permission from the rights-holder(s) directly, unless additional rights are indicated by a Creative Commons license in the record and/ or on the work itself. This Dissertation has been accepted for inclusion in WVU Graduate Theses, Dissertations, and Problem Reports collection by an authorized administrator of The Research Repository @ WVU. For more information, please contact researchrepository@mail.wvu.edu. 
An ecological study of Panax quinquefolius in central Appalachia: seedling growth, harvest impacts and geographic variation in demography

\author{
Martha E. Van der Voort
}

\author{
Dissertation submitted to the \\ Eberly College of Arts and Sciences \\ at West Virginia University \\ in partial fulfillment of the requirements \\ for the degree of
}
Doctor of Philosophy
in Biology

\author{
James B. McGraw, Ph.D., Chair \\ Brent Bailey, Ph.D. \\ Donna I. Ford-Werntz, Ph.D. \\ Ray Hicks, Jr., Ph.D. \\ Richard B. Thomas, Ph.D.
}

Department of Biology

\author{
Morgantown, West Virginia \\ 2005
}

Keywords: American ginseng, demographic matrix modeling, seedling ecology, plant conservation biology, wild-harvested products, harvest impacts, vegetative reproduction 


\section{ABSTRACT}

An ecological study of Panax quinquefolius in central Appalachia: seedling growth, harvest impacts and geographic variation in demography

\section{Martha E. Van der Voort}

American ginseng (Panax quinquefolius L.) is a long-lived, slow-maturing understory perennial herb found in eastern North American forests. The economic value of $P$. quinquefolius on the world market has remained strong for nearly 300 years. It has high economic and social value in the central Appalachians as well. Persistent harvest of ginseng combined with habitat loss has reduced populations in the wild, threatening the future of the species and its continued harvest. American ginseng was placed on the CITES Appendix II list in 1973 due to population declines. These concerns led to a series of studies investigating the population dynamics of ginseng in the center of its range. In the first study, I found that populations in the range center were projected to decline at a rate of 7 percent per year while those at the northern margin were projected to increase at a rate of 3 percent per year. The causes for the difference included significantly lower fertilities in the range center, and lower stasis and growth in all classes but growth from seedlings to 1-leaf plants in the populations in West Virginia. In the second study, the size structure of a wild population of ginseng was slow to recover following a fully destructive harvest, but the presence of seeds in the soil conveyed some resilience to the removal of all juvenile and adult plants from a site. In the third study, a seed bank viable beyond 20 months was documented for the first time for $P$. quinquefolius, indicating the need to restructure future demographic models to incorporate seed dormancy. In a series of harvester simulation studies, I found that harvester behavior dramatically impacts projected population growth rates of ginseng. By planting seeds at a depth of $2 \mathrm{~cm}$, harvesters can reverse declining population growth rates. Current regulations for legal harvest in nearly three quarters (i.e., $71 \%$ ) of the states in the range center are not adequate to protect $P$. quinquefolius in the long-term. This research led to the improvement of demographic models and documented the critical role that harvesters can play in maintaining healthy populations of wild ginseng. 


\section{DEDICATION}

This work is lovingly dedicated to Helen Baker Straley, Harriet Straley Clowes, Jan Van der Voort Portman and Willa Baker Egan 


\section{ACKNOWLEDGMENTS}

Hillary was talking about raising children when she said "it takes a village..." In the case of my dissertation, it has taken a village to complete, in part because of a child, my daughter, Willa. We headed out for my 1999 field season when she was only 5 weeks old-the overwhelming support and generous help I received that summer from family and friends will always be remembered and held dear.

I want to thank my committee members, Brent Bailey, Donna Ford-Werntz, Ray Hicks and Richard Thomas, for their guidance and thoughtful suggestions throughout my research and preparation of my final document. Very special thanks to my committee chair, Jim McGraw, who stayed the distance with me in spite of my northward migration. The intellectual stimulation and creative thinking have taught me so much, thank you.

There are many to thank for their assistance in the field and the lab over the years: Mary Deinlein, Bob Driscole, Mary Ann Fajvan, Bill Grafton, Erin Hackney, Iris, Gera Jochum, Rebecca Kenyon, Rick Landenberger, Chris Packert, Jan Portman and family, Roo, Suzanne Sanders, Mindi Spencer. Special thanks to Mary Ann Furedi who was incredibly helpful during the last mile. And many thanks to staff in the Department of Biology of WVU, especially Marlene DeWitt, Pat Lutsie and Heather Malone. Enormous thanks to Kathy Fletcher of WVU's OIT.

Huge thanks to my Morgantown support group: Annie, David and Emma Berry, Laurie Cohen, Jeanne and Joe Hagan and family, Ida Holaskova, Eileen and Stan Schmidt and family, Gale Simplicio and Jorge Flores. Special thanks to David and Cathy Samuel and their unwavering support. My 'out-of-town support groups' were a constant source of encouragement as well: the Maine writer's group (l'd love to meet at 6:30am and not discuss my dissertation), Cassie Hennessey and Diane Wood.

There are several individuals who time and again, went far beyond the call of friendship during this process. Marty and Max Lees provided airport shuttle service, free car rentals, numerous delicious meals and spectacular hospitality for many years - I will sorely miss having the excuse to fly into Pittsburgh airport on a somewhat regular basis. My sister and brother, Jan Portman and Mark Van der Voort always had encouraging words regardless of my frame of mind. My folks, Harriet and George Clowes have provided constant support throughout the years. In this project that ranged from data collection in the field to childcare-the assistance was invaluable and countless times it made the difference in terms of progress. An entire chapter could be devoted to Brent Bailey and Liz Cohen and their immediate and extended family. From their initial guidance in choosing a dog at the pound, to their final stint of taking my daughter and I into their home for 5 months for the last push, their help is too great to enumerate here.

Finally, of course, I thank my husband Dewey-I am really looking forward to the next chapter without the dissertation. 


\section{TABLE OF CONTENTS}

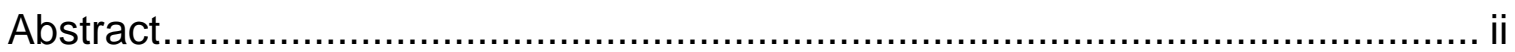

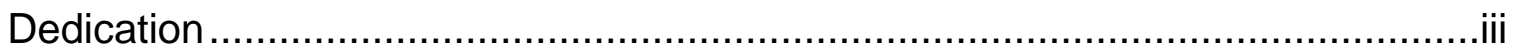

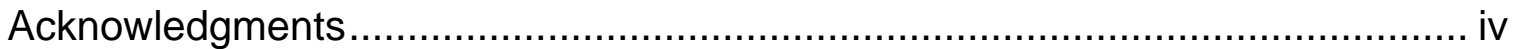

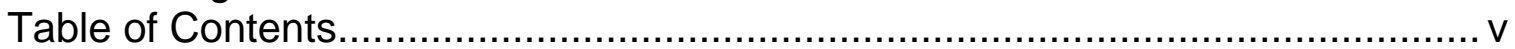

List of Figures .............................................................................................

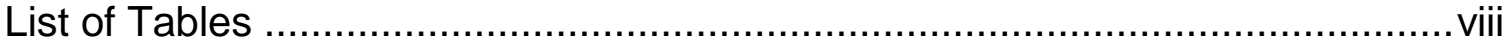

\section{CHAPTER 1}

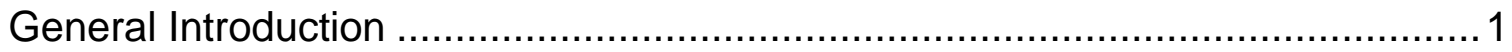

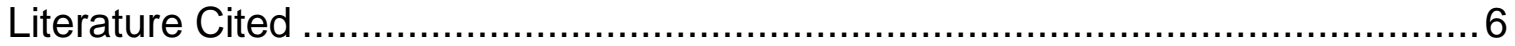

\section{CHAPTER 2}

A comparative demographic study of American ginseng (Panax

quinquefolius L.) at the northern margin and the range center ......................... 9

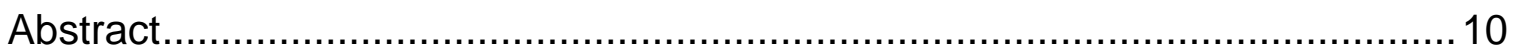

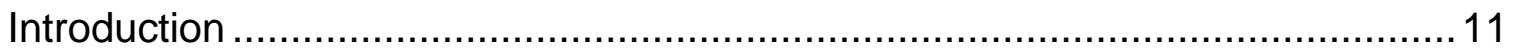

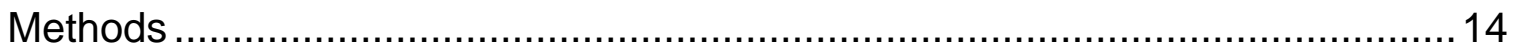

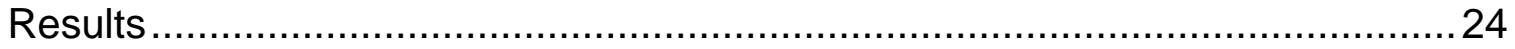

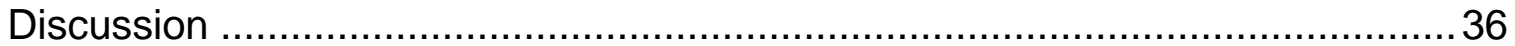

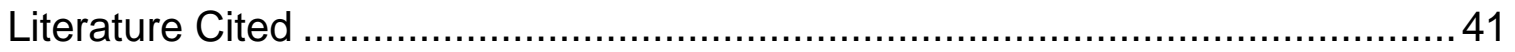

\section{CHAPTER 3}

Recovery of populations of goldenseal (Hydrastis canadensis L.) and American ginseng (Panax quinquefolius L.) following harvest ......................... 48

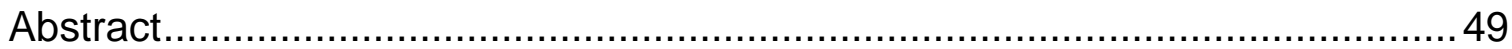

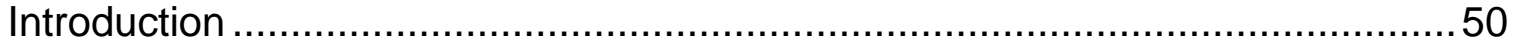

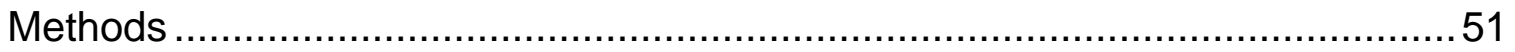

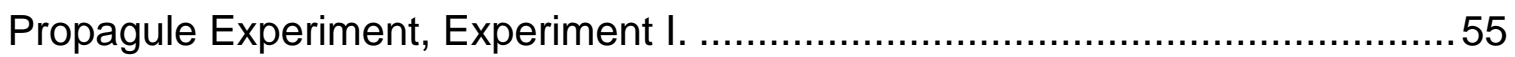

Recovery Following Harvest in Wild Populations, Experiment II.......................58

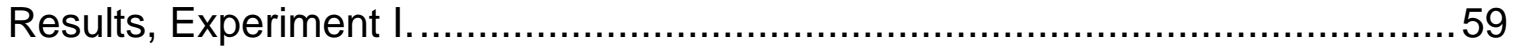

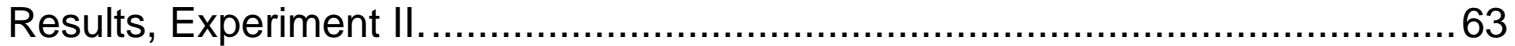

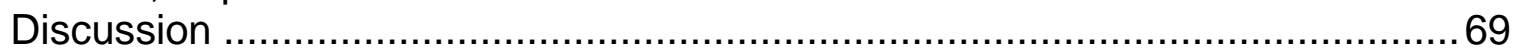

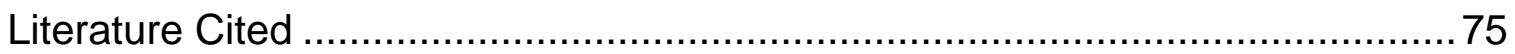

\section{CHAPTER 4}

Controls over seed emergence, survival and early seedling growth in American ginseng (Panax quinquefolius L.) 


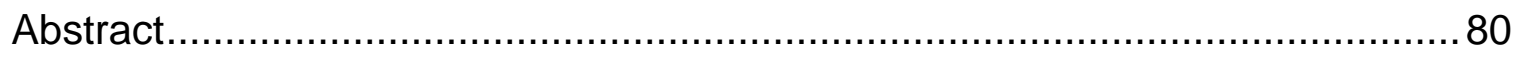

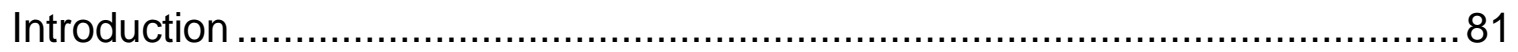

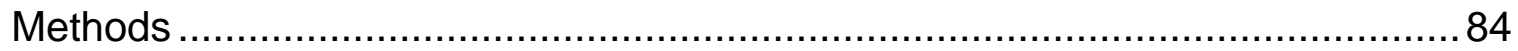

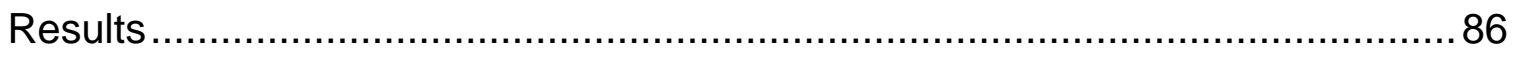

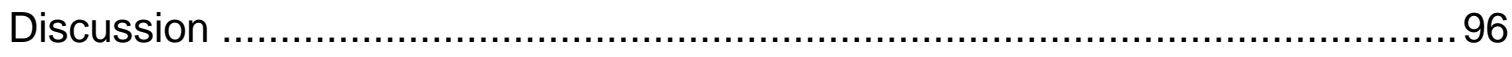

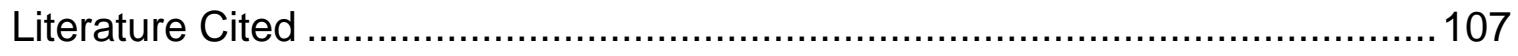

\section{CHAPTER 5}

Effect of harvester behavior on population growth rate affects sustainability of ginseng trade ................................................................................. 111

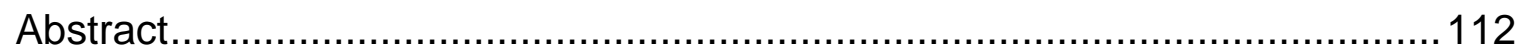

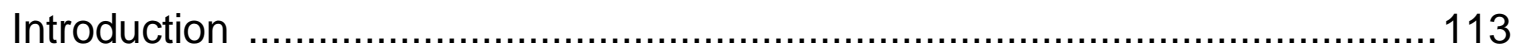

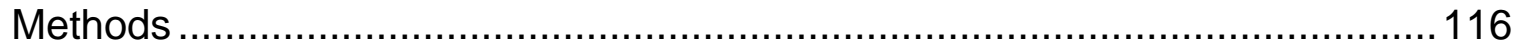

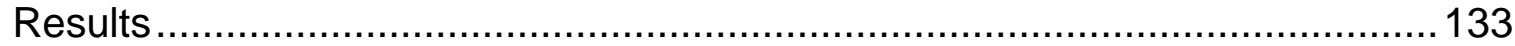

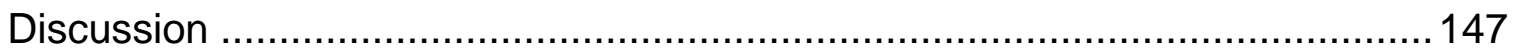

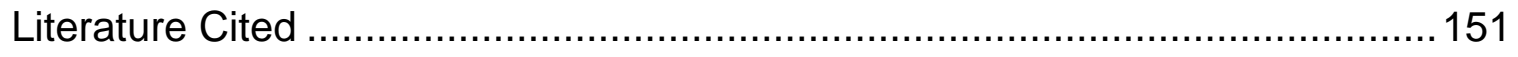

CHAPTER 6

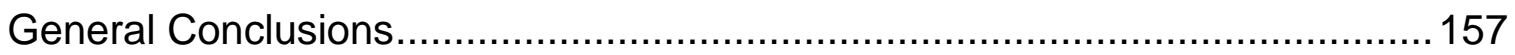

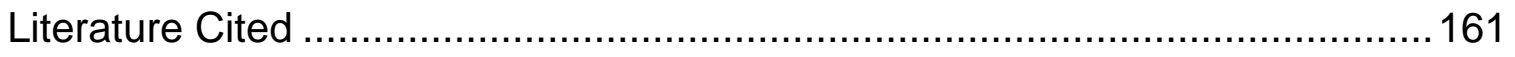

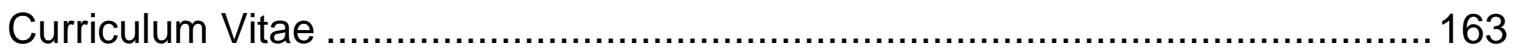




\section{LIST OF FIGURES}

Fig. 2.1. Population growth rate estimates for each of the four West Virginia Panax quinquefolius populations for two transition periods (i.e., 1998-1999 and 1999-2000), and for each of the four Québec populations

Fig. 2.2. Life cycle diagrams for Panax quinquefolius populations in West Virginia and southern Québec

Fig. 3.1. Diagrammatic key to treatments for goldenseal and American ginseng used in propagule experiment

Fig. 3.2. Demographic structure of Panax quinquefolius population ten years postharvest

Fig. 4.1. Emergence of wild ginseng seeds at two planting densities ( $50 \mathrm{~m}$ and 5 $\mathrm{m})$, on two aspects (north and south), over three years (1998-2000) 88

Fig. 4.2. Dispersal distances of the total number of seedlings that emerged over three years on north and south aspects. Dispersal occurred in each of three years of the study on both aspects

Fig. 4.3. Survival of ginseng seedlings on north aspects on $50 \mathrm{~m}$ and $5 \mathrm{~m}$ transects

Fig. 4.4. Comparison of mean root:shoot ratios for Panax quinquefolius seedlings from four transects on north aspects

Fig. 4.5. Comparison of mean biomass for Panax quinquefolius seedlings from four transects on north aspects

Fig. 5.1. Life cycle diagram of Panax quinquefolius when (a) all plants were included in the calculation of a mean ambient matrix (i.e., no harvesting), when (b) the non-compliant harvester treatments were applied, when (c) the compliant harvester treatments were applied and (d) when the steward harvester treatments were applied.

Fig. 5.2. The population growth rate (and 95\% confidence intervals from the mean SE of 10 jackknifed mean matrices for each harvest type) of a single population of Panax quinquefolius under four varying conditions of harvest 


\section{LIST OF TABLES}

Table 2.1. Transition probability matrix (A) for Panax quinquefolius

Table 2.2. Elasticities $\left(e_{i j}\right)$ corresponding to the mean West Virginia matrix ( $A_{w v}$ ) and the mean Québec matrix $\left(A_{P Q}\right)$

Table 2.3. Life table response experiment (LTRE) of Panax quinquefolius populations in West Virginia (WV) and southern Québec (PQ).

Table 3.1. Experiment I. Rate of production of viable aboveground sprouts, reproductive status and final stem height (with SE in parentheses) one year following planting for goldenseal.

Table 3.2. Experiment II. Numerical and morphological traits of goldenseal following a natural harvest event

Table 3.3. Experiment II. Changes in size structure and reproductive plant number in a harvested ginseng population

Table 4.1. Results of 2-way ANOVA with interaction on the total number of seeds that emerged on north and south aspects after five years

Table 4.2. Results of 2-way ANOVA test on the log-transformed root:shoot proportions showing the effect of age on allocation patterns of harvested seedlings on north aspects

Table 4.3. Results of 2-way ANOVA test on the log-transformed biomass of harvested seedlings on north aspects

Table 5.1. Transition probability matrix (A) for Panax quinquefolius (seed bank estimates included and stage class for small/large adults based on leaf area). 119

Table 5.2. Description of three harvester types with explanation of harvest intensity and adjustments for deer browse and seed germination dependent on berry color, time of harvest and seed fate.

Table 5.3. Elasticities $\left(e_{i j} S\right)$ corresponding to the mean matrices for harvester type under four varying conditions of harvesting: ambient (no harvest), noncompliant, compliant and steward.

Table 5.4. Comparison Set I. Life table response experiment (LTRE) for three harvester type comparisons to the mean ambient matrix (no harvesting) for Panax quinquefolius. 
Table 5.5. Comparison Set II. Life table response experiment (LTRE) with results for a pairwise comparison of three harvester types of

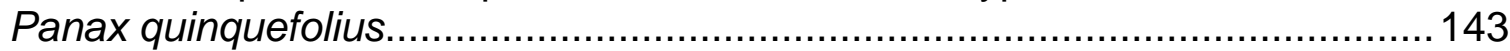




\section{CHAPTER 1}

General Introduction

Panax quinquefolius L. (American ginseng) is an uncommon native species of mesic eastern North American deciduous forest habitats. Harvesting by humans has the potential to depress $P$. quinquefolius population growth to non-replacement levels in the wild. Studies of ginseng at the northern margin of its range suggest that many if not most, populations are below their minimum viable population size. No comparable studies have been carried out in the central portion of its range where harvesting is most intense.

Humans have hunted plant and animal species in the wild for thousands of years. Demand for wild-collected plants for the herbal trade has increased recently (Bannerman 1998, Robbins 2000), possibly putting economically valuable woodland perennial herbs, such as $P$. quinquefolius, at risk. Harvested species face additional challenges to persistence. Repeated harvest of species with low intrinsic rates of increase make these species more susceptible to decline (Mangel et al. 1993, Caughley 1994, Bodmer 1995, Freese 1998). P. quinquefolius can reach sexual maturity as early as 4 years (Lewis and Zenger 1982, Anderson et al. 1993), but reproductive plants are usually at least 7-8 years old (Carpenter and Cottam 1982, Charron and Gagnon 1991). Examples of long-term sustainable use of natural resources are rare (Mangel et al. 1993). Typically, moves toward sustainable harvest of wild species occur only when management programs are implemented after severe population depletion (Freese 1998).

Chinese ginseng (Panax ginseng), has been used medicinally since at least the first century AD (Millspaugh 1974; Kimmens 1975; Robbins 1998). Wild populations were nearly extirpated from over-harvesting and deforestation (Kimmens 1975). P. quinquefolius has been harvested and sold commercially 
since the 1700s when depletion of $P$. ginseng created a demand for other species of Panax (Millspaugh 1974). Reliable figures are not available, but between 1820 and 1903 nearly 8 million kilograms of wild $P$. quinquefolius were exported from the United States (Kimmens 1975). Kimmens (1975) reported that overexploitation nearly eliminated wild populations of American ginseng, which stimulated large-scale cultivation of $P$. quinquefolius in the early part of the twentieth century. Wild-harvested ginseng retained its importance in Chinese and Korean trade, however, and export to Asia continues to this day (Robbins 1998).

Historically, P. quinquefolius was thought to be limited to rich, mesic, north-facing sites. Recent research (McGraw et al. 2003) indicates otherwise, suggesting that $P$. quinquefolius has a broader niche than thought, or that the species may have persisted in less than optimal habitat as harvest pressure depleted populations in optimal sites. Demography of wild populations of $P$. quinquefolius may vary across the species' range. In my first study, demographic analyses of central $P$. quinquefolius populations were compared with analyses conducted at the northern margin (Chapter 2).

P. quinquefolius was listed on Appendix II of CITES (Convention on International Trade in Endangered Species of Wild Fauna and Flora) in 1973. Shortly thereafter, per requirements of CITES regulations, the US Fish and Wildlife Service determined, on an annual basis, whether continued harvest from individual states was detrimental to wild populations. Such determinations are based on annual rates of harvest alone (i.e., the number of kilograms exported per state), and do not take into account other variables, such as socioeconomic factors, which could substantially influence harvest rates (Bailey 1999). Concern about the effects of harvest on today's small ginseng populations led me to conduct a long-term experimental harvest to document immediate effects and long-term recovery (Chapter 3). Goldenseal (Hydrastis canadensis L.), another 
socially and economically important perennial herb in the central Appalachians, was used in this experiment as well for comparative purposes.

The northern limit of $P$. quinquefolius is southern Québec (Charron and Gagnon, 1991). The range extends south to northern Georgia, east to the Carolina piedmont and west to Missouri (Millspaugh 1974). While not rare in the central part of its range, $P$. quinquefolius individuals are typically scattered (McGraw et al. 2003) and populations vary widely in size. Historical accounts suggest that populations often measured in the thousands prior to widespread harvest (Kimmens 1975), but more recent research indicates much smaller numbers. Mean population size in four ginseng populations in southern Québec was 86 (SE = 14.7; Charron and Gagnon 1991). A median population size of 5 individuals was found in a previous study of 43 West Virginia populations containing a total of 961 plants (Van der Voort, 1998 and unpubl. data). In 36 populations totaling 4448 individuals studied in the range center, McGraw and Furedi (2005) found a median population size of 93. A population of over 1000 genets was located in North Carolina in the 1980s (R. Sutter, pers. comm. 1995), but that is atypical.

The leaves of $P$. quinquefolius are arranged in a whorl on top of a single aerial "stem" consisting of fused leaf petioles (the sympodium) attached to an underground rhizome (Charron and Gagnon 1991). The rhizome is attached to one or more thicker taproots. Seedlings produce a single shoot consisting of 1 compound leaf with 3 leaflets. A juvenile period during which plants may have 1 or 2 leaves, each with 3-5 leaflets, is followed by a reproductive adult period which begins around age 7 or 8 (Carpenter and Cottam 1982, Charron and Gagnon 1991). Reproductive plants typically have 3-4 leaves, with 3-7 leaflets each (Carpenter and Cottam 1982). P. quinquefolius proliferates primarily through sexual reproduction (Schlessman 1987), although asexual reproduction occurs rarely (Lewis and Zenger 1982, Anderson et al. 1993, Van der Voort et al. 2003). Perfect flowers produce 1 to 3 -seeded berries which ripen from August- 
September when berries are dispersed beneath the plant (Lewis and Zenger 1982, Anderson et al. 1993), or by rodents and other animals (Lewis and Zenger 1982, pers. obs.). At dispersal, embryos are immature and require both warm and cold stratification for 16-20 months before germination will occur (Hu et al. 1980, Baskin and Baskin 1998). Moisture is important for germination and seedling establishment (Lewis, 1984).

Seeds and seedlings are vulnerable life history stages for many plants (Harper 1977). Little is known about natural germination and survival rates of $P$. quinquefolius (Lewis and Zenger 1982, Anderson et al. 1993). The embryos of ginseng seeds are immature at dispersal and germination is delayed for at least 16 months. Data from both of the previous studies provided recruitment rates, ranging from $0.55 \%$ to $66 \%$ respectively. Anderson et al.'s (1993) estimate, however, may not be relevant to naturally dispersed seeds as the experimental design included cleaning the seeds of the fleshy pericarp prior to planting at a uniform depth and spacing. Dormancy in ginseng seed has been suggested but not tested experimentally in the wild, nor supported in the literature. Lewis (1988) observed recovery of a wild ginseng population five years following its harvest and attributed regrowth to the presence of a viable seed bank. Charron and Gagnon (1991) failed to detect any seed dormancy exceeding 20 months in a small garden germination experiment in southern Québec.

Seedling survival data from wild populations is sparse and conflicting. Lewis and Zenger (1982) found high rates of survival: 100\% and $94 \%$ for 8 seedlings and 17 seedlings followed for two and one year(s) respectively. In another population they found a 30\% rate of survival. Charron and Gagnon (1991) found annual survival of seedlings varied from $8-31 \%$ in four populations studied over 2 one-year intervals in southern Québec. The highly variable rates of germination, unknown seed bank properties, and early seedling properties of ginseng, led to my in-depth study of seed and seedling dynamics (Chapter 4). 
Collection of $P$. quinquefolius requires informal or formal permitting (unless the digging is done on one's property) and must be harvested in season. Opening dates vary among states and range from 1 August to 15 September (McGraw et al. 2005). Multiple types of harvesting behavior have been documented, both legal and illegal (Bailey 1999, McGraw and Furedi 2005). I explored the potential consequences of alternative harvester behaviors for the population dynamics of $P$. quinquefolius, and partitioned the sources of differences in population growth rates between different harvesting behaviors using life table response experiments (LTREs). I investigated whether certain practices (e.g., ignoring size class limits and harvest season opening dates, or planting ginseng seeds at the time of harvest) affect the sustainability of wild populations (Chapter 5). 


\section{Literature Cited}

Anderson, R.C., J.S. Fralish, J.E. Armstrong, and P.K. Benjamin. 1993. The ecology and biology of Panax quinquefolium L. (Araliaceae) in Illinois. Am. Midl. Nat. 129:357-372.

Bailey, B. 1999. Social and economic impacts of wild harvested products. Ph.D. Dissertation. Morgantown, West Virginia. 111 p.

Bannerman, J.E. 1998. Goldenseal in world trade: pressures and potentials. HerbalGram, 41:51-52.

Baskin, C.C. and J.M. and Baskin. 1998. Seeds. Ecology, biogeography, and evolution of dormancy and germination. Academic Press. San Diego, California. $666 \mathrm{p}$.

Bodmer, R.E. 1995. Managing Amazonian wildlife: biological correlates of game choice by detribalized hunters. Ecol. Applic., 5:872-877.

Carpenter W.G. and G. Cottam. 1982. Growth and reproduction of American ginseng (Panax quinquefolius) in Wisconsin, USA. Can. J. Bot. 60:2692-2696.

Caughley, G. 1994. Directions in conservation biology. Journal of Animal Ecology 63:215-244.

Charron D. and D. Gagnon. 1991. The demography of northern populations of Panax quinquefolium (American ginseng). J. Ecol. 79:431-445.

Freese, C.H. 1998. Wild species as commodities. Island Press, Washington, DC, USA. 319pp. 
Harper, J.L. 1977. Population biology of plants. Academic Press, New York. $892 \mathrm{pp}$.

Hu, S.Y., L. Rüdenberg, and P.D. Tredici. 1980. Studies of American ginseng. Rhodora 82:627-636.

Kimmens, A.C. [ed.]. 1975. Tales of the ginseng. William Morrow and Company, Inc. New York.

Lewis, W.H. 1984. Population structure and environmental corollaries of Panax quinquefolium (Araliaceae) in Deleware county, New York. Rhodora 86:431-437.

Lewis, W.H. 1988. Regrowth of a decimated population of Panax quinquefolium in a Missouri climax forest. Rhodora 90(861):1-5.

and V.E. Zenger. 1982. Population dynamics of the American ginseng Panax quinquefolium (Araliaceae). Amer. J. Bot. 69(9):1483-1490.

Mangel , M., R.J. Hofman, E.A. Norse, and J.R. Twiss, Jr. 1993. Sustainability and ecological research. Ecological Applications 3(4):573-575.

McGraw, J.B., S.M. Sanders and M.E. Van der Voort. 2003. Distribution and abundance of Hydrastis canadensis L. (Ranunculaceae) and Panax quinquefolius L. (Araliaceae) in the central Appalachian region. J. Torr. Bot. Soc. 130(2):62-69.

,and M.A. Furedi. 2005. Deer browsing and population viability of a forest understory plant. Science 307: 920-922.

, K. Maiers, C. Carroll, G. Kauffman, A. Lubbers, J. Wolf, R.C.

Anderson, M.R. Anderson, B. Wilcox, D. Drees, M.E. Van der Voort, M.A. 
Albrecht, A. Nault, H. MacCulloch and A. Gibbs. 2005. Berry ripening and harvest season in wild American ginseng. Northeastern Naturalist 12(2), 141-152.

Millspaugh, C.F. 1974. American medicinal plants. Dover Publications, New York, USA 806pp. First published in 1892 as Medicinal plants: an illustrated and descriptive guide to the American plants used as homoeopathic remedies. John C. Yorston and Company, Philadelphia.

Robbins, C. S. 1998. American ginseng: the root of North America's medicinal herb trade. TRAFFIC North America. Washington, DC. 94 p.

2000. Comparative analysis of management regimes and medicinal plant trade monitoring mechanisms for American ginseng and goldenseal. Cons. Biol., 14:1422-1434.

Schlessman, M.A. 1987. Gender modification in North American ginsengs. Dichotomous sex choice versus adjustment. BioScience 37(7):469-475.

Van der Voort, M.E. 1998. An inventory of wild-harvested plants in the Otter Creek Wilderness Area. M.Sc. thesis, Department of Wildlife, West Virginia University, WV

B. Bailey, J.B. McGraw and D.E. Samuel. 2003. Recovery of populations of goldenseal (Hydrastis canadensis L.) and American ginseng (Panax quinquefolius L.) following harvest. Am. Mid. Nat. 149:282-292. 


\section{CHAPTER 2}

A demographic comparison of American ginseng (Panax quinquefolius) populations in the range center and the northern margin 


\begin{abstract}
Panax quinquefolius L., American ginseng, is an uncommon, but widelydispersed, long-lived perennial understory herb found in eastern North America. Due to its high economic value, the species has been harvested commercially for nearly 300 years. Harvest pressure has been more persistent throughout the central Appalachians than in Canada. Intensive demographic studies of $P$. quinquefolius were made at the northern margin of the species' range in southern Québec in the mid-1980s. Demographic comparisons of $P$. quinquefolius at the northern margin and the range center have not been conducted before now. Population size structures were similar between the regions, but large differences in key vital rates were found. Germination and early survival of seedlings were higher in the range center, but fertilities and survival of large adults were lower in West Virginia. Projected population growth rates were mostly increasing (i.e., $\lambda$ was greater than 1.0) in Québec while mostly decreasing in West Virginia ( $\lambda$ was less than 1.0). The sources of differences in the population growth rates between the two regions were partitioned using a life table response experiment (LTRE). Persistent harvesting combined with higher deer densities in the range center may account for the observed differences in demographic patterns between the regions.
\end{abstract}


Introduction

Demand for wild-collected plants for the herbal trade has increased over the past decade, possibly putting economically valuable woodland perennial herbs, such as American ginseng (Panax quinquefolius L.), at risk. Harvested species face additional challenges to persistence. Repeated human harvest of slow-maturing species may negatively impact long-term population dynamics and viability (Caughley 1994; Bodmer 1995; Mangel et al. 1993; Freese 1998). Stellar's sea cow (Hydrodamalis gigas) was extirpated within 27 years of its discovery in 1741 due to harvest (Marmontel et al. 1997). Another long-lived species, the desert tortoise (Gopherus agassizii), faces the possibility of extinction over large portions of its range because of habitat alteration and a reduction in available habitat (Doak et al. 1994). Panax ginseng (known as Chinese, Asiatic or Korean ginseng) abundance was severely reduced in the wild due to overharvesting and habitat alteration (Prescott-Allen and Prescott-Allen 1986).

Panax quinquefolius L., American ginseng, is an uncommon, but widelydispersed, long-lived perennial understory herb found in eastern North America (Millspaugh 1974; Anderson et al. 1993; McGraw et al. 2003). Economically valuable, $P$. quinquefolius has been harvested commercially for almost 300 years (selling at US\$937/dry kg in 1999, Hankins 2000). While used medicinally by Native Americans and in traditional medicines throughout the Appalachians (Kephart 1926), commercial harvest of American ginseng began when $P$. ginseng was nearly extirpated in the wild in the 1700s (Millspaugh 1974). Demand for wild material has persisted in China and Korea since the $18^{\text {th }}$ century and nearly all wild $P$. quinquefolius collected in the US is exported (Robbins 1998).

Intensive demographic studies of $P$. quinquefolius were made at the northern margin of the species' range in southern Québec in the mid-1980s (Charron and 
Gagnon 1991). These studies provided some of the first strong population viability analyses which attempted to guide the management of harvested species. Population growth rate varied but the majority of the estimates showed finite rates of increase $(\lambda)$ greater than 1.0 (i.e., the populations were increasing). Elasticity analyses revealed that changes affecting larger adult plants had the greatest impact on the populations (Charron and Gagnon 1991). In a later analysis of the same demographic data (Nantel et al. 1996), the authors estimated a minimum viable population (MVP) size of 170 plants needed to prevent population extinction from stochastic environmental variation (probability of population survival $>95 \%$ over $100 \mathrm{y}$ ). There are only one dozen known $P$. quinquefolius populations in Canada that exceed this minimum number (Nantel et al. 1996). Population viability analysis of wild ginseng populations in central Appalachia by McGraw and Furedi (2005) estimated an MVP of 800 individuals. The authors know of two ginseng populations in the region that exceed this size although there are many thousands of populations in the area, only a small fraction of which are known.

Ecologists have spent decades trying to understand the mechanisms regulating species distribution and abundance. In general, species density is greater in the range center with a gradual reduction in abundance toward the periphery of the species' distribution (Hengeveld and Haeck 1982; Brown 1984, Lawton 1993). Mayr (1963) suggested that species occupying the range center will often be in more favorable environments. The greater the distance away from the center, it is proposed, the more unfavorable the conditions and thus lower population density (Gaston 1990). Populations at the margin often appear to be living in environments stressful to individuals resulting in signs of physiological stress, such as stunting or higher rates of population extinction (Shumaker and Babble 1990; Lesica and Allendorf 1995). Ecological research on species distributions and population dynamics has shown that peripheral limits can be associated with an array of environmental, geographic and genetic factors. For example, light (e.g., Ward 1969), temperature (e.g., Repasky 1991), length of growing season 
(e.g., Galen and Stanton 1993), or a combination of environmental, geographic and genetic factors (e.g., Grant and Antonovics 1978; Santelmann 1991) all impact the population dynamics and distributions of species. Nantel and Gagnon (1999) suggested that demographic parameters should show greater variability in marginal populations.

Demographic comparisons of $P$. quinquefolius at the northern margin and the center of the range have not been conducted but several differences between regions might be expected to alter survival, growth and reproduction in the two areas. Duration of harvest has been longer in the range center than at the margin (Evans 1985) and harvesting is an important part of the social fabric of many Appalachian family units (Bailey 1999), unlike in Canada. A biotic factor which could influence ginseng population dynamics differently in the range center and the northern margin is the impact of white-tailed deer (Odocoileus virginianus Zimm.). McGraw and Furedi (2005) found that deer browsed up to $45 \%$ of adult plants in $P$. quinquefolius populations in West Virginia, where deer densities are higher than in southern Canada (Furedi 2004; Huot personal communication, 2005). Further, wild ginseng populations in southern Québec experience lower mean temperatures and shorter growing seasons, both of which could affect annual growth rates, survival and other demographic parameters. Given the large number of differences between the ginseng environments in the northern and central portions of the range, can we generalize about demographic patterns across both regions?

The primary objectives of this study were to 1) compare basic life history statistics and population growth rates of $P$. quinquefolius $L$. in the central part of the range with that at the northern margin, and 2) partition the sources of differences in population growth rates between the two regions using a life table response experiment (LTRE). 
Methods

Study species

Panax quinquefolius is a long-lived, perennial herb native to the rich, moist, deciduous forest of eastern North America (Millspaugh 1974). It emerges in early spring before full canopy leaf emergence. Although populations were once reported to be much larger (Maxwell 1898) they typically consist of from 1 to 200 individuals (Carpenter and Cottam 1982; Lewis 1984; Schlessman 1985; Lewis 1988; Charron and Gagnon 1991; Van der Voort 1998), the majority of which are distinct genets (Lewis 1988; Charron and Gagnon 1991).

Following warm and cold stratification over a period of 18-21 months, seed germination occurs (Hu et al. 1980; Baskin and Baskin 1998). A juvenile period of 3 or more years follows, during which plants may retain a single trifoliate leaf or have 2 leaves, each with 3-5 leaflets. A reproductive adult period (3 or more leaves) may begin as early as age 7 or 8 (Carpenter and Cottam 1982; Charron and Gagnon 1991) and occasionally even earlier (Lewis 1982; Anderson et al. 1993). Virtually all 3-leaf plants produce flowers although many do not produce fruit, thus acting functionally as males in the population. Panax quinquefolius proliferates primarily by sexual reproduction (Schlessman 1987), although asexual reproduction occurs rarely (Lewis and Zenger 1982; Anderson et al. 1993; Van der Voort et al. 2003). One- to 3-seeded berries ripen from AugustSeptember and are typically dispersed beneath the plant (Lewis and Zenger 1982; Anderson et al. 1993), although rodent and other animal dispersal does occur (Lewis and Zenger 1982; Van der Voort personal observation, 1998). 
Study sites

Six study populations were located in north central West Virginia in second-growth mixed mesophytic hardwoods. Acer saccharum L. (sugar maple) was common at all sites. Liriodendron tulipifera L. (tulip poplar), Fagus grandifolia Ehrh. (American beech), Prunus serotina Ehrh. (black cherry), Tilia americana L. (American basswood) and Tsuga canadensis L. (Eastern hemlock) were also present at some sites. Common shrubs and understory species included Lindera benzoin L. (spice bush), A. pensylvanicum L. (striped maple) and Tilia americana. Commonly associated herbaceous species found at the sites included Cimicifuga racemosa (L.) Nutt. (black cohosh), Caulophyllum thalictroides L. (blue cohosh), Hepatica nobilis Schreb. var. (roundlobe and sharplobe hepatica), Urtica dioica L. (stinging nettle), Eupatorium rugosum (L.) King and H.E. Robins (white snakeroot) and Botrychium virginianum L. (rattlesnake fern).

All study populations were randomly located by searching through mixed hardwood forests (see McGraw et al. 2003 for discussion of sampling this widespread but scarce understory herb). When found, individuals were marked with unique, underground tags and censused for 3 years. Detailed maps of each population were made to assist future relocation. Where necessary, photographs were taken to further aid in relocation.

Four of the 6 populations were located on northerly aspects (bearing $3^{\circ}$ $\left.24^{\circ}\right)$. One was located on an eastern aspect $\left(54^{\circ}\right)$ and one on a southeastern aspect $\left(146^{\circ}\right)$. The latter was found on rich limestone soil and the overstory and herbaceous layer was dominated by species characteristic of north-facing slopes (e.g., Liriodendron tulipifera, Tilia americana, Hepatica spp., U. dioica). All populations were on moderate to steep slopes (ca. $30^{\circ}$ to $60^{\circ}$ ), two of which had unstable soils. Elevations varied among populations and ranged from 475- $810 \mathrm{~m}$. 


\section{Demography}

All individuals were censused at least twice annually from 10 June to 8 July and then again (for reproductive data) from 11 August to 26 August in 1998, 1999 and 2000. Leaf and leaflet counts were made for each individual. Reproductive status was recorded, including the number of buds and/or flowers present. Any signs of herbivory, disease or other unusual characteristics were noted. As with many plants, $P$. quinquefolius seed production is concentrated during a single period of the year resulting in a birth-pulse population (Caswell 2001). At the August census, berries were ripe or ripening but not yet dispersed, and seed number could be determined accurately.

Population projection matrix models

Matrix population models project numerical change over time and provide a link between the individual and the population (Caswell 2001). The models also provide a theoretical basis for population management, and because most management problems involve vital rates, demographic models are essential tools in conservation and population management (Caswell 2001). Recent studies (e.g., Bierzychudek 1999; de Kroon et al. 2000) caution against designing conservation programs based on perturbation measures (i.e., elasticity and sensitivity) alone. An LTRE is also used here to provide a combination of analyses to explore the demography of $P$. quinquefolius populations in the range center and the northern margin.

A projection matrix model specifies a matrix of transition probabilities between different classes (see Table 2.1), from time $t$ to $t+1$, with the transition probabilities representing observed class- 
Table 2.1. Transition probability matrix (A) for Panax quinquefolius. Each element $a_{i j}$ represents the number of size $i$ individuals in year 2 per size $j$ individual in year 1. Modified from Charron and Gagnon (1991), classes are defined as: $1=$ seed, $2=$ seedling, $3=1$-leaf, $4=2$-leaf and $5=3 / 4$-leaf. The $a_{11}$ element is $=0$. 


\begin{tabular}{lllllll}
\hline \multicolumn{7}{c}{ FROM stage class } \\
& & 1 & 2 & 3 & 4 & 5 \\
& 1 & 0 & 0 & 0 & $a_{14}$ & $a_{15}$ \\
& 2 & $a_{21}$ & 0 & 0 & 0 & 0 \\
$\begin{array}{l}\text { Stage } \\
\text { class }\end{array}$ & 3 & 0 & $a_{32}$ & $a_{33}$ & $a_{34}$ & 0 \\
& 4 & 0 & 0 & $a_{43}$ & $a_{44}$ & $a_{45}$ \\
& 5 & 0 & 0 & 0 & $a_{54}$ & $a_{55}$ \\
& & & & & & \\
\hline
\end{tabular}


specific rates of survival, growth, stasis, regression in size, fertility and recruitment (Bierzychudek 1999). This can be expressed as follows:

$$
n(\mathrm{t}+1)=\mathrm{A} n(\mathrm{t})
$$

where $\boldsymbol{n}$ is a column vector whose values represent the numbers of individuals in each class, and $\mathbf{A}$ is a square, non-negative matrix. Each element, $a_{i j}$, gives the number of size $i$ individuals in year 2 per size $j$ individual in year 1 (Table 2.1). The dominant eigenvalue of $\mathbf{A}$ gives the finite rate of increase $(\lambda)$ of the population. When $\lambda=1$, the population is stable. When $\lambda<1$, the population is declining and when $\lambda>1$ the population is increasing. In addition to the dominant eigenvalue, $\lambda$, the right $(\boldsymbol{w})$ and left $(\boldsymbol{v})$ eigenvectors are other summary statistics of interest. The stable stage distribution $(\boldsymbol{w})$ is a unique vector containing the ultimate proportions of the population in each class, given the constant projection matrix $\mathbf{A}$ (Morris and Doak 2002). The left eigenvector $(\boldsymbol{v})$ is the reproductive value of each class at the stable stage distribution. The reproductive value is of less interest in a size-structured plant model where larger size classes typically contribute more to the growth of the population.

Model parameterization and matrix construction

Once censuses were completed, every individual was assigned to a size class. The five classes in the matrix model were defined as follows: seeds (class 1 ), seedlings (class 2), 1-leaf plants (class 3 ), 2-leaf plants (class 4 ), 3 and 4-leaf adults (class 5 ) and death due to harvest or some other factor (class 6).

Although not all transitions were possible for all individuals, plants could transition in more than one way depending on class. For example, a 2-leaf plant could remain in the same class from one year to the next (stasis, $a_{i j}$, where $i=j$ ), regress in size $\left(a_{i j}\right.$, where $\left.i<j\right)$, grow $\left(a_{i j}\right.$, where $\left.i>j\right)$, or die. Assumptions were necessary when data were missing on individuals during the annual census 
periods (i.e., due to browse, harvest or some other factor). If a plant was recorded as missing for two years in a row, its fate was considered class 6 (death) in the first year it was missing. Harvest is fully destructive to an individual; a plant was considered dead if harvested. When a plant was present in years 1 and 3 , but missing in year 2, class assignments were dictated by status in the first year. The number of individuals following this pattern varied among populations, but ranged from $0-12 \%$, with a mean of approximately $5 \%$ per population.

Individuals present in the first two years of the study but missing in the third, were assigned to classes based on the probability of survival, death, or transition to growth, stasis or regression calculated from known fates of other individuals. The number of individuals that needed assignments also varied among populations in this category. Values ranged from $14-51 \%$, with a mean of about

$28 \%$. A population missing one half of the individuals for the year 3 census was browsed heavily by white-tailed deer early in the season. The probability of surviving increased with size, however, large adults were 1.5 times more likely to need probability assignments. Furedi (2004) found significantly higher rates of browsing of large $P$. quinquefolius plants by deer, which may explain the need for more fate assignments in this class. For adequate estimation, probability assignments were based on a mean of the 6 study populations. A one year time step from June to June was used to calculate the vital rates and for projecting the future size and structure of the populations.

Charron and Gagnon's (1991) class assignments for demographic studies of $P$. quinquefolius in southern Québec were based on leaf number. The seed bank was assumed to be 18 months and the $a_{11}$ element (seeds remaining seeds) was therefore 0 in all matrices. The $a_{21}$ element (seeds germinating) was estimated by the quotient of seedlings and the total number of seeds found in the same year. Charron and Gagnon (1991) acknowledged that this was an 
unrealistic estimate (seeds need a minimum of 18 months prior to germination), but argued it was the best available. The $a_{21}$ element represented an average recruitment over two years. Two of their four populations had two transition matrices (i.e., demographic data collected over a three year period), while the other two had a single transition. The value of the $a_{21}$ element was the same within a population for multiple years, while unique to each population. Fertilities $\left(a_{1 j}\right)$ were the mean number of seeds produced by class size $j$. Germinants (i.e., seedlings) were distinguished from older 1-leaf plants. The parameter estimation procedure used for the West Virginia data was the same as that used by Charron and Gagnon (1991) to make possible a direct comparison of $P$. quinquefolius populations at the northern margin of its range (southern Québec), and the central Appalachians (West Virginia).

For analysis, the three smallest West Virginia populations were combined to ensure adequate parameterization (all numbered less than 50 ). If small populations "behave" in similar ways (e.g., demographic rates of $P$. quinquefolius may be influenced by the Allee effect, Hackney and McGraw 2001), this will be better reflected in a matrix composed of small populations than one made by combining large populations. The combined West Virginia small population (all 3 small populations) numbered 102 genets at the start of the study and will be referred to as "PS." The other 3 populations (WS2, P4 and P5) varied in size from 97-387. Due to a very low number of 4-leaf plants in the West Virginia populations, 3- and 4-leaf plants were pooled to provide adequate parameter estimation for the model. The matrix elements for the 3- and 4-leaf plants for the Québec populations (Charron and Gagnon 1991) were collapsed and recalculated, after weighting according to plant size. 
Model Analyses

Individual annual matrices $(A)$ were estimated for each of the four West Virginia populations studied from 1998-2000 and compared to the 4 populations in the Québec study. Comparisons of $\lambda s$, sensitivities and elasticities in the two sets of matrices were made on these identically-structured matrices. Sensitivity analysis provides the absolute effects of small changes in each $a_{i j}$ on $\lambda$.

Sensitivities were calculated as follows:

$$
S_{i j}=\frac{\delta \lambda}{\delta a_{i j}}=\frac{v_{i} w_{j}}{\langle w, v\rangle} .
$$

Elasticity values can be interpreted as relative contributions of each transition element to $\lambda$ (Horvitz et al. 1997), and were calculated as follows:

$$
e_{i j}=\frac{a_{i j}}{\lambda} * \frac{\delta \lambda}{\delta a_{i j}}=\frac{\delta(\log \lambda)}{\delta\left(\log a_{i j}\right)} .
$$

Sensitivity and elasticity analyses aim to quantify the contribution of each of the vital rates to the variability in $\lambda$ (Horvitz et al. 1997), but they are partial derivatives, quantifying the slope at one particular $a_{i j}$ (Caswell 1997). LTRE's provide a formal method for quantifying the underlying causes of differences between $\lambda$ 's for two populations by decomposing the $\Delta \lambda$ into contributions from the effects on each of the vital rates (Caswell 2001). In this case the $\Delta \lambda$ is due to the net additive and interactive effects of all the environmental and genetic differences between the West Virginia and Québec populations. LTREs combine sensitivity analysis with information on the change in the $a_{i j}$ (Caswell 1997). Weighted mean matrices were estimated for the West Virginia $\left(A_{w v}\right)$ and Québec $\left(A_{P Q}\right)$ populations and the difference $\left(\Delta a_{i j}\right)$ between the two was calculated.

Sensitivity values from the average matrix $\left(\left[A_{W V}+A_{P Q}\right] / 2\right)$, were multiplied by the 
$\Delta a_{i j}$ from the mean matrices to estimate the contribution of each element to the difference in $\lambda$ (Caswell 1997, Knight 2004):

$$
\left.\lambda_{W V}-\lambda_{P Q} \cong \sum\left(a_{i j, W V}-a_{i j, P Q}\right)\right)_{i j}
$$

Year 1 was chosen to estimate the mean matrices for both populations. Only two of the four populations in Québec had two transitions, and the data from year 1 for the West Virginia sample required the fewest indirect estimates of fate.

MATLAB (Mathworks, Version 4.0) was used for all calculations for the demographic analyses including estimation of standard errors, which were calculated using jackknifing. 
Results

Individual matrices

Ginseng populations in West Virginia and Québec had similar size structures; a majority of individuals were of reproductive size (i.e., plants with 2, 3 and 4 leaves). There was no significant difference in annual germination among populations (West Virginia, $F=3.2660, P=0.0803$; Québec, $F=0.7174, P=$ 0.5768 ) or among years (West Virginia, $F=0.1045, P=0.9019$; Québec, $F=$ $3.7891, P=0.0767)$ in either West Virginia or Québec.

Seedling mortality was significantly lower in West Virginia than Québec ( $F$ $=6.4969, P=0.0255)$. There was no difference in mortality of two-leaf $(F=$ $0.0825, P=0.7788)$ or adult (i.e., 3/4-leaf) plants $(F=1.8394, P=0.2000)$ between the regions.

Flowering patterns were also similar between the two regions with nearly all 3- and 4-leaf plants flowering and approximately half of the 2-leaf plants flowering. Seed production differed between regions, with significantly higher numbers in the Québec populations for both the 3/4-leaf $(F=58.9720, P<$ $0.0001)$ and the 2-leaf $(F=5.7751, P=0.0333)$ individuals. Seed production of larger adult plants was seven-fold higher in Québec than in West Virginia.

Five of the 6 estimates of population growth rate $(\lambda)$ for the Québec populations showed stable or increasing numbers (i.e., $\lambda$ was greater than or equal to 1.0, ranging from 1.00 to 1.20), while 7 of 8 West Virginia $\lambda$ estimates were less than 1.0 (six of which were $\leq 0.95$ ). (Fig. 2.1). 
Elasticity analysis of individual matrices

Stasis of large adults $\left(a_{55}\right)$ contributed most to $\lambda$ in all matrices in both regions. High elasticity values were also associated with stasis of 2-leaf plants $\left(a_{44}\right)$ in West Virginia for all populations for both years, while stasis of 2- and 1leaf plants $\left(a_{33}\right)$ accounted for half of the next highest elasticity values in the Québec matrices. Fertility of 3/4-leaf plants $\left(a_{15}\right)$ contributed substantially to $\lambda$, as did growth of 2-leaf $\left(a_{54}\right)$ and 1-leaf plants $\left(a_{43}\right)$ in Québec (although less than stasis of 2-leaf plants in both cases). (Table 2.2). 
Fig. 2.1. Population growth rate estimates were calculated for each of the four West Virginia Panax quinquefolius populations for two transition periods (i.e., 1998-1999 and 1999-2000), and for each of the four Québec populations. Two of the Québec populations were censused for three years creating two transitions (i.e., 1986-1987 and 1987-1988) while the remaining two Québec populations have a single estimate of $\lambda$ for the transition period from 1986-1987. The paired bars in the histogram represent $\lambda$ estimates for individual populations. When $\lambda=$ 1 , the population is neither increasing nor declining. When $\lambda<1$, the population is declining and when $\lambda>1$ the population is growing. 


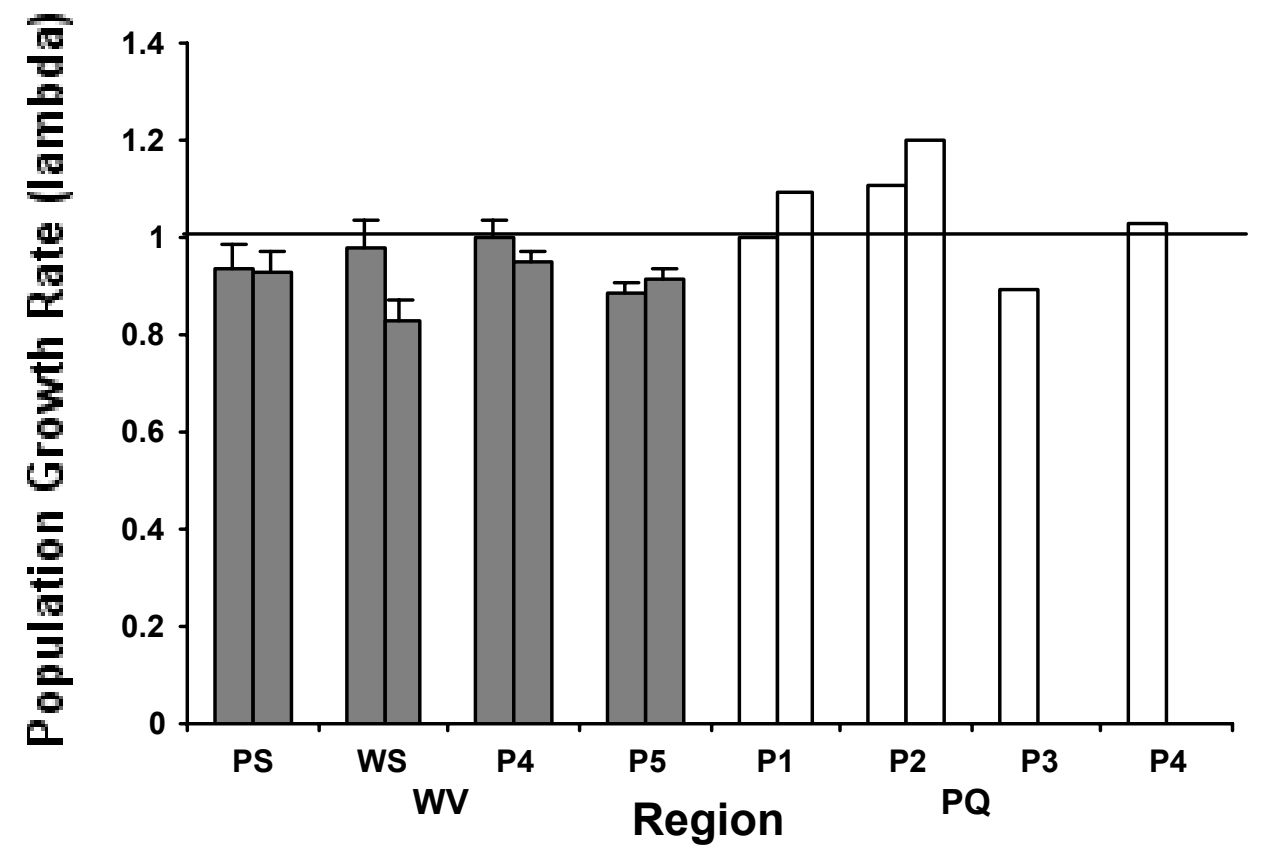


Table 2.2. Elasticities $\left(e_{i j}\right)$ corresponding to the mean West Virginia matrix (Awv) and the mean Québec matrix $\left(\mathrm{A}_{\mathrm{PQ}}\right)$. Elasticity values reflect the proportional effect of small changes in each $a_{i j}$ on $\lambda$. The matrix elements having the greatest effect on population growth rate are in bold. 


\begin{tabular}{|c|c|c|c|c|c|}
\hline \multicolumn{3}{|c|}{ Size at time $t$} & \multirow[b]{2}{*}{ Class 3} & \multirow[b]{2}{*}{ Class 4} & \multirow[b]{2}{*}{ Class 5} \\
\hline Size at time $t+1$ & Class 1 & Class 2 & & & \\
\hline \multicolumn{6}{|l|}{ West Virginia } \\
\hline Class 1 & - & - & - & 0.0009 & 0.0446 \\
\hline Class 2 & 0.0615 & - & - & - & - \\
\hline Class 3 & - & 0.0489 & 0.0819 & 0.0365 & 0.0094 \\
\hline Class 4 & - & - & 0.0426 & 0.1705 & 0.0383 \\
\hline Class 5 & - & - & - & 0.0624 & 0.4328 \\
\hline \multicolumn{6}{|l|}{ Québec } \\
\hline Class 1 & - & - & - & 0.0007 & 0.0620 \\
\hline Class 2 & 0.0627 & - & - & - & - \\
\hline Class 3 & - & 0.0627 & 0.0725 & 0.0014 & 0.0035 \\
\hline Class 4 & - & - & 0.0582 & 0.0993 & 0.0086 \\
\hline Class 5 & - & - & 0.0094 & 0.0646 & 0.4944 \\
\hline
\end{tabular}


Transition Matrix Comparison

The West Virginia population was estimated to be declining at a rate of $7 \%$ per year $(\lambda=0.93)$, while the Québec population $\left(A_{P Q}\right)$ was estimated to be growing at $3 \%$ per year $(\lambda=1.03)$. Two of the estimated 13 vital rates occurred very rarely (3/4-leaf plants regressing to 1-leaf plants, $a_{35}$, and 1-leaf individuals growing to the 3/4-leaf class, $a_{53}$ ) and will not be discussed further. None of the estimated transition elements was identical for the two populations (Fig. 2.2.). Stasis, growth and fertility were usually lower in West Virginia than Québec, while there was always more regression in West Virginia. There was a $14 \%$ and $6 \%$ reduction in the stasis of large adults $\left(a_{55}\right)$ and 2-leaf $\left(a_{44}\right)$ plants, respectively, in West Virginia compared to Québec. Growth of 1-leaf to 2-leaf plants $\left(a_{43}\right)$ and 2leaf to $3 / 4-$ leaf plants $\left(a_{54}\right)$ occurred at a rate $27 \%$ and $12 \%$ lower, respectively, in West Virginia than Québec. Fertilities (i.e., seed production) of 3/4-leaf plants $\left(a_{15}\right)$ were $86 \%$ lower in West Virginia than Québec, while fertilities of 2-leaf plants $\left(a_{14}\right)$ were $54 \%$ lower. There was $78 \%$ less regression of $3 / 4$-leaf to 2 -leaf plants $\left(a_{45}\right)$ in Québec than West Virginia, as well as $85 \%$ less regression of 2leaf to 1-leaf plants $\left(a_{43}\right)$.

Stasis of one-leaf plants $\left(a_{33}\right)$ was $7 \%$ lower in Québec than West Virginia. New seedling growth $\left(a_{32}\right)$ and germination rates $\left(a_{21}\right)$ were $64 \%$ and $17 \%$ lower, respectively, in Québec than West Virginia (Fig. 2.2).

Life table response experiment

The LTRE indicated that the lower population growth rate in West Virginia than in Québec was primarily due to changes in three of the 13 vital rates. Low fertility of large adults $\left(a_{15}\right)$ in the West Virginia populations had the largest negative effect on the change in $\lambda$. This was due to the magnitude of the reduction $\left(\Delta a_{15}\right)$ in seed set of the West Virginia population (86\% lower than Québec) and not to the sensitivity of population growth rate to this transition, 
which was very low (Table 2.3). The lower proportion of 3/4-leaf plants remaining in that class $\left(a_{55}\right)$ in West Virginia (8\% lower than in Québec), combined with the high sensitivity of $\lambda$ to this transition (population growth rate was only more sensitive to germination), also contributed negatively to the change in $\lambda$. Growth from the 1-leaf stage to the 2-leaf stage $\left(a_{43}\right)$ was lower in West Virginia than Québec, and $\lambda$ was very sensitive to this transition, so this difference was important as well (Table 2.3). 
Fig. 2.2. Life cycle diagram for Panax quinquefolius populations in West Virginia and southern Québec. Values above the arrows represent the probability of individuals transitioning from one stage class to the next. Transition values are based on the mean matrices $A_{W v}$ and $A_{P Q}$. 


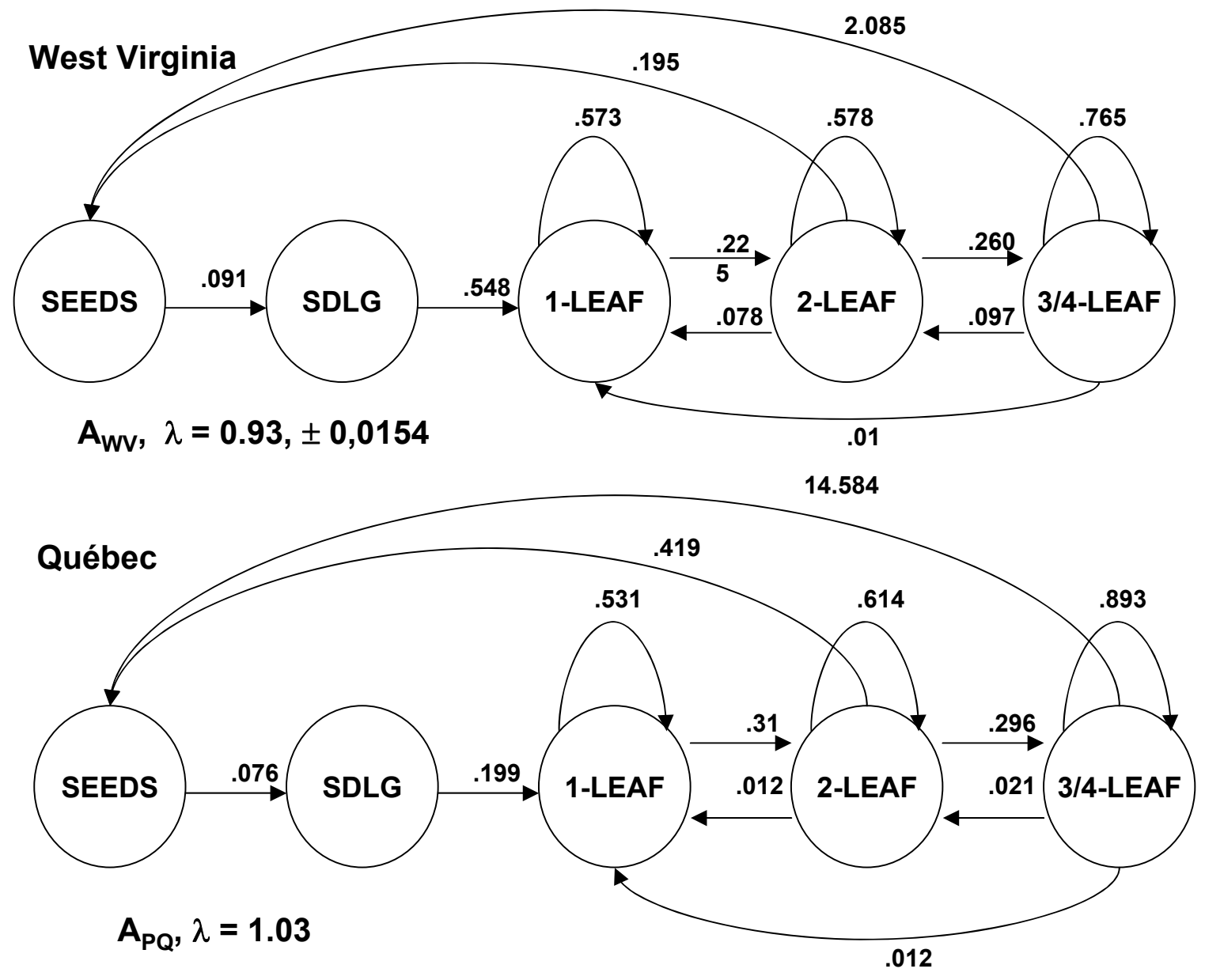


Table 2.3. Life table response experiment (LTRE) of Panax quinquefolius populations in West Virginia (WV) and southern Québec (PQ). 


\begin{tabular}{cccccc}
\hline & & & & & \\
\hline element & & & & $\hat{S_{i j}}$ & $\begin{array}{c}\text { Contribution } \\
\text { to } \Delta \lambda\end{array}$ \\
\hline$a_{21}$ & 0.0910 & 0.0757 & 0.0153 & 0.7665 & 0.0117 \\
$a_{32}$ & 0.5481 & 0.1985 & 0.3496 & 0.1712 & 0.0599 \\
$a_{33}$ & 0.5733 & 0.5312 & 0.0421 & 0.1613 & 0.0068 \\
$a_{43}$ & 0.2253 & 0.3097 & $-\mathbf{0 . 0 8 4 4}$ & $\mathbf{0 . 2 4 6 2}$ & $\mathbf{- 0 . 0 2 0 8}$ \\
$a_{53}$ & 0.0054 & 0.0371 & -0.0317 & 0.3295 & -0.0104 \\
$a_{14}$ & 0.1952 & 0.4187 & -0.2235 & 0.0044 & -0.0010 \\
$a_{34}$ & 0.0778 & 0.0119 & 0.0659 & 0.1408 & 0.0093 \\
$a_{44}$ & 0.5784 & 0.6139 & -0.0355 & 0.2149 & -0.0076 \\
$a_{54}$ & 0.2603 & 0.2957 & -0.0354 & 0.2876 & -0.0102 \\
$a_{15}$ & 2.0854 & 14.5837 & $\mathbf{- 1 2 . 4 9 8 3}$ & $\mathbf{0 . 0 0 7 5}$ & $\mathbf{- 0 . 0 9 3 7}$ \\
$a_{35}$ & 0.0098 & 0.0118 & -0.0020 & 0.2431 & -0.0005 \\
$a_{45}$ & 0.0965 & 0.0209 & 0.0756 & 0.3709 & 0.0280 \\
$a_{55}$ & 0.7646 & 0.8927 & $-\mathbf{0 . 1 2 8 1}$ & $\mathbf{0 . 4 9 6 4}$ & $\mathbf{- 0 . 0 6 3 6}$ \\
\hline
\end{tabular}


Two vital rates had a moderately high positive contribution to the growth rate in West Virginia (vis-à-vis Québec); growth of new seedlings $\left(a_{32}\right)$ and regression of 3/4-leaf to 2-leaf plants $\left(a_{45}\right)$. The change in the vital rate for $a_{32}$ was the second highest value (behind fertility of large adults) and $\lambda$ was moderately sensitive to this growth, however, the positive contribution was not enough to counteract the multiple negative effects lowering growth rate. Despite the positive contribution of $a_{45}$, shrinking from a 3/4- leaf to a 2-leaf plant likely occurs at the expense of remaining in that class $\left(a_{55}\right)$. The high negative value of $\Delta a_{55}$ combined with the high sensitivity of population growth rate to this vital rate, negatively affects $\lambda$. Lower stasis of large plants negatively affected $\lambda$ in the West Virginia population.

Discussion

Individuals in the center of a species' range might be expected to have higher rates of survival, growth and fecundity than those in marginal populations, at least within suitable habitat at low densities. The results of this study suggest that $P$. quinquefolius populations in the range center did not generally perform as well as those at the northern margin. The populations studied in West Virginia were expected to decline at an average rate of approximately $7 \%$ per year when the stable stage distribution is reached while Québec populations were expected to increase at an average rate of approximately $3 \%$ annually.

With limited field data, one can ask whether the differences in demographic parameters between the West Virginia and Québec populations of $P$. quinquefolius were meaningful. Later demographic research conducted on the same populations in West Virginia from 2000-2004 estimated values of $\lambda$ similar to those estimated here (Furedi 2004). The range of values from the more recent study was larger: $0.87-1.09$, compared with 0.83-1.0. However, the demographic model used to analyze the later study was constructed differently. Most importantly, a seed bank was incorporated into the parameterization. When 
the same model was used to analyze the present West Virginia data, estimated values of $\lambda$ ranged from 0.84-1.17 (Van der Voort and McGraw, in review). Fertility values for 2-leaf and larger plants were also similar between the two West Virginia studies.

When harvesting of American ginseng commenced in North America (ca. 1722), harvest pressure was widespread and intense (Millspaugh 1974; Kimmens 1975; Evans 1985; Gagnon personal communication, 2004). Wild populations were rapidly depleted in many regions, hundreds of thousands of kilograms of $P$. quinquefolius were exported, and numerous anecdotal reports suggest that it became much harder to find (Maxwell 1989; Kimmens 1975). Export of ginseng from the province of Québec was second (in monetary value) only to furs in the early part of the $18^{\text {th }}$ century (Evans 1985). Trade in ginseng stopped nearly as abruptly as it started in Québec and wild $P$. quinquefolius populations there have experienced little harvesting since (Evans 1985; Gagnon personal communication, 2004). Conversely, ginseng populations in the range center have been commercially harvested for nearly 300 years. Bailey (1999) found that ginseng was one of a larger group of wild harvested products that are taken throughout the year and serve as an intergenerational thread for many family groups in West Virginia. Current annual harvest figures are much reduced from the historic figures (Carlson 1986; Robbins 2000), but export of roots occurs every year.

The difference in geographic patterns of harvest may have resulted in the opportunity for populations in Québec to recover. In the absence of intense harvest for ca. 300 years, ginseng plants may have grown older and larger, and may have higher rates of seed production. In the presence of chronic harvest pressure, on the other hand, central populations may now have an abbreviated age and size structure which could lead to smaller and younger plants and perhaps, lower seed production. McGraw's (2001) study of 915 herbarium specimens from across the geographic range of ginseng found no decline in size 
of northern populations of $P$. quinquefolius over the past 200 years, but significant declines in size of plants in the midwest, Appalachian and southern regions.

Higher fertilities in northern populations could be related to larger storage capacity in larger roots. Alternatively (or perhaps, concomitantly), higher fertilities in the north may reflect a community Allee effect occurring in the central populations (Hackney and McGraw 2001). Generalist pollinators may be less abundant in the range center than at the northern margin, or perhaps less attracted to the much smaller populations, and thus flower display, that are common in the central range.

Another factor which could explain lower population growth rates and reduced fertilities in populations in the range center is the high density of whitetailed deer in the central Appalachians. Furedi (2004) found reduced fruit production and increased regression into smaller size classes with repeated browse of $P$. quinquefolius by deer. Furedi and McGraw (2004) also documented that white-tailed deer act as predators and not dispersers of American ginseng seed. Although hunted to near extinction in the late $19^{\text {th }}$ and early $20^{\text {th }}$ centuries, deer densities increased dramatically and are now at historic high population densities in the central Appalachians (Furedi 2004). Furedi (2004) estimated mean deer density over 4 years at $46 \mathrm{~km}^{-2}$ in the West Virginia study sites. Huot (personal communication, 2005) estimated mean deer densities in the mid-late 1980s at one quarter that rate for the southern Québec study areas. McGraw and Furedi (2005) projected that current deer densities threaten the long-term persistence of wild ginseng populations. Huot (personal communication, 2005) estimated that deer densities in southern Québec have increased substantially in the past decade, which could result in higher rates of browsing in more northern populations of $P$. quinquefolius. 
In theory, environmental conditions near the range center of a species are closer to optimal than at the margin (Hoffmann and Blows 1994). Thus, for plants, higher germination, growth and survival might be expected in the range center. As expected, germination $\left(a_{21}\right)$ and survival of first year seedlings $\left(a_{32}\right)$ were elements which had higher transition probabilities in West Virginia. However, growth of most size classes was lower in West Virginia populations than Québec populations, and regression to smaller classes was greater for West Virginia populations. Likewise, survival in the larger classes was greater in Québec, as were fertilities. Most of these effects might be explained by the negative effects of harvest and deer browse. Even reduced fertility in West Virginia may be related to long-term browse effects (Furedi, 2004), although there may also be genetic differences between populations that account for the demographic contrasts. For example, selection may have favored higher allocation to seed production at the northern margin to compensate for lower seedling survival there. There may also be an adverse effect of climate on fertility (i.e., drought could impact seed production) which could become increasingly important over time.

Some research suggests that marginal populations may often be relatively better-adapted to unfavorable conditions but perform poorly under most other conditions (Hoffmann and Blows 1994). Reciprocal transplant experiments of northern and central $P$. quinquefolius plants is the logical next step in a research program along with genetic studies to explore genotypic differences between the regions. Demographic research at the southern margin, along with an increased effort to intensify research throughout the range of $P$. quinquefolius may also illuminate causes of the differences found in this study and provide useful direction to conservation and management efforts for this important species. 


\section{Acknowledgments}

The authors express appreciation to B. Bailey, H. and G. Clowes, M. Deinlein, M. A. Furedi, E. Hackney, R. Kenyon, R. Landenberger, C. Packert, J.Portman, S. Sanders and M. Spencer for their help in the field, and D. Gagnon for his thoughtful comments on the manuscript. This research was supported in part by National Science Foundation grant DEB-0212411 and USDOI/U.S. Geological Survey-Biological Resources Division, grant 1434-HQ-97-RU-01563 to J.B. McGraw. 


\section{Literature Cited}

Anderson, R.C., J.S. Fralish, J.E. Armstrong, and P.K. Benjamin. 1993. The ecology and biology of Panax quinquefolium L. (Araliaceae) in Illinois. Am. Midl. Nat. 129: 357-372.

Bailey, B. 1999. Social and economic impacts of wild harvested products. Ph.D. dissertation, Department of Wildlife, West Virginia University, Morgantown, WV.

Baskin, C.C. and J.M. and Baskin. 1998. Seeds. Ecology, biogeography, and evolution of dormancy and germination. Academic Press, San Diego.

Bierzychudek, P. 1999. Looking backwards: assessing the projections of a transition matrix model. Ecol. Applics. 9(4): 1278-1287.

Bodmer, R.E. 1995. Managing Amazonian wildlife: biological correlates of game choice by detribalized hunters. Ecol. Applics. 5: 872-877.

Brown, J.H. 1984. On the relationship between abundance and distribution of species. Am. Nat. 124(2): 255-279.

Carlson, A.W. 1986. Ginseng: America's botanical drug connection to the Orient. Econ. Bot. 40: 233-249.

Carpenter W.G. and G. Cottam. 1982. Growth and reproduction of American ginseng (Panax quinquefolius) in Wisconsin, USA. Can. J. Bot. 60: 2692-2696.

Caswell, H. 1997. Matrix methods for population analysis. In Structuredpopulation models in marine, terrestrial, and freshwater systems. Edited by S.Tuljapurkar and H. Caswell. Chapman and Hall, New York, NY. pp. 19-58. 
Caswell, H. 2001. Matrix population biology. Second edition. Sinauer Assoc., Inc., Sunderland.

Caughley, G. 1994. Directions in conservation biology. J. Anim. Ecol. 63: 215244.

Charron D. and D. Gagnon. 1991. The demography of northern populations of Panax quinquefolium (American ginseng). J. Ecol. 79: 431-445.

Doak, D., P. Kareiva and B. Klepetka. 1994. Modeling population viability for the desert tortoise in the western Mojave desert. Ecol. Applics. 4(3): 446-460.

Evans, B.L. 1985. Ginseng: root of Chinese-Canadian relations. Can. Hist. Rev. 66: 1-48.

Freese, C.H. 1998. Wild species as commodities. Managing markets and ecosystems for sustainability. Island Press, Washington, DC.

Furedi, M.A. 2004. Effects of herbivory by white-tailed deer (Odocoileus virginianus Zimm.) on the demography and conservation biology of American ginseng (Panax quinquefolius L.). Ph.D. dissertation, Department of Biology, West Virginia University, Morgantown, WV.

Furedi, M.A. and J.B. McGraw. 2004. White-tailed deer: dispersers or predators of American ginseng seeds? Am. Midl. Nat. 152: (268-279).

Galen, C. and M.L. Stanton. 1993. Short-term responses of alpine buttercups to experimental manipulations of growing season length. Ecol. 74(4): 1052-1058. 
Gaston, K.J. 1990. Patterns in the geographical ranges of species. Biol. Rev. 65: 105-129.

Grant, M.C. and J. Antonovics. 1978. Biology of ecologically marginal populations of Anthoxanthum odoratum. I. Phenetics and dynamics. Evol. 32(4): 822-838.

Hackney, E.E. and J.B. McGraw. 2001. Experimental demonstration of an Allee effect in American ginseng. Cons. Biol. 15(1): 129-136.

Hankins, A. 2000. Producing and marketing wild simulated ginseng in forest and agroforestry systems. Available from the Virginia Cooperative Extension, Publ. No. 354-312.

Hengeveld, R. and J. Haeck. 1982. The distribution of abundance. I. Measurements. J. Biogeog. 9: 303-316.

Hoffmann, A.A. and M.W. Blows. 1994. Species borders: ecological and evolutionary perspectives. TREE 9 (6): 223-227.

Horvitz, C., D.W. Schemske and H. Caswell. 1997. The relative "importance" of life-history stages to population growth: prospective and retrospective analyses. In Structured-population models in marine, terrestrial, and freshwater systems. Edited by S.Tuljapurkar and H. Caswell. Chapman and Hall, New York, NY. pp. 247-271.

Hu, S.Y., L. Rüdenberg, and P.D. Tredici. 1980. Studies of American ginseng. Rhodora 82: 627-636. 
de Kroon, H., J. van Groenendael, and J. Ehrlen. 2000. Elasticities: a review of methods and model limitations. Ecol. 81(3): 607-618.

Kephart, H. 1926. Our southern highlanders: a narrative of adventure in the southern Appalachians and a study of life among the mountaineers. $4^{\text {th }}$ printing. The MacMillan Company, New York.

Kimmens, A.C. [ed.]. 1975. Tales of the ginseng. William Morrow and Company, Inc., New York.

Knight, T.M . 2004. The effects of herbivory and pollen limitation on a declining population of Trillium grandiflorum. Ecol. Applics. 14(3) :915-928.

Lesica, P. and F.W. Allendorf. 1995. When are peripheral populations valuable for conservation? Cons. Biol. 9(4): 753-760.

Lewis, W.H. 1982. Population structure and environmental corollaries of Panax quinquefolium (Araliaceae) in Delaware County, New York. Rhodora 86: 431437.

Lewis, W.H. 1984. Population structure and environmental corollaries of Panax quinquefolium (Araliaceae) in Deleware county, New York. Rhodora 86: 431437.

Lewis, W.H. 1988. Regrowth of a decimated population of Panax quinquefolium in a Missouri climax forest. Rhodora 90(861): 1-5.

Lewis, W.H. and V.E. Zenger. 1982. Population dynamics of the American ginseng Panax quinquefolium (Araliaceae). Am. J. Bot. 69(9): 1483-1490. 
Mangel, M., R.J. Hofman, E.A. Norse and J.R. Twiss, Jr. 1993. Sustainability and ecological research. Ecol. Applics. 3(4): 573-575.

Marmontel, M., S.R. Humphrey and T.J. O'Shea. 1997. Population viability analysis of the Florida manatee (Trichechus manatus latirostris), 1976-1991. Cons. Biol. 11(2): 467-481.

MATLAB. 1993. MATLAB, Version 4.0. Mathworks, Natick, Massachusetts.

Maxwell, H. 1898. The history of Randolph county. From its earliest settlement to the present. The Acme Publishing Company, Morgantown.

Mayr, E. 1963. Animal species and evolution. Harvard University Press, Cambridge.

McGraw, J.B. 2001. Evidence for decline in stature of American ginseng plants from herbarium specimens. Biol. Cons. 98: 25-32.

McGraw, J.B. and M.A. Furedi. 2005. Deer browsing and population viability of a forest understory plant. Science 307: 920-922.

McGraw, J.B., S.M. Sanders and M.E. Van der Voort. 2003. Distribution and abundance of Hydrastis canadensis L. (Ranunculaceae) and Panax quinquefolius L. (Araliaceae) in the central Appalachian region. J. Torr. Bot. Soc. 130(2): 62-69.

Millspaugh, C.F. 1974. American medicinal plants. Dover Publications, New York. First published in 1892 as Medicinal plants: an illustrated and descriptive guide to the American plants used as homoeopathic remedies. John C. Yorston and Company, Philadelphia. 
Morris, W.F. and D.F. Doak. 2002. Quantitative conservation biology. Theory and practice of population viability analysis. Sinauer Assoc., Inc., Sunderland.

Nantel, P. and D. Gagnon. 1999. Variability in the dynamics of northern peripheral versus southern populations of two clonal plant species, Helianthus divaricatus and Rhus aromatica. J. Ecol. 87: 748-760.

Nantel, P., D. Gagnon and A. Nault. 1996. Population viability analysis of American ginseng and wild leek harvested in stochastic environments. Cons. Biol. 10(2): 608-621.

Prescott-Allen, C. and R. Prescott-Allen 1986. The first resource: wild species in the North American economy. Yale University Press, New Haven.

Repasky, R.R. 1991. Temperature and the northern distribution of wintering birds. Ecol. 72(6): 2274-2285.

Robbins, C. S. 1998. American ginseng: the root of North America's medicinal herb trade. Available from TRAFFIC North America, Washington, D.C.

Robbins, C. S. 2000. Comparative analysis of management regimes and medicinal plant trade monitoring mechanisms for American ginseng and goldenseal. Cons. Biol., 14(5): 1422-1434.

Santelmann, M.V. 1991. Influences on the distribution of Carex exlilis: an experimental approach. Ecol. 72(6): 2025-2037.

Schlessman, M.A. 1985. Floral biology of American ginseng (Panax quinquefolium). Bull. Torr. Bot. Club 112(2): 129-133. 
Schlessman, M.A. 1987. Gender modification in North American ginsengs. Dichotomous sex choice versus adjustment. BioSci. 37(7): 469-475.

Schumaker, K.M and G.R. Babble. 1980. Patterns of allozymic similarity in ecologically central and marginal populations of Hordeum jubatum in Utah. Evol. 34(1): 110-116.

Van der Voort, M.E. 1998. An inventory of wild-harvested plants in the Otter Creek Wilderness Area. M.Sc. thesis, Department of Wildlife, West Virginia University, WV

Van der Voort, M.E. and J.B. McGraw. In review. Effects of harvester behavior on population growth rate affects sustainability of ginseng trade. Biol. Cons.

Van der Voort, M.E., B. Bailey, D.E. Samuel and J.B. McGraw. 2003. Recovery of populations of goldenseal (Hydrastis canadensis L.) and American ginsneg (Panax quinquefolius L.) following harvest. Am. Midl. Nat. 149: 282-292.

Ward, R.T. 1969. Ecotypic variation in Deschampsia caespitosa (L.) Beauv. from Colorado. Ecol. 50(3): 519-522. 


\section{CHAPTER 3}

Recovery of populations of goldenseal (Hydrastis canadensis L.) and American ginseng (Panax quinquefolius L.) following harvest. 


\begin{abstract}
Goldenseal (Hydrastis canadensis L.) and American ginseng (Panax quinquefolius L.) have been harvested commercially for the past few centuries. Harvested populations can recover if vegetative propagules remain in the soil. Experiment I tested the efficacy of vegetative reproduction in goldenseal and ginseng. Partial and intact rhizomes and roots were planted in garden experiments in West Virginia and monitored for $1 \mathrm{y}$ (goldenseal), and for $4 \mathrm{y}$ (ginseng). During the experiment, more than $40 \%$ of the propagule types of goldenseal $(n=5)$ and ginseng $(n=7)$ sprouted. Sprouting varied from year to year in ginseng, and dormancy and/or death occurred in both species. Of the ginseng propagules that sprouted, $77 \%$ were dormant for at least one year and half of those were not present in the final year of the experiment. Sprouting and reproductive status were dependent on propagule type for both species. In Experiment II we monitored recovery of wild populations of goldenseal and ginseng following natural and simulated harvests. After a harvest event leaving only 4 visible plants at the site, a goldenseal population recovered to 932 stems in the first growing season. In the subsequent $3 y$, the population declined numerically, but the size of individuals increased significantly. In a harvested ginseng population, less than half the original number of ginseng plants were present $1 \mathrm{y}$ after harvest. By the second year, stem number exceeded the preharvest count, but the demographic structure of the population had changed dramatically: $78 \%$ of the population was reproductive before harvest, while $0 \%$, $4 \%, 7 \%, 18 \%$ and $26 \%$ respectively, were reproductive in the $5 \mathrm{y}$ following harvest. Both rhizomes and roots of goldenseal and ginseng are capable of regenerating plants, conferring a degree of short term resiliency following harvest.
\end{abstract}


Introduction

Conservation of wild animal and plant species consumed by humans presents difficult management challenges (Freese, 1997). Harvest by humans decreases populations of wild species, which, unless counteracted by equal or greater recruitment, can drive populations to commercial and biological extinction. Many wild herbaceous perennials are being harvested to supply an increasing global demand for herbal products (Robbins, 1998). Two examples in the eastern deciduous forest of North America are goldenseal (Hydrastis canadensis L.) and American ginseng (Panax quinquefolius L.). The June 1997 listing of goldenseal in CITES (Convention on International Trade in Endangered Species of Wild Fauna and Flora) Appendix II (export of any species in Appendix II requires a federal permit) reflected the concern on the part of the US government that increased goldenseal exports merit monitoring and regulatory intervention (Robbins, 2000). Ginseng was placed on the same list in 1973, prompting the US Fish and Wildlife Service to determine annually states which may continue to export wild harvested ginseng.

Goldenseal and ginseng are economically valuable, generating millions of dollars annually for harvesters who dig and sell them (Robbins, 2000). The rhizomes of goldenseal and taproot with attached rhizome of ginseng are the harvested structures. Intense harvesting may reduce the abundance of both species in some areas (Millspaugh, 1974; Strausbaugh and Core, 1953; Foster and Duke, 1990; Davis, 1994; Bannerman, 1998; Robbins, 2000), though rigorous quantitative information on population status and recovery remains scarce. The status of goldenseal and ginseng throughout their ranges is unknown because there are insufficient biological data to judge the extinction risk (Nantel et al., 1996; Bannerman, 1998). Six states (North Carolina, Vermont, Connecticut, Georgia, Massachusetts and Minnesota) list goldenseal as endangered (Bannerman, 1998) and ginseng appears on one state (Rhode Island) endangered list (Robbins, 1998). 
Life history characteristics of long-lived perennial plants may vary greatly, making harvest impacts variable within this class of plants. Goldenseal commonly occurs in patches of dozens to hundreds of interconnected ramets (defined here as a rhizome plus connected leaf petioles and blades; Eichenberger and Parker, 1976; Sinclair and Catling, 2000a). The clonal growth form and rarity of seedlings in the field (Harding, 1936; pers. obs. 1998, 1999; Sinclair and Catling, 2000a) suggests dependence on vegetative propagation. Recovery of goldenseal from harvest by vegetative means has not been documented, however. By contrast, ginseng normally occurs as distinct individuals (i.e. genets) and splitting of rhizomes is rare (Lewis, 1988; Charron and Gagnon, 1991). This pattern suggests reliance of ginseng on sexual reproduction.

The objectives of the present study were twofold. First, we evaluated the ability of intact and fractional goldenseal and ginseng rhizomes and roots to regenerate plants. Understanding rates of success of such propagules is an important component of predicting recovery after harvest. The second goal was to document recovery of natural populations of goldenseal and ginseng after harvest, and to relate the patterns of recovery to the life history differences between the species.

Methods

Study species

Goldenseal and American ginseng are native to eastern North America and are found in rich, moist, deciduous woods in well-drained soils. Both species emerge in early spring before full canopy closure. A ginseng population consists of a group of individual plants, most of which are distinct genets (Lewis, 1988; Charron and Gagnon, 1991). We use the word "patch" to describe a cluster of 
goldenseal plants rather than "population" because the plants may not consist of more than one genet (Sinclair and Catling, 2000a).

The erect stems of goldenseal are attached to irregularly knotty bright yellow rhizomes (Sinclair and Catling, 2000a). Many adventitious roots emerge from the rhizome (Fig. 3.1.). Goldenseal plants with a single leaf are sterile, whereas two-leaved plants bear flowers. An inconspicuous, greenish-white flower, consisting of three petal-like sepals and numerous stamens and carpels (Strausbaugh and Core, 1953; Sinclair and Catling, 2000a) emerges briefly in April or May. The fruit ripens in mid- to late-July or August. Seeds are dispersed shortly thereafter (Harding, 1936; Baskin and Baskin, 1998; Sinclair and Catling, 2000a), with birds as the likely primary dispersers (Harding, 1936; Eichenberger and Parker, 1976; Sinclair et al., 2000).

Ginseng leaves are arranged in a whorl on top of a single aerial "stem" consisting of fused leaf petioles (the sympodium) attached to an underground rhizome. The rhizome is attached to a primary taproot which serves as a fleshy storage organ (Fig. 3.1). Adventitious roots can form from several nodes on the rhizome (Anderson et al., 1984) as the plant ages. Scars form on the rhizome each year as a result of annual abscission of the sympodium (Charron and Gagnon, 1991). Annual bud scars allow the plants to be aged. A juvenile period during which plants may have 2 or 3 leaves (also referred to as "prongs"), each with 3-5 leaflets is followed by a reproductive period which begins around age seven or eight (Carpenter and Cottam, 1982; Charron and Gagnon, 1991; Anderson et al., 1993). Reproductive plants typically have 3-4 leaves, with 3-7 leaflets each (Carpenter and Cottam, 1982).

Ginseng is typically found in scattered populations (Lewis and Zenger, 1982; Charron and Gagnon, 1991). Population size ranged from 1-348 individuals $($ mean $=21.5, \mathrm{SE}=8.45)$ in 43 
Fig. 3.1. Diagrammatic key to treatments for goldenseal and American ginseng used in propaule experiment. $P=$ proximal root propagule, $D=$ distal root propagule, $p=$ proximal rhizome propagule, $m=$ middle rhizome propagule and $d$ = distal rhizome propagule. 


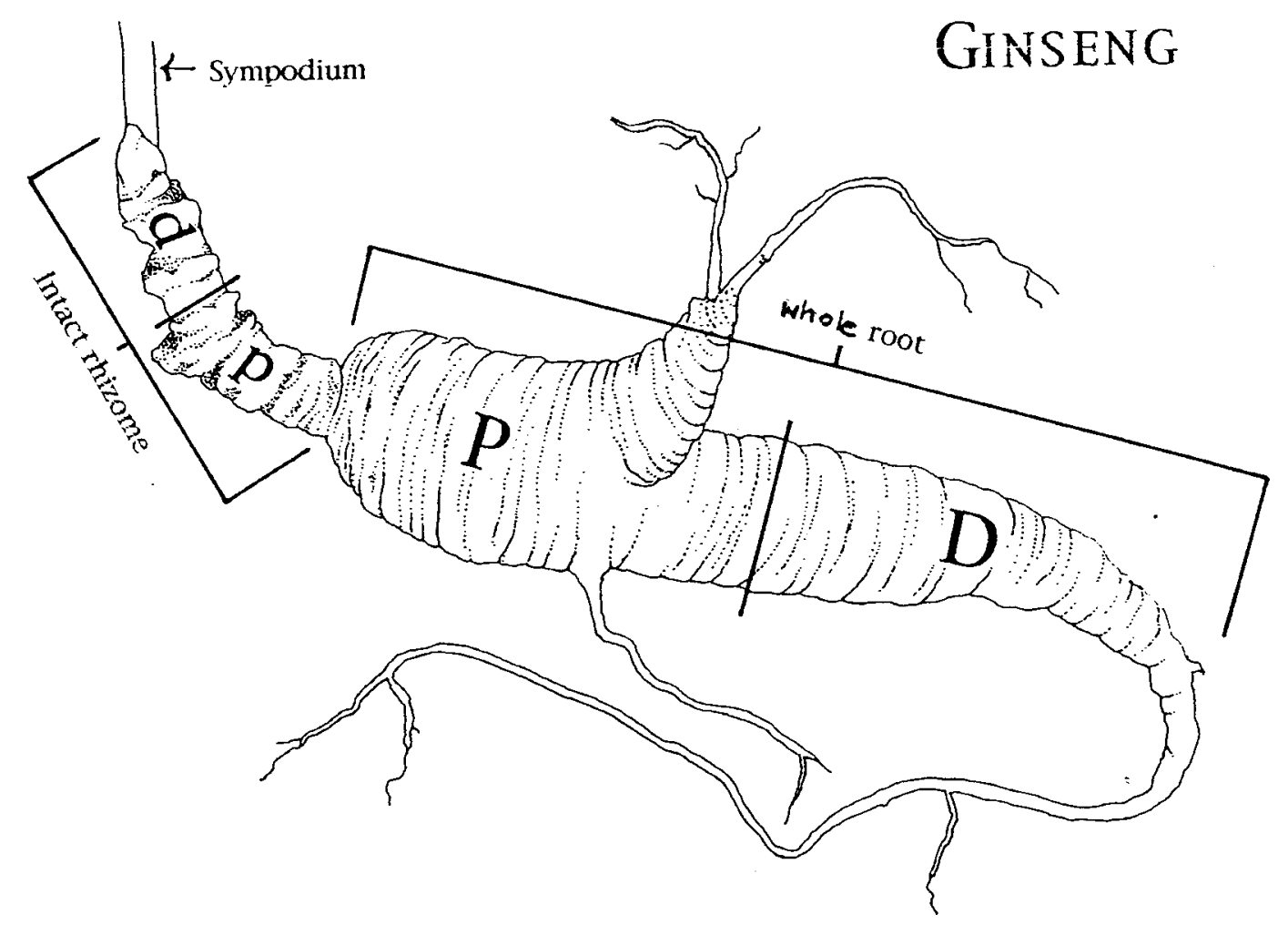


populations located in West Virginia during two summer field seasons (Van der Voort, 1998). The majority of populations had fewer than 10 individuals $(65 \%)$, $21 \%$ had $10-25$ individuals and $14 \%$ had over 25 individuals. Only two populations had more than 100 individuals. Population size data for other locations are limited. Single populations studied in Wisconsin and Missouri in 1982 and 1985 respectively, were 95 and 98 (Carpenter and Cottam, 1982; Lewis, 1988). Two populations studied in New York in 1984 and 1985 were 211 and 220 individuals, respectively (Lewis, 1984; Schlessman, 1985). Four populations studied in Quebec from 1986-1988, ranged in size from 60-128 genets (mean = 86; Charron and Gagnon, 1991). A population located in North Carolina in the late 1980s numbered over 1000 (R. Sutter, pers. comm.)

Small, greenish white perfect flowers on a solitary umbel appear from May to August (Strausbaugh and Core, 1953; Lewis and Zenger, 1982). Flowers mature centripetally over a period of 1-3 wk (Schlessman, 1985). One to three seeded berries ripen from August-September. Berries are dispersed beneath the plant (Lewis and Zenger, 1982; Anderson et al., 1993) or may be dispersed by rodents and other animals (Lewis and Zenger, 1982; pers. obs.).

Propagule Experiment: Experiment I.

Goldenseal

Live plant material was collected in Wirt County, West Virginia on 30 September 1995 in a mixed hardwood forest. Only plants with aboveground vegetation and attached rhizomes were collected. All plants were placed in containers with several centimeters of water and stored for $4 \mathrm{~d}$ at ca. $24 \mathrm{C}$. On 4 October the rhizomes were washed to remove excess soil, then randomly assigned to 1 of 5 treatment groups: intact plants, distal, middle, and proximal 
rhizome propagules, and root buds (small swellings on the adventitious roots branching off the main goldenseal rhizome (Fig. 3.1). Rhizome propagules were prepared by severing 25 intact rhizomes into roughly equal pieces. Adventitious roots were present on all propagules. Propagule sizes varied from very small root swellings (mean fresh biomass $=0.2 \mathrm{~g}, \mathrm{SE}=0.03$ ) to larger rhizome fragments (mean fresh biomass of distal fragments $=1.1 \mathrm{~g}, \mathrm{SE}=0.13$ ) to whole rhizomes (mean fresh biomass $=3.9 \mathrm{~g}, \mathrm{SE}=0.40$ ).

\section{American ginseng}

Eighteen plants, ranging in age from ca. 5-21-y old were collected from a natural population in Monongalia County, West Virginia on 30 August 1996 from a sugar maple (Acer saccharum Marsh.) dominated forest. The elevation of the site was $294 \mathrm{~m}$ and had a southwestern aspect $\left(240^{\circ}\right)$. To our knowledge, harvest had not occurred at the site. Roots were stored individually for $6 \mathrm{~d}$ at ca. $24 \mathrm{C}$ in plastic bags containing soil from the point of harvest. Roots/rhizomes were washed, then randomly assigned to 1 of 7 treatment groups: intact plants (rhizome with attached taproot and adventitious roots, $n=6$ ), intact rhizomes ( $n=$ 6 ), distal and proximal rhizomes ( $n=6$ for both groups), whole roots $(n=17)$, proximal and distal roots ( $n=14$ for both groups; Fig. 3.1). Sixteen of the harvested plants had a taproot and varying numbers of adventitious roots. The "whole root" class was composed of single, adventitious roots created by severing plants with multiple roots. Middle rhizome propagules were not used as a treatment because ginseng rhizomes were too small to be cut into three pieces. Propagules for the distal and proximal root and rhizome classes were prepared by severing whole roots and intact rhizomes roughly in half. Propagule sizes varied from small rhizome (mean fresh biomass of distal fragments $=0.4 \mathrm{~g}, \mathrm{SE}=$ 0.06 ) and root fragments (mean fresh biomass of distal fragments $=1.5 \mathrm{~g}, \mathrm{SE}=$ 0.22 ) to larger intact rhizomes (mean fresh biomass $=4.8 \mathrm{~g}, \mathrm{SE}=2.14$ ) and whole roots (mean fresh biomass $=4.1 \mathrm{~g}, \mathrm{SE}=0.99$ ) to intact plants (mean fresh biomass $=13.7 \mathrm{~g}, \mathrm{SE}=2.65$ ). The six propagules used to create the distal and 
proximal rhizome pieces ranged in age from 5 to $16 \mathrm{y}$. The $n$ for all treatment classes was not equal because individual ginseng plants varied in the number of adventitious roots present.

All material was planted in a completely random design in a $1 \times 5 \mathrm{~m}$ plot. Goldenseal was planted in the West Virginia University Core Arboretum on 4 October 1995 in forest with a dominant red oak (Quercus rubra L.) canopy and well developed sugar maple/hickory (Carya sp.) subcanopy. The elevation of the site was $250 \mathrm{~m}$ and the aspect was west-southwest $\left(275^{\circ}\right)$. Ginseng was planted in a nature preserve $8 \mathrm{~km}$ northeast of Morgantown, West Virginia on 6 September 1996 in a tulip poplar (Liriodendron tulipifera L.)/sugar maple dominated forest. The elevation of the site was $290 \mathrm{~m}$ and had a southwestern aspect $\left(200^{\circ}\right)$. Both plots were established at approximately the same aspect and elevation as natural wild populations located nearby (an elevation of $250 \mathrm{~m}$ and aspect of $285^{\circ}$ for goldenseal; an elevation of $290 \mathrm{~m}$ and aspect of $190^{\circ}$ for ginseng). The garden plots were not prepared for planting i.e., all vegetation and other material remained in situ. Each propagule was assigned a unique number and marked either with a wooden stake (for goldenseal, $N=125$ ) or underground numbered metal band (for ginseng, $N=69$ ). The propagules were planted with $20 \mathrm{~cm}$ spacing, at a depth of $3 \mathrm{~cm}$. To facilitate census, $x, y$ coordinates for each propagule were recorded. All propagules were lightly watered following planting. Goldenseal stems first emerged on 28 April 1996. The plot was censused every $10 \mathrm{~d}$ beginning 7 May through 25 August 1996, and sprouting status, stem height, leaf width and length, and reproductive status were recorded. The ginseng plot was censused in 1997, 1998, 1999 and 2000 between 22 May and 3 July, and sprouting and reproductive status were recorded. Stems of both species were considered reproductive if flowers or fruiting structures were present. We monitored ginseng longer than goldenseal (i.e., for 3 additional years) because of its reported propensity to remain dormant through entire growing seasons (Carpenter and Cottam, 1982). 
We observed whether goldenseal and ginseng propagules sprouted in the different propagule classes, then tested the null hypotheses that different propagules were equally able to sprout, and that different classes of propagule were equally able to produce reproductive stems (G-test, Sokal and Rohlf, 1995).

Recovery Following Harvest in Wild Populations: Experiment II.

\section{Goldenseal}

Following notification from a local landowner that a wild goldenseal patch he had been observing for $7 \mathrm{y}$ had been harvested in late August 1995, a complete census of the area was conducted on 12 September 1995. The patch was located in a mature red oak forest with a well developed sugar maple/hickory subcanopy. The elevation of the site was $390 \mathrm{~m}$ and had a northwestern aspect $\left(310^{\circ}\right)$. Only four plants were located in a $5 \mathrm{~m} \times 5 \mathrm{~m}$ area where leaf litter and soil were disturbed from the harvest. Some portion of the population may have senesced before the harvest, so our estimate of the remaining population may be low. We established an $8 \mathrm{~m} \times 8 \mathrm{~m}$ grid which included the original patch, to track growth of the population should recovery occur. Permanent markers were buried at the four corners of the grid. The plot was censused monthly the following growing season beginning 25 May 1996 and ending in September.

Since recovery did occur, complete censuses were made during the fourth week of June (when leaf expansion was complete) in the summers of 1996, 1997, 1998 and 1999. The total number of stems in the recovering population and their stage class (1 leaf, non reproductive, or 2 leaved, reproductive) were recorded. A random subsample of 100 individuals was taken each year and stem height, leaf width and length were recorded for all plants in the subsample. The numerical dynamics and size structure of the goldenseal population were compared among years using an ANOVA (SAS JMP, V.3.0.2, SAS, Inc., 1989). When the results were statistically significant, multiple comparisons tests using Tukey-Kramer's HSD were performed to determine which years differed. 
American ginseng

Collection of live plant material on 30 August 1996 for the garden experiment served as a simulated, "complete" harvest. It is likely that some plants had senesced by this date, however, the harvest was conducted carefully and included plants without aboveground vegetation. The outside perimeters of the population were permanently marked (the harvest area was approximately 1 $\mathrm{m} \times 2.5 \mathrm{~m}$ ). The plot was censused the following spring (1997). Ginseng plants were discovered in ensuing years. Complete censuses were made in the summers of 1997, 1998, 1999, 2000 and 2001 between 30 May and 4 July, noting the size class and reproductive status of each stem. Ginseng population recovery was monitored for $5 \mathrm{y}$ to provide comparison data to similar research conducted in the mid 1980s (Lewis, 1988).

Results

Propagule Experiments: Experiment I.

\section{Goldenseal}

Nearly half of the vegetative propagules sprouted and all five propagule types produced stems (Table 3.1, $n=25$ for all 5 classes). Contingency analysis revealed that sprouting status of goldenseal varied with propagule type ( $G=$ 18.206, $P=0.0011)$. Intact rhizome and distal rhizome propagules had the highest rate of sprouting. Root swellings had the lowest rate (Table 3.1). Reproductive status also depended on propagule type $(G=17.431, P=0.0016)$. Intact rhizome propagules produced the most reproductive stems, followed by distal and proximal propagules. Of the propagules which sprouted, slightly more than one fourth (28\%) produced reproductive plants. 
Plants emerging from different propagule classes grew to different sizes as measured by mean stem height (ANOVA, $F=10.9254, P<0.0001$. Table 3.1). Intact rhizomes produced plants with significantly greater mean stem height than the other propagule classes (Tukey-Kramer HSD).

\section{American Ginseng}

Sprouting status of ginseng propagules varied over $4 \mathrm{y}$. Thirty of 69 propagules (44\%) sprouted during the experiment, and new plants sprouted in all $4 \mathrm{y}$. Although the sample size for the rhizome treatments was small, all seven propagule types produced stems in at least $1 \mathrm{y}$. Only intact plants and whole roots sprouted in all $4 \mathrm{y}$. Patterns of sprouting across years showed that rhizome and root propagules were capable of remaining dormant for up to three seasons after planting before emergence. Some propagules were dormant in years 1 and 3 and present in years 2 and 4 . Dormancy occurred in $77 \%$ of the propagules. Contingency analysis revealed that sprouting status of ginseng depended on propagule type in 3 of 4 y $(G=27.377, P=0.0001 ; G=18.764, P=0.0046 ; G=$ 14.887, $P=0.0212$; and $G=9.119, P=0.1670$ in 1997, 1998, 1999 and 2000 respectively). Six of the seven propagule types produced reproductive stems (only distal rhizome propagules did not produce a reproductive stem). Reproductive status depended on propagule type in all 4 y $(G=25.682, P=$ 0.0003; $G=23.021, P=0.0008 ; G=13.202, P=0.0399$; and $=13.202, P=$ 0.0399 for 1997, 1998, 1999 and 2000, respectively). 
Table 3.1. Experiment I. Rate of production of viable aboveground sprouts, reproductive status and final stem height (with SE in parentheses) one year following planting for goldenseal. Data reported here are from the 26 June 1996 census. Means in a column with different letters are significantly different. 


\begin{tabular}{lccc} 
Propagule type & Sprouted & Reproductive & Stem height \\
& $(\%)$ & $(\%)$ & $(\mathrm{cm})$ \\
\hline Total $(N=125)$ & 46 & 28 & - \\
Intact rhizomes & 64 & 63 & $13.7 \mathrm{a}$ \\
$(n=25)$ & & 31 & $(1.08)$ \\
Distal rhizome & 64 & & $7.5 \mathrm{~b}$ \\
propagules $(n=25)$ & & 0 & $(0.72)$ \\
Middle rhizome & 44 & & $8.2 \mathrm{~b}$ \\
propagules $(n=25)$ & & 8 & $(0.91)$ \\
Proximal rhizome & 48 & & $7.6 \mathrm{~b}$ \\
propagules $(n=25)$ & & 0 & $(0.91)$ \\
Root swellings $(n=25)$ & 12 & & $5.1 \mathrm{~b}$ \\
& & & $(0.93)$ \\
\hline
\end{tabular}


Survival of propagules from year to year varied. Of the 30 propagules that sprouted, $50 \%$ survived all 4 y $(n=15 ; 3$ intact plants, 1 intact rhizome, 1 distal rhizome propagule, 4 whole roots, 5 proximal root propagules and 1 distal root propagule), $17 \%$ survived 3 y ( $n=5 ; 1$ intact plant, 2 whole roots and 2 proximal root propagules), $27 \%$ survived 2 y ( $n=8 ; 1$ intact plant, 2 intact rhizomes, 4 whole roots and 1 distal root propagule) and $7 \%$ survived only 1 y $(n=2 ; 2$ proximal rhizome propagules).

In general, more ginseng stems were produced by whole root and root propagules than intact rhizome and rhizome propagules (18\% vs. $11 \%$ averaged over $4 \mathrm{y}$ ). Whole root and root propagules produced reproductive plants with almost 4 times the frequency of intact rhizome and rhizome propagules (49\% vs. $13 \%$ averaged over $4 \mathrm{y}$ ). The root is larger than the rhizome and presumably is capable of storing larger carbohydrate reserves.

Recovery From Harvest: Experiment II.

Goldenseal

The "naturally harvested" goldenseal patch had only 4 plants remaining immediately following harvest. The following spring a total of 932 stems sprouted in the same area. In the three subsequent years, the total population declined slightly in numbers. However, mean stem height, leaf width and length were all significantly greater in 1997, 1998 and 1999 than in 1996 following harvest (ANOVA, $\mathrm{P}<0.001$ in all cases; Table 3.2).

\section{American Ginseng}

We were not aware of any aboveground plants at the site following the simulated harvest of the ginseng population in 1996, however, one 2-leaved plant was located the first year after harvest. In 1997, less than half the number of 
plants present before harvest were found. By 1998, there were more plants present than before harvest, but the stage structure of the population was very different. Before harvest, reproductive plants accounted for $78 \%$ of the population. There were no reproductive plants in the year immediately following harvest. In years 2, 3, 4 and 5 postharvest, $4 \%, 7 \%, 18 \%$ and $26 \%$ of the genets were reproductive, respectively. In the first 4 y following harvest, well over $60 \%$ of all genets were 1 leaved, 3 leaflet plants (Table 3.3). These stems were never excavated to determine seedling status because we did not want to disturb the site further. Based on seed counts made in August 1996 one month before harvest, as many as 89 seeds may have been left at the site before harvest. We do not know the fate of the 89 seeds missing in September but we assume some fraction remained in the soil and germinated in 1998 and 1999. Typically seeds must remain 
Table 3.2. Experiment II. Numerical and morphological traits of goldenseal following a natural harvest event. Means in a column with different letters are significantly different. SEs are in parentheses. 


\begin{tabular}{|c|c|c|c|c|c|c|}
\hline Year & $\begin{array}{c}\text { Population } \\
\text { number } \\
\text { following } \\
\text { harvest }\end{array}$ & $\begin{array}{c}\text { Population } \\
\text { number, } \\
1^{\text {st }} \text { growing } \\
\text { season }\end{array}$ & $\begin{array}{c}\text { Number } \\
\text { of } \\
\text { flowering } \\
\text { plants }\end{array}$ & $\begin{array}{l}\text { Mean } \\
\text { stem } \\
\text { height } \\
(\mathrm{cm})\end{array}$ & $\begin{array}{l}\text { Mean } \\
\text { leaf } \\
\text { width } \\
(\mathrm{cm})\end{array}$ & $\begin{array}{c}\text { Mean } \\
\text { leaf } \\
\text { length } \\
\text { (cm) }\end{array}$ \\
\hline 1995 & 4 & - & - & - & - & - \\
\hline 1996 & - & 932 & 11 & $\begin{array}{c}8.5 a \\
(0.49)\end{array}$ & $\begin{array}{c}7.8 \mathrm{a} \\
(0.51)\end{array}$ & $\begin{array}{c}4.6 a \\
(0.29)\end{array}$ \\
\hline 1997 & - & 840 & 20 & $\begin{array}{c}13.0 \mathrm{bc} \\
(0.63)\end{array}$ & $\begin{array}{c}11.6 b c \\
(0.58)\end{array}$ & $\begin{array}{l}6.5 b c \\
(0.30)\end{array}$ \\
\hline 1998 & - & 849 & 20 & $\begin{array}{c}11.7 b \\
(0.54)\end{array}$ & $\begin{array}{c}9.6 b \\
(0.39)\end{array}$ & $\begin{array}{c}5.5 b \\
(0.22)\end{array}$ \\
\hline 1999 & - & 819 & 5 & $\begin{array}{l}14.1 c \\
(0.44)\end{array}$ & $\begin{array}{l}11.5 c \\
(0.41)\end{array}$ & $\begin{array}{c}6.6 c \\
(0.23)\end{array}$ \\
\hline
\end{tabular}


Table 3.3. Experiment II. Changes in size structure and reproductive plant number in a harvested ginseng population. 


\begin{tabular}{lcccccc}
\hline Stage & $\begin{array}{c}1996 \\
\text { (Preharvest) }\end{array}$ & 1997 & 1998 & 1999 & 2000 & 2001 \\
\hline 1 leaf & 4 & 10 & 25 & 20 & 14 & 7 \\
2 leaves & 1 & 1 & 1 & 7 & 7 & 9 \\
3 leaves & 18 & 0 & 1 & 1 & 1 & 2 \\
4 leaves & 0 & 0 & 0 & 0 & 0 & 1 \\
TOTAL & 23 & 11 & 27 & 28 & 22 & 19 \\
Number & 18 & 0 & 1 & 2 & 4 & 5 \\
Reproductive & & & & & & \\
\hline
\end{tabular}


dormant for at least two winters before germination. This is due to incomplete embryo development by the first spring, followed by the need for cold stratification after completed embryo development before germination (Baskin and Baskin, 1998).

Discussion

Underground parts of both goldenseal and ginseng are capable of regenerating plants. Vegetative reproduction has been observed in ginseng only rarely before our experiment in which we planted root and rhizome fragments (Lewis, 1988). All propagule types of both species produced aerial stems.

The methods harvesters use to remove goldenseal and ginseng are quite different, leading to different probabilities that the various propagule types will be left behind. Because the most valuable ginseng roots are large, slow-growing and intact, ginseng diggers are careful to remove as much of the plant as possible (Bailey, 1999). Our study suggests that vegetative growth from severed parts is possible, however, due to such thorough excavation by harvesters, this is unlikely to account for much population recovery of ginseng

With goldenseal, in contrast to ginseng, there is no economic premium on keeping roots intact (Bailey, 1999). In addition, the tight, interwoven clonal growth form makes it difficult to excavate individual plants with a high degree of care or precision. Thus, in digging a patch of goldenseal, it is highly likely that portions of rhizomes and adventitious roots will be left at the site. Thus, a priori, one should expect that vegetative recovery from harvest of goldenseal should be possible. Further, Sinclair and Catling (2000a, b) conducted ecological research on goldenseal in southwestern Ontario (the northern extension of its range), and found that goldenseal may benefit from disturbance. Although they did not address disturbance resulting from harvest, they cited soil disturbance as a factor that may be beneficial to goldenseal growth and spread. 
The patterns of recovery from harvests in natural populations suggest a greater reliance on sexual reproduction in ginseng than in goldenseal. No goldenseal seedlings were located in the monitored patch. No evidence of seedling development was found by Sinclair and Catling (2000a) in Ontario. Conversely, $91 \%$ of the plants present the year following harvest of the ginseng population had 1 leaf (with 3 leaflets). Because we did not wish to disturb the small ginseng plants we could not determine their age; however, the original harvest was conducted thoroughly. It is unlikely that many vegetative fragments were left in the soil. In addition, we know from the propagule experiment that sprouts from fragments usually (>85\%) produce 2 and 3 leaved phenotypes. Therefore, we inferred that most small ginseng plants after the harvest event were seedlings.

Lewis (1988) monitored a naturally harvested ginseng population in southwestern Missouri. The one remaining genet following harvest in 1979 was aged by counting bud scars on the rhizome $(a g e=1)$. Lewis returned after a $5 \mathrm{y}$ hiatus and aged all plants in the recovered population. He did not cite any signs of disturbance to the population. Seventy nine percent of the original population was present in 1984 (25\% of which were reproductive, compared to $66 \%$ before harvest). Five years following harvest of the West Virginia ginseng population, $83 \%$ of the original number of plants were present, $26 \%$ of which were reproductive. We did not observe any signs of disturbance during the study period. Lewis concluded that the Missouri ginseng population was restored because of the viable propagules that had previously accumulated in a seed bank. Our results support his conclusion, though probably a decade or more of observation will be required before we could conclude that the reproductive potential has returned to its preharvest condition.

Despite contrasting patterns of harvest, we observed similarities between goldenseal and ginseng in recovery of natural harvested populations. We did not 
have a preharvest ramet count for goldenseal, but numerical recovery following harvest was rapid for both species. The stage structures of goldenseal and ginseng recovered more slowly than their numbers. Both goldenseal and ginseng plants were small in the first growing season immediately following harvest. Plants of both species grew larger but fewer in number as they aged.

We do not know if the apparent resilience we observed in one wild goldenseal patch and one wild ginseng population is typical. In addition, we cannot predict whether recovery is sufficient for complete population regeneration or, if populations would decline with repeated harvest. Our study has shown that populations of both species are not necessarily eliminated by a single harvest.

The viability of ginseng rhizomes demonstrated in this study (albeit with a limited sample size) suggests an additional opportunity for harvesters to maintain natural populations. Indeed, interviews with harvesters have revealed that some of them purposely plant rhizomes in order to improve the likelihood of future harvests (Bailey, 1999; Hufford, 1999). Recent federal regulations now prevent this practice by requiring that rhizomes remain attached to roots as proof of sufficient age (plants must be $\geq 5$ years to be considered harvestable).

Regulations such as these could change if future research indicates that wild populations are declining. Most states require (and all at least encourage) harvesters to leave ginseng seeds at the harvest site. Removal and planting of the rhizome may be a logical additional step harvesters could take to encourage population growth. While rhizomes had a relatively low long term success rate in our study, this site is known to be heavily browsed by deer which could be influencing that result.

Differences in life history can have a large impact on the suitability of a given species for collection for commercial markets. In general, long-lived species that reach reproductive age after a lengthy juvenile period may be more 
vulnerable to overharvesting than species that reach reproductive maturity quickly (Bodmer, 1995; Freese, 1997). Long-lived perennials such as goldenseal and ginseng may therefore be vulnerable to harvest effects.

Acknowledgments

Many thanks to A. Egan, E. Hackney, R. Landenberger, J. Martin, C. Packert, W. Peterjohn, and M. Senus for help in the field, S. Sanders for reference material, D. Ford-Werntz and S. Studlar for assistance with morphological discussions and M. LaFarge for her superb line drawing. Grant support was provided by the West Virginia State Division of Forestry, the National Forest Foundation, the Mellon Foundation and the USGS Biological Resources Division Cooperation Agreement No. 1434-HQ-97-RU-01563.

NOTE: The experimentally harvested ginseng population has continued to be monitored. Ten years postharvest, the demographic structure of the population remains very different than preharvest; less than $40 \%$ of the genets are large, reproductive adults (Fig. 3.2). 
Fig. 3.2. Demographic structure of experimentally harvested Panax quinquefolius population, 1996-2005. 


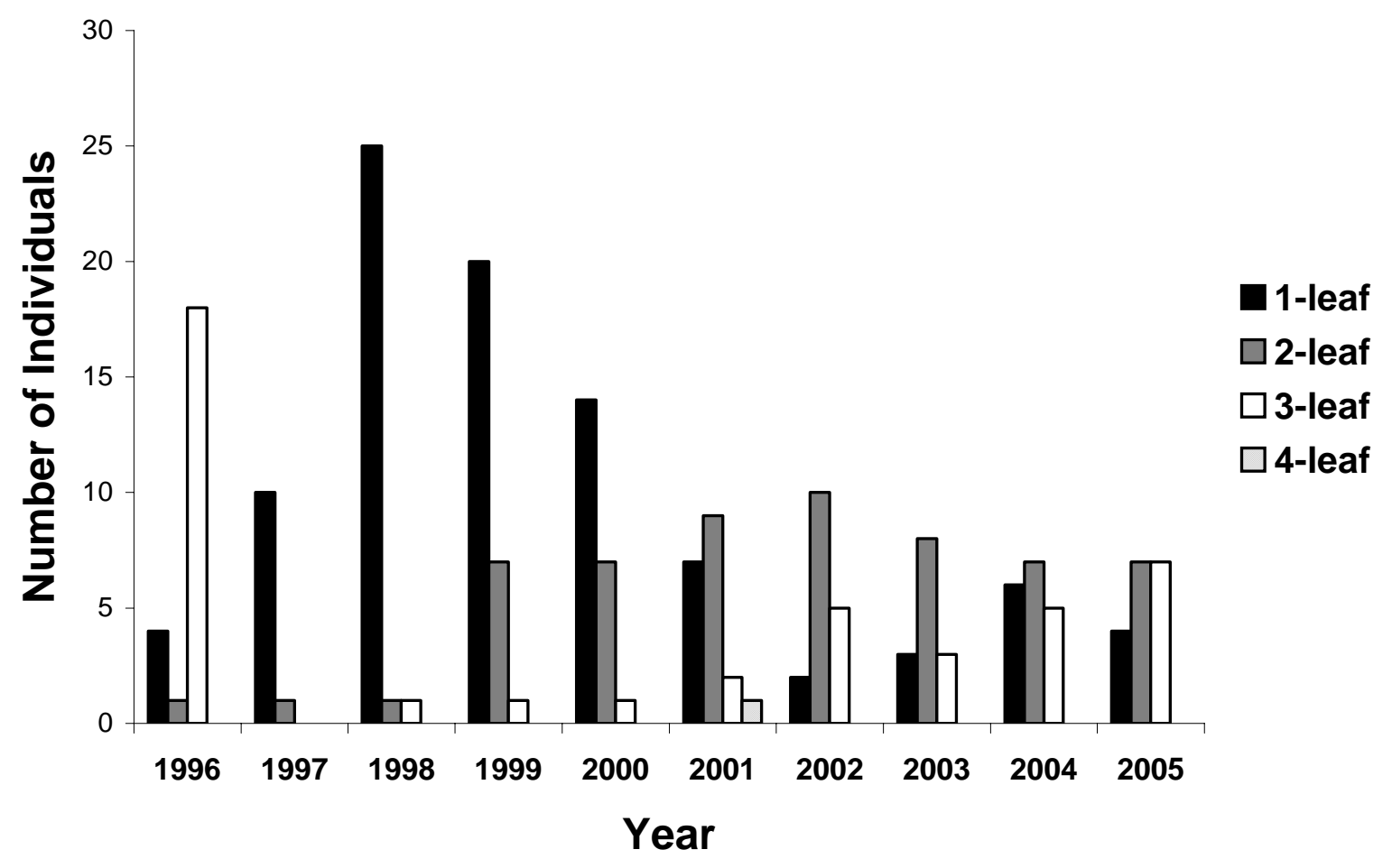




\section{Literature Cited}

Anderson, R. C., J. S. Fralish, J. E. Armstrong and P. K. Benjamin. 1984.

Biology of ginseng (Panax quinquefolium) in Illinois. Department of Conservation, Division of Forest Resources and Natural Heritage. Springfield, Illinois. $32 \mathrm{p}$.

Anderson, R. C., J. S. Fralish, J. E. Armstrong and P. K. Benjamin. 1993. The ecology and biology of Panax quinquefolium L. (Araliaceae) in Illinois. Am. Midl. Nat., 129:357-372.

Bailey, B. 1999. Social and economic impacts of wild harvested products. Ph.D. Dissertation. Morgantown, West Virginia. $111 \mathrm{p}$.

Bannerman, J. E. 1998. Goldenseal in world trade: pressures and potentials. HerbalGram, 41:51-52.

Baskin, C. C. and J. M. Baskin. 1998. Seeds. Ecology, biogeography, and evolution of dormancy and germination. Academic Press. San Diego, California. $666 \mathrm{p}$.

Bodmer, R. E. 1995. Managing Amazonian wildlife: biological correlates of game choice by detribalized hunters. Ecol. Applic., 5:872-877.

Carpenter, S. G. and G. Cottam. 1982. Growth and reproduction of American ginseng (Panax quinquefolius) in Wisconsin, U.S.A. Can. J. Bot., 60:2692-2696.

Charron, D. and D. Gagnon. 1991. The demography of northern populations of Panax quinquefolium (American ginseng). J. Ecol., 79:431-445. 
Davis, J. M. 1994. Advances in goldenseal cultivation. Proceedings of Herbs '94. Ninth National Herb Growing and Marketing Conference. International Herb Growers and Marketers Assoc., p. 39-44.

Eichenberger, M. D. and G. R. Parker. 1976. Goldenseal (Hydrastis canadensis L.) distribution, phenology and biomass in an oak-hickory forest. Ohio J. Sci., 76:204-210.

Foster, S. and J. A. Duke. 1990. A field guide to medicinal plants. Houghton Mifflin Company. Boston, Massachusetts. 366 p.

Freese, C. H. 1997. Harvesting wild species. Implications for biodiversity conservation. The Johns Hopkins University Press. Baltimore, Maryland. 703 p.

Harding, A. R. 1936. Ginseng and other medicinal plants. Revised ed. 1966. A. R. Harding. Columbus, Ohio. 367 p. (1936 edition published by A.R. Harding. Columbus, Ohio).

Hufford, M. 1999. American ginseng and the idea of the commons. In: Tending the commons. Folklife and landscape in southern West Virginia. Library of Congress (web address:

http://memory.loc.gov/ammem/cmnshtml/cmnshome.html).

Lewis, W. H. 1984. Population structure and environmental corollaries of Panax quinquefolium (Araliaceae) in Delaware County, New York. Rhodora, 86:431437.

, 1988. Regrowth of a decimated population of Panax quinquefolium in a Missouri climax forest. Rhodora, 90:1-5. 
and V. E. Zenger. 1982. Population dynamics of the American ginseng Panax quinquefolium (Araliaceae). Am. J. Bot., 69:1483-1490.

Millspaugh, C.F. 1974. American medicinal plants. Dover Publications. New York, New York. 806 p. First published in 1892 as Medicinal plants. John C. Yorston and Company, Philadelphia.

Nantel, P., D. Gagnon and A. Nault. 1996. Population viability analysis of American ginseng and wild leek harvested in stochastic environments. Cons. Biol., 10:608-621.

Robbins, C. S. 1998. American ginseng: the root of North America's medicinal herb trade. TRAFFIC North America. Washington, DC. 94 p.

2000. Comparative analysis of management regimes and medicinal plant trade monitoring mechanisms for American ginseng and goldenseal. Cons. Biol., 14:1422-1434.

SAS, Institute. 1989. JMP. Version 3.0.2. SAS Institute. Cary, North Carolina.

Schlessman, M.A. 1985. Floral biology of American ginseng (Panax quinquefolium). Bull Torr. Bot. Club 112:129-133.

Sinclair, A. and P.M. Catling. 2000a. Status of goldenseal, Hydrastis canadensis (Ranunculaceae), in Canada. Can. Field-Nat. 114:111-120.

2000b. Ontario goldenseal, Hydrastis canadensis, populations in relation to habitat size, paths, and woodland edges. Can. Field-Nat. 114:652655. 
and L. Dumouchel. 2000. Notes on the pollination and dispersal of goldenseal, Hydrastis canadensis L., in southwestern Ontario. Can. Field-Nat. 114:499-501.

Sokal, R. R. and F. J. Rohlf. 1995. Biometry. The principles and practice of statistics in biological research. Third edition. W. H. Freemand and Company. New York, New York. 887 p.

Strausbaugh, P. D. and E. L. Core. 1953. Flora of West Virginia. 2nd ed. Seneca Books. Morgantown, West Virginia. 1079 p.

Van der Voort, M.E. 1998. An inventory of wild-harvested plants in the Otter Creek Wilderness Area of the Monongahela National Forest, West Virginia. M.Sc. Thesis. Morgantown, West Virginia. 77 p. 


\section{CHAPTER 4}

An ecological study of American ginseng (Panax quinquefolius L.) seed emergence, seedling growth and early survival 


\begin{abstract}
American ginseng (Panax quinquefolius L.) is a long-lived, slow-maturing understory herb native to mesic forests in eastern North America. Seed emergence, seedling growth and early survival are little understood in this economically valuable species. For species dependent on sexual reproduction, these early life history processes are critical. The embryos of ginseng seeds are immature at dispersal and emergence is delayed for at least 18 months.

Dormancy in ginseng seed has been suggested but not tested experimentally. In autumn, prior to leaf fall, 16,000 P. quinquefolius berries were dispersed along transects on two aspects (north and south), at two densities (40 seeds/10 cm and 4 seeds $/ 10 \mathrm{~cm}$ ) to estimate seed emergence rates. Study sites were censused 20 months following planting and monitored for three years. Seeds emerged in all three years at both aspects, documenting dormancy beyond 18 months. Significantly more ginseng seeds emerged on north-facing, $50 \mathrm{~m}$ transects, but survival of emergents on the $5 \mathrm{~m}$ transects was significantly higher. Seed age significantly affected survival, younger seeds (i.e., seeds that emerged at 20 months) survived at a higher rate than older seeds (seeds that emerged at 32 months). Differences in allocation patterns (measured by root:shoot) were observed across transects, most markedly in year one of growth. Seedlings varied in size among the transects suggesting microsite variation in site quality. Secondary dispersal of seeds was quantified, providing useful information for adjusting recruitment rates in demographic modeling.
\end{abstract}


Introduction

American ginseng (Panax quinquefolius L.) is an economically valuable understory perennial herb native to eastern North American deciduous forests (Harding 1936). P. quinquefolius has been harvested and sold commercially since the 1700s when depletion of native ginseng populations in China and Korea created a demand for other species of Panax (Millspaugh 1974, Evans 1985). The demand for American ginseng has not diminished in Asia and a recent interest in the medicinal root in Europe and the United States (Bannerman 1998; Robbins 2000) has resulted in additional pressure on wild populations. Slow-maturing species with low intrinsic rates of increase may be especially susceptible to the negative effects of repeated harvest (Caughley 1994, Bodmer 1995, Mangel et al. 1993, Freese 1998). American ginseng is a long-lived species that does not typically reach reproductive maturity until at least 7 years of age (Carpenter and Cottam 1982, Charron and Gagnon 1991).

P. quinquefolius was placed on the Appendix II list of CITES (Convention on International Trade of Endangered Species of Fauna and Flora) in 1973. Listing on Appendix II requires a permit for any material that is harvested with the expectation of export. Since listing, the US federal government must determine on an annual basis whether continued collection of ginseng is detrimental to wild populations. Ginseng is listed as endangered in 2 states (Maine and Rhode Island) and is not considered 'secure' in any of the 19 states where export is approved. No-detriment findings are, theoretically, based on the best available data about a specific species. While the general life history and biology of ginseng are well studied, details on the dispersal and emergence of seeds and early seedling survival are not well understood for this species. Further, the paucity of data for these important processes limit the completeness of demographic models for ginseng, one of the strongest tools available to evaluate the health of wild populations over time. 
Dispersal and emergence of seeds are critical processes for plants dependent on sexual reproduction. $P$. quinquefolius proliferates primarily by sexual reproduction (Schlessman 1985) and the heavy, large fruits are typically gravity-dispersed (Lewis and Zenger 1982; Anderson et al. 1993). The embryos of ginseng seeds are immature at dispersal resulting in delayed emergence for a minimum of 18-20 months (Lewis and Zenger 1982). Dormancy in ginseng seed has been suggested (Lewis 1988, observed partial recovery of a population that was completely harvested; Van der Voort et al. 2003 and Chapter 2), but not supported in the literature nor demonstrated experimentally.

Seeds and seedlings are vulnerable life history stages for many plants (Harper 1977). Removal of fruits and predation of ginseng seed by rodents was observed in populations in Missouri (Lewis and Zenger 1982) and in the range center (Van der Voort personal observation 1998-1999; Van der Voort et al. 2003; Furedi 2004). Furedi and McGraw (2004) documented seed predation and complete elimination of germination potential after ingestion of seeds by whitetailed deer (Odocoileus virginianus Zimm.). Hackney and McGraw (2001) demonstrated a decline in seed production as population size declined using experimental populations. Although $P$. quinquefolius populations were once reported to be much larger (Maxwell 1898), they typically consist of from 1 to 200 individuals (Carpenter and Cottam 1982; Lewis 1984; Schlessmann 1985; Lewis 1988, Charron and Gagnon 1991; Van der Voort 1998, Chapters 2 and 5). Van der Voort (Chapter 2) found significantly lower seed production in populations in the range center than at the northern margin.

Lewis and Zenger (1982) found a recruitment rate of $0.55 \%$ for 3 wild ginseng populations in Missouri, while Anderson et al. (1993) estimated a mean recruitment rate of $66 \%$ for wild ginseng seeds planted at 3 sites in Illinois (mean based on $<75$ seeds). The latter estimate, however, may not be relevant to naturally dispersed seeds as the experimental design included cleaning the seeds of the fleshy pericarp prior to planting at a uniform depth and spacing 
regime. McGraw (unpublished data 2002) found significantly higher rates of emergence for buried rather than scattered seeds.

Data on survival rates of seedlings in the wild are also scarce and conflicting (Lewis and Zenger 1982, Lewis 1988, Anderson et al. 1993). Lewis and Zenger (1982) found high rates of survival: $100 \%$ for 8 seedlings followed for 2 years, and $94 \%$ for 17 seedlings followed for one year. In a Missouri population that was harvested during the study period but then recensused 5 and 6 years later, Lewis (1988) found a $30 \%$ survival rate in 1 year old seedlings (4 of 13 seedlings present in 1984 were present in 1985). Charron and Gagnon (1991) found annual survival of seedlings varied from $8 \%$ to $31 \%$ in 2 populations studied over 3 years and 2 populations studied over two years in southern Quebec.

Seeds of $P$. quinquefolius face a suite of challenges to successful emergence and survival. Although substantial natural history and general ecological research has been conducted on ginseng, little work has examined the seed and seedling stages of the species. Questions arising from previous work on ginseng need to be answered in order to better parameterize demographic models. The appearance of new seedlings during recovery of a harvested population of ginseng (Chapter 3 ) strongly suggested that a seed bank is present. Finding all of the new seedlings in a population and following the fates of all seeds is difficult, particularly if seeds experience secondary dispersal. Further, the number of observations in both the seed and seedling stage classes of demographic models are typically low, increasing the importance of refining the accuracy of the estimates for these elements. The high incidence of disease in cultivated ginseng and numerous observations of the presence of pathogens on leaves (possibly due to fungal organisms) in wild populations in the range center (Furedi, McGraw, Van der Voort, personal observation 1995-2004), suggest the need to document whether or not density influences the rate of emergence and subsequent survival of seedlings. Given the large variation in 
observed emergence and survival of ginseng seedlings, our demographic models may also need to be spatially explicit. Allocation patterns of seedlings (measured with root:shoot ratios and biomass) provide insight into microsite quality.

The objectives of the following research were to (1) experimentally test seed viability beyond 20 months, (2) document secondary dispersal patterns if they exist, (3) test the effect of density on seed emergence and survival and (4) examine spatial variation in seed emergence and survival.

Methods

Study species

Ginseng emerges in early spring before full canopy leaf emergence. Seedlings produce a single shoot consisting of 1 compound leaf with 3 leaflets. A juvenile period of 3 or more years follows, during which plants may retain a single trifoliate leaf or have 2 leaves, each with 3-5 leaflets. A reproductive adult period ( 3 or more leaves) may begin as early as age 7 or 8 (Carpenter and Cottam 1982, Charron and Gagnon 1991). Virtually all 3-leaf plants produce flowers although many do not produce fruit, thus acting functionally as males in the population. P. quinquefolius proliferates primarily by sexual reproduction (Schlessman 1985) and produces one- to 3-seeded berries which ripen from August-September. Berries typically are dispersed beneath the plant (Lewis and Zenger 1982, Anderson et al. 1993), although rodent and other animal dispersal does occur (Lewis and Zenger 1982, Van der Voort pers. obs). Seeds of $P$. quinquefolius have deep simple morphophysiological dormancy (MPD) (Baskin and Baskin 1998). At dispersal, the immature embryos begin to mature, breaking morphophysiological dormancy. Following warm and cold stratification over a period of 18-21 months, seed emergence occurs (Hu et al. 1980, Baskin and Baskin 1998). 
Experimental design

Emergence and survival studies of $P$. quinquefolius were conducted from 1996-2000 on contrasting north and south aspects east of Morgantown in northcentral West Virginia in mixed deciduous hardwoods. Contrasting slopes were chosen to bracket expected rates of emergence (north: high, south; low). North slopes were dominated by black cherry (Prunus serotina) and sugar maple (Acer saccharum $L$ ). The southern aspect was dominated by oaks (Quercus spp). A natural ginseng population existed near the study site. Eight transects were randomly located, with four transects established on each of the 2 aspects (two $50 \mathrm{~m}$ and two $5 \mathrm{~m}$ transects on each aspect).

P. quinquefolius berries were obtained from a private source in West Virginia. Although the material was from plants that were in cultivation for 20 years, the original stock was collected within $25 \mathrm{~km}$ of the experimental site. Berries were not processed (i.e. stratified or cleaned) and contained the pulp of the ripe fruit. Between 17-22 October 1996, 16,000 berries were placed on the surface of the leaf litter, simulating natural dispersal of wild ginseng. Berries were dropped pre complete leaf-fall and no effort was made to bury them. Each transect was planted with 2000 berries, resulting in 2 planting densities: 40 berries $/ 10 \mathrm{~cm}$ for the $5 \mathrm{~m}$ transects and, 4 berries $/ 10 \mathrm{~cm}$ for the $50 \mathrm{~m}$ transects.

Emergence was first assessed in Spring 1998. Each seedling was marked with an underground, unique tag and the location of all individuals were recorded. Distance measurements were made (perpendicular fall line distance) for any seedlings that were more than $10 \mathrm{~cm}$ off the center line of the transect. When dispersal greater than $5 \mathrm{~m}$ beyond the transect, distance measures (i.e., dispersal distance) were taken from the center point of the transect. Censuses performed in the two subsequent summers (1999 and 2000) provided survival data. All plants were harvested in Summer 2000 and dried at $65^{\circ} \mathrm{C}$ for $72 \mathrm{~h}$. 
Shoots were severed from roots after drying and weights were recorded for all of the plant material for subsequent analysis.

Data Analysis

To test whether emergence on the north or south aspect depended on density, a 2-way ANOVA with interaction was used (aspect $x$ density). The $y$ variate was the total number of seeds that emerged on each transect.

The effect of density, seed age and seedling age on survival were examined with likelihood ratio tests (G-test). The effect of seed age and transect length on survival was also tested with a likelihood ratio test. I used SAS, StatView for the analyses (SAS, 1998).

To test whether seedling growth differed between transects, a 2-way, full factorial nested ANOVA was used, with age and density as the main fixed effects. The random effect of transect (microsite quality) was nested within density. Spatial variation in growth rate was tested with the interaction term, age $x$ transect(density), and growth as a function of density was tested with the age $x$ density interaction term. Two tests were run with the same model. In the first test, the root:shoot (r:s) ratio from the dried seedlings collected in 2000 was used to measure allocation patterns on the transects. In the second test, the total biomass of each seedling was used as a measure of microsite quality. In both tests, the original data were log-transformed to improve normality prior to analysis. I used SAS, JMP v. 3.2 (SAS, 1994) for the analyses.

Results

Seedlings emerged in all three years of the study on both aspects (Fig. 4.1). Thus significant dormancy beyond 20 months was documented in the field, 
Fig. 4.1. Emergence of wild ginseng seeds at two planting densities $(5 \mathrm{~m}$ and 50 $\mathrm{m})$, on 2 aspects (north and south), over three years (1998-2000). Significantly more seeds emerged on $50 \mathrm{~m}$ north transects. White bars represent $5 \mathrm{~m}$ transects and black bars represent $50 \mathrm{~m}$ transects. 


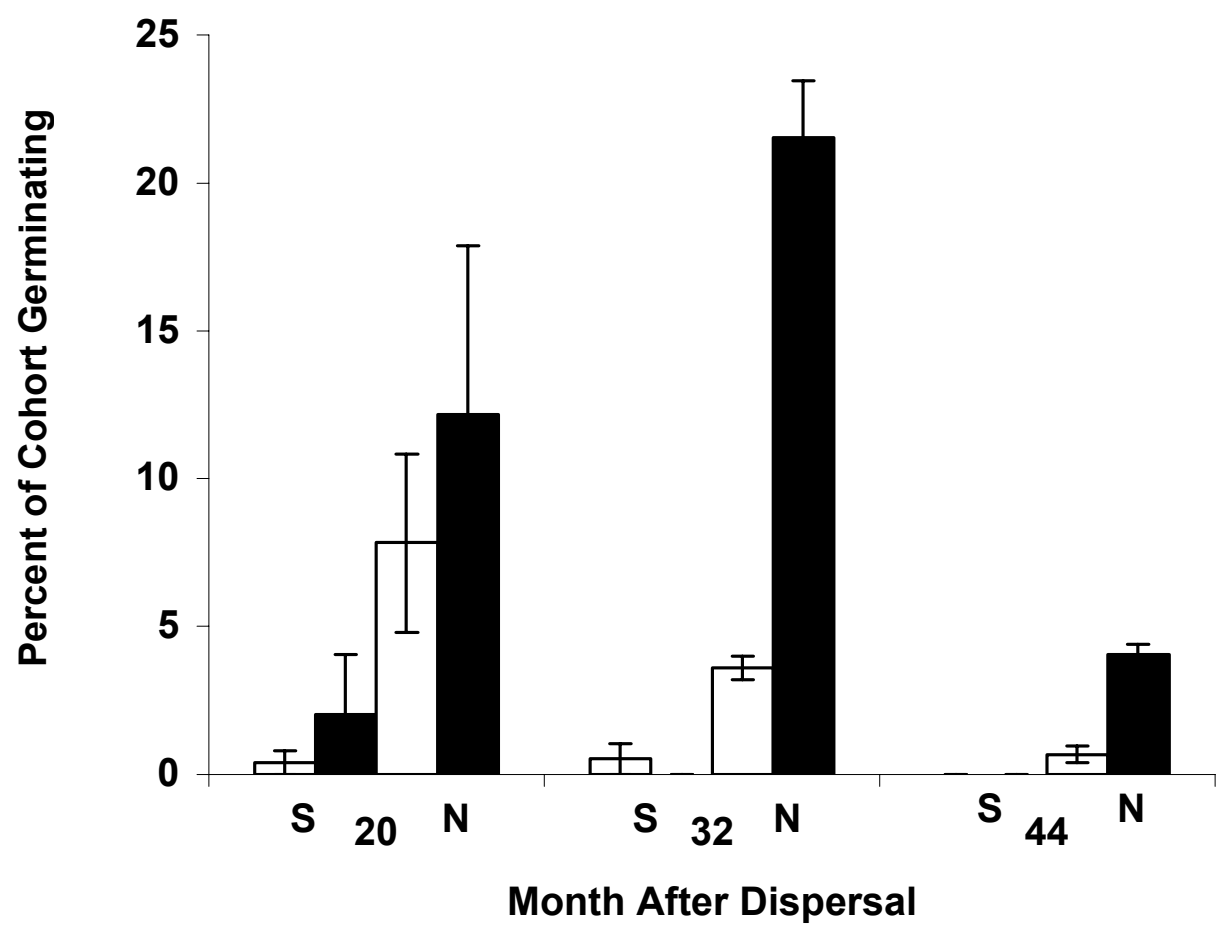


implying the presence of a seed bank for ginseng. The overall rate of emergence for both aspects and all three years combined was $13.25 \%(n=2120)$. The effect of aspect depended on density (2-way interaction; $F=24.0208, P=$ 0.0080 ), with greater seed emergence on $50 \mathrm{~m}$, north-facing aspects. (Table. 4.1.). About $12.5 \%$ of the seeds emerged on the north-facing transects ( $n=$ $1994)$, while $0.008 \%$ emerged on the south-facing transects $(n=126)$.

Secondary dispersal of seeds was also observed. The majority of dispersed seeds moved downhill, but uphill movement was also documented. (Fig. 4.2). The greatest dispersal distance was over $37 \mathrm{~m}$. Long-distance dispersal (defined here as greater than $2 \mathrm{~m}$ from the 'planting site') was only observed on the $5 \mathrm{~m}$ transects. About $85 \%$ of all seeds (i.e., from the $50 \mathrm{~m}$ and 5 $\mathrm{m}$ treatments) remained within $2 \mathrm{~m}$ of the transect (Fig. 4.2).

Due to the low rate of emergence on the south-facing transects, subsequent results relate to the north-facing transects only. In the first census year (i.e., 1998), 10\% of the seeds emerged, ca. 12.5\% emerged in year 2 (i.e., 1999), and $2.4 \%$ emerged in year 3 (i.e., 2000). The total number of emergents on the $50 \mathrm{~m}$ transects outnumbered emergents on the $5 \mathrm{~m}$ transects by threefold, i.e., ca. $19 \%$ vs. ca. $6.1 \%$ respectively. However, significantly more seedlings survived on the $5 \mathrm{~m}$ transects ( $G=46.491$, $\mathrm{P}<0.0001$; Fig. 4.3). The age of the seed at emergence significantly affected survival; younger seeds (i.e., emergents from seeds that were 20 months old) survived at a higher rate than older seeds (i.e., emergents from seeds that were 32 months old; $G=427.674$, P $<0.0001)$. Survival rates were estimated for two cohorts of seeds: cohort 1 emerged in 1998 and survived through 2000; cohort 2 emerged in 1999 and survived to 2000. Unexpectedly, there was a significantly higher rate of survival of new seedlings to 1-leaf plants than 1-leaf to 1-leaf genets $(G=14.727, P=$ 0.0001 ) for seedlings in cohort 1 . Survival rates for the this cohort ranged from $56-90 \%$ in the first year of survival (i.e., seedlings that emerged in 1998 and 
Table 4.1. Results of 2-way ANOVA with interaction on the total number of seeds germinated after five years on north and south aspects. 


$\begin{array}{lllll}\text { Effect } & \underline{\mathrm{df}} & \underline{\mathrm{SS}} & \underline{\text { F Ratio }} & \text { Prob > F } \\ \text { Aspect } & 1 & 436178.0 & \mathbf{8 8 . 3 5 3 3} & \mathbf{0 . 0 0 0 7} \\ \text { Density } & 1 & 145260.5 & \mathbf{2 9 . 4 2 4 3} & \mathbf{0 . 0 0 5 6} \\ \text { Aspect x density } & 1 & 118584.5 & \mathbf{2 4 . 0 2 0 8} & \mathbf{0 . 0 0 8 0}\end{array}$


Fig. 4.2. Dispersal distances of the total number of seedlings that germinated over three years on north and south aspects. Dispersal occurred in each of three years of the study on both aspects. 


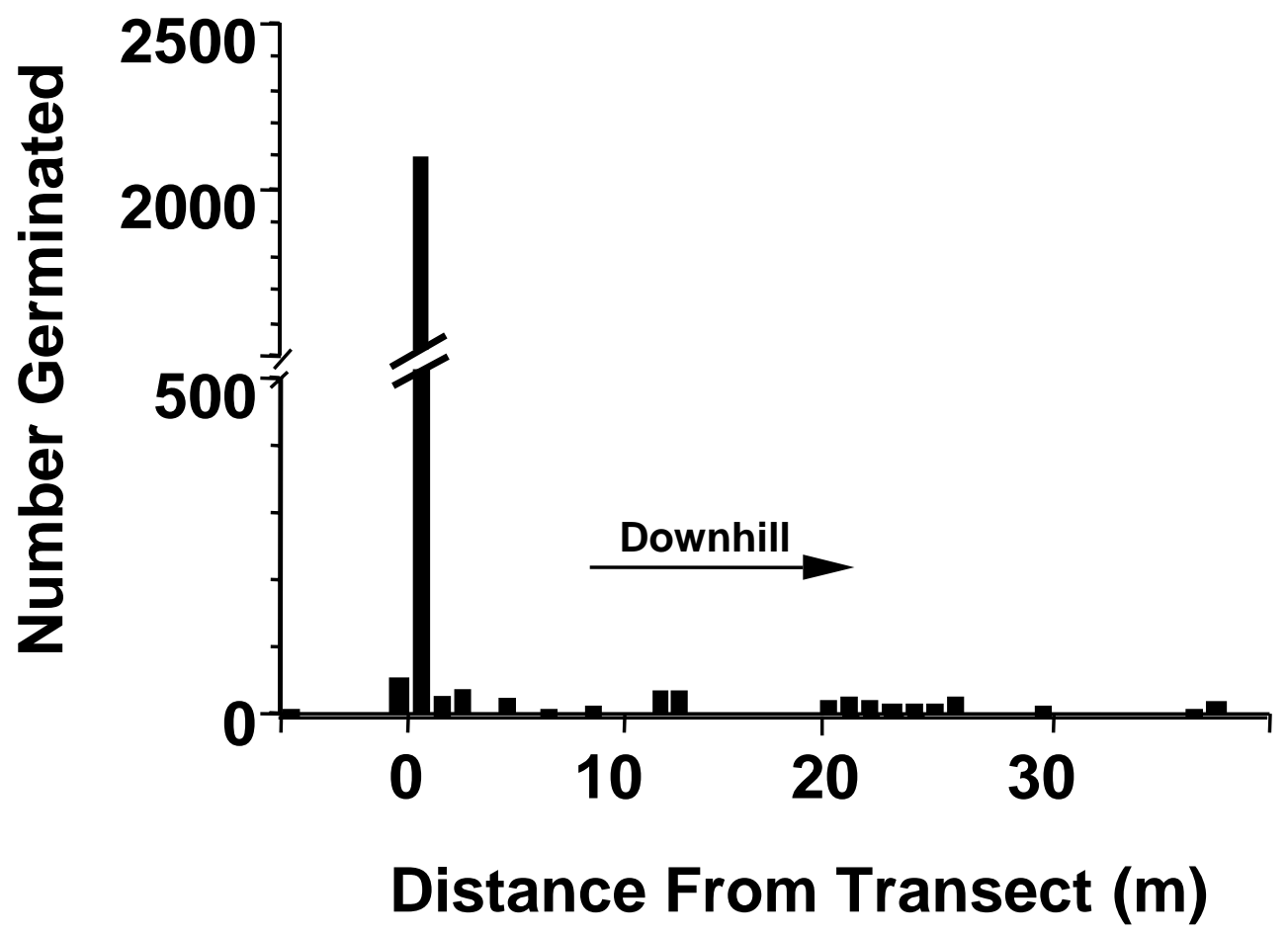


Fig. 4.3. Survival of ginseng seedlings on north aspects on $50 \mathrm{~m}$ and $5 \mathrm{~m}$ transects. The numerals ' 1 ' and ' 2 ' on the $X$ axis refer to year 1 and year 2 , respectively. Year 1 survival estimates are for seeds that emerged in 1998 and survived to 2000 (i.e., cohort 1). Year 2 estimates are for seedlings that emerged in 1999 and survived to 2000 (i.e., cohort 2). Significantly higher rates of survival were found on $5 \mathrm{~m}$ transects. 


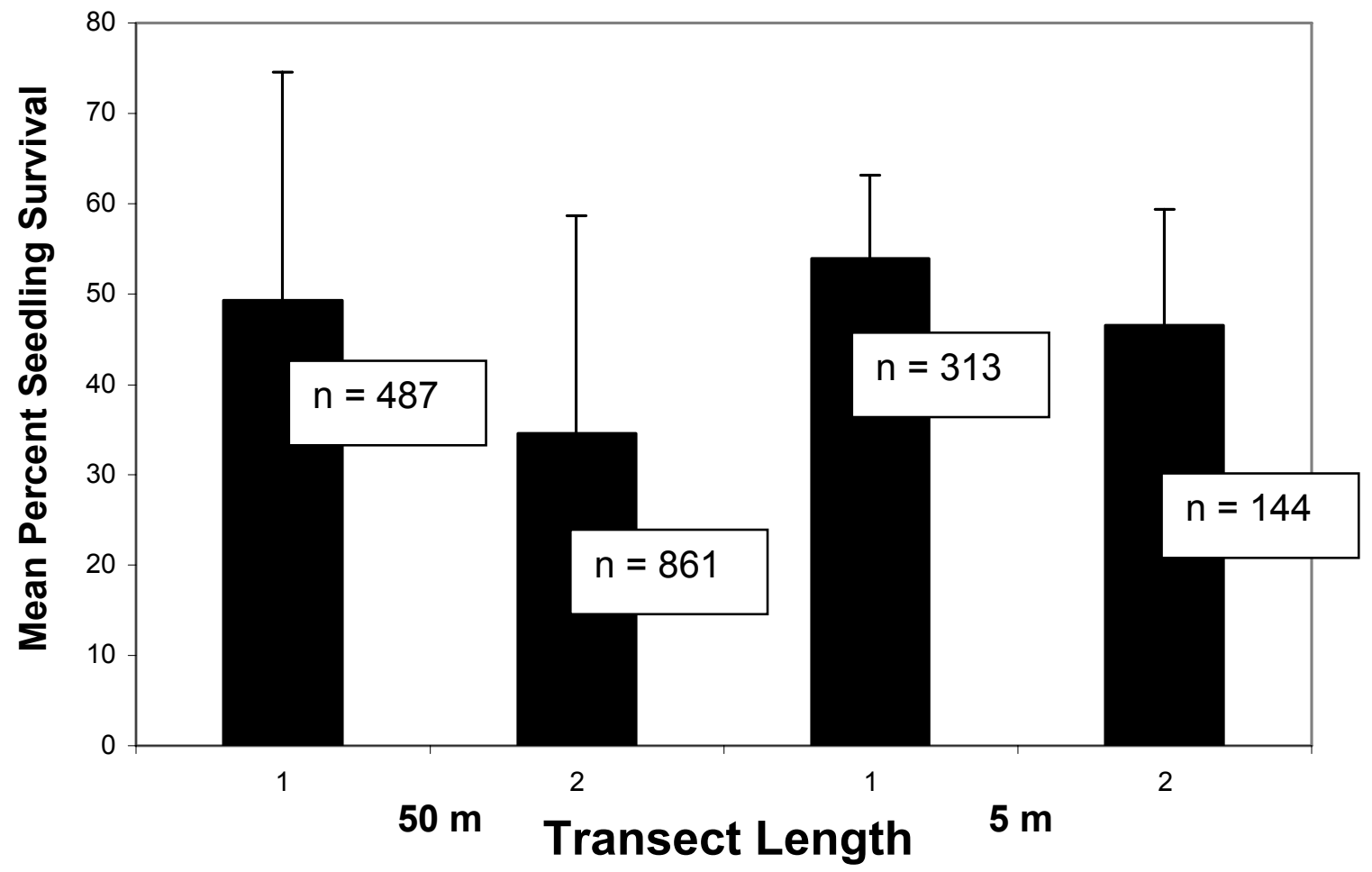


survived to 1999) while $43-83 \%$ of those seedlings survived to year 3 (2000). The seedling survival estimate for the second cohort ranged from $10-59 \%$.

The age effect on allocation pattern (measured by root:shoot) differed among transects (age $x$ transect [density]; $F=33.8566, P<0.0001$, Table 4.2). While there were differences in allocation patterns among the transects for the older seedlings (i.e., 1998 and 1999 emergents), the differences were more pronounced for the youngest seedlings. Allocation of resources in the first year of growth differed more dramatically than in later years among transects (Fig. 4.4).

Seedlings varied in size among transects (Table 4.3). As expected, seedlings added biomass with age. The growth in size varied among transects (Table 4.3). There was a higher accumulation of biomass (about $25 \%$ ) on two of the transects (N1, $50 \mathrm{~m}$, and N2, $5 \mathrm{~m}$. Fig. 4.5).

Discussion

Emergence of ginseng seeds beyond 20 months of dispersal was documented for the first time. From his observations of recovery in a harvested population of $P$. quinquefolius in Missouri, Lewis (1988) suggested that ginseng had a seed bank, but it had not been tested experimentally. My similar observations following an experimental harvest of ginseng supported Lewis (Van der Voort et al. 2003, Chapter 2), but this study was the first to document longterm viability of ginseng seed. The presence of a seed bank has important implications for the parameterization of demographic models of $P$. quinquefolius. Previous demographic studies of ginseng (Charron and Gagnon 1991, Nantel et al. 1996) assumed no long-term viability of seeds. McGraw and Furedi's (2005) recent study of $P$. quinquefolius incorporated a seed bank in their demographic model based on additional seed bank work stimulated by the present findings. (See Chapter 5 as well). 
Table 4.2. Results of 2-way ANOVA test on the log-transformed root:shoot proportions showing the effect of age on allocation patterns of harvested seedlings on north aspects. 


\begin{tabular}{lllll}
\hline Effect & df & SS & F Ratio & Prob > F \\
\hline Age & 2 & 22.2276 & 1.7682 & 0.2747 \\
Density & 1 & 0.07703 & 0.0128 & 0.9195 \\
Transect [density] & 2 & 27.9195 & 1.0000 & 0.4444 \\
Age $x$ density & 2 & 2.97773 & 0.2369 & 0.7987 \\
Age x transect [density] & $\mathbf{4}$ & $\mathbf{5 6 . 7 7 2 1}$ & $\mathbf{3 3 . 8 5 6 6}$ & $<.0001$ \\
\hline
\end{tabular}


Fig. 4.4. Comparison of mean root:shoot ratios for Panax quinquefolius seedlings from 4 transects on north aspects (mean, $\pm 1 \mathrm{SE}$ ). N1-2, N2-2, etc. refer to transect ID and year of emergence (i.e., age of seedling); e.g., N1-2 refers to a seedling that emerged on transect N1 at 32 months. Year 1 does not have a suffix. 


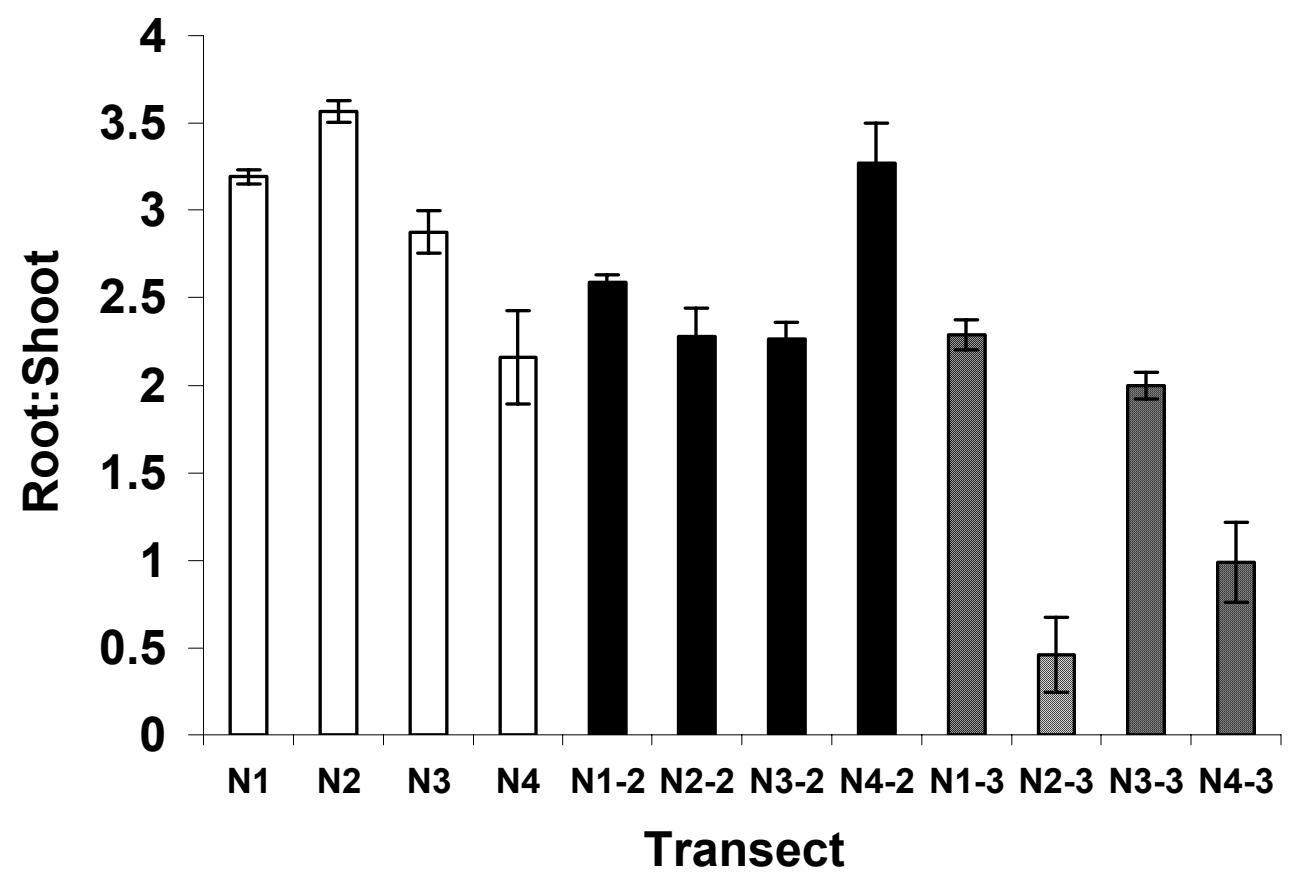


Table 4.3. Results of 2-way ANOVA test on the log-transformed biomass of harvested seedlings on north aspects. 


\begin{tabular}{lllll}
\hline Effect & df & SS & F Ratio & Prob > F \\
\hline Age & $\mathbf{2}$ & $\mathbf{2 3 . 7 5 0 3}$ & $\mathbf{3 1 . 9 2 6 0}$ & $<.0001$ \\
Density & 1 & 0.01154 & 0.0033 & 0.9586 \\
Transect [density] & $\mathbf{2}$ & $\mathbf{1 5 . 6 9 4 5}$ & $\mathbf{2 1 . 0 9 7 1}$ & $<.0001$ \\
Age x density & 2 & 1.68706 & 2.2678 & 0.1042 \\
Age x transect [density] & 4 & 0.10018 & 0.0673 & 0.9917 \\
\hline
\end{tabular}


Fig. 4.5. Comparison of mean biomass for Panax quinquefolius seedlings from 4 transects (two $50 \mathrm{~m}$ and two $5 \mathrm{~m}$ transects) on north aspects (mean, $\pm 1 \mathrm{SE}$ ). 


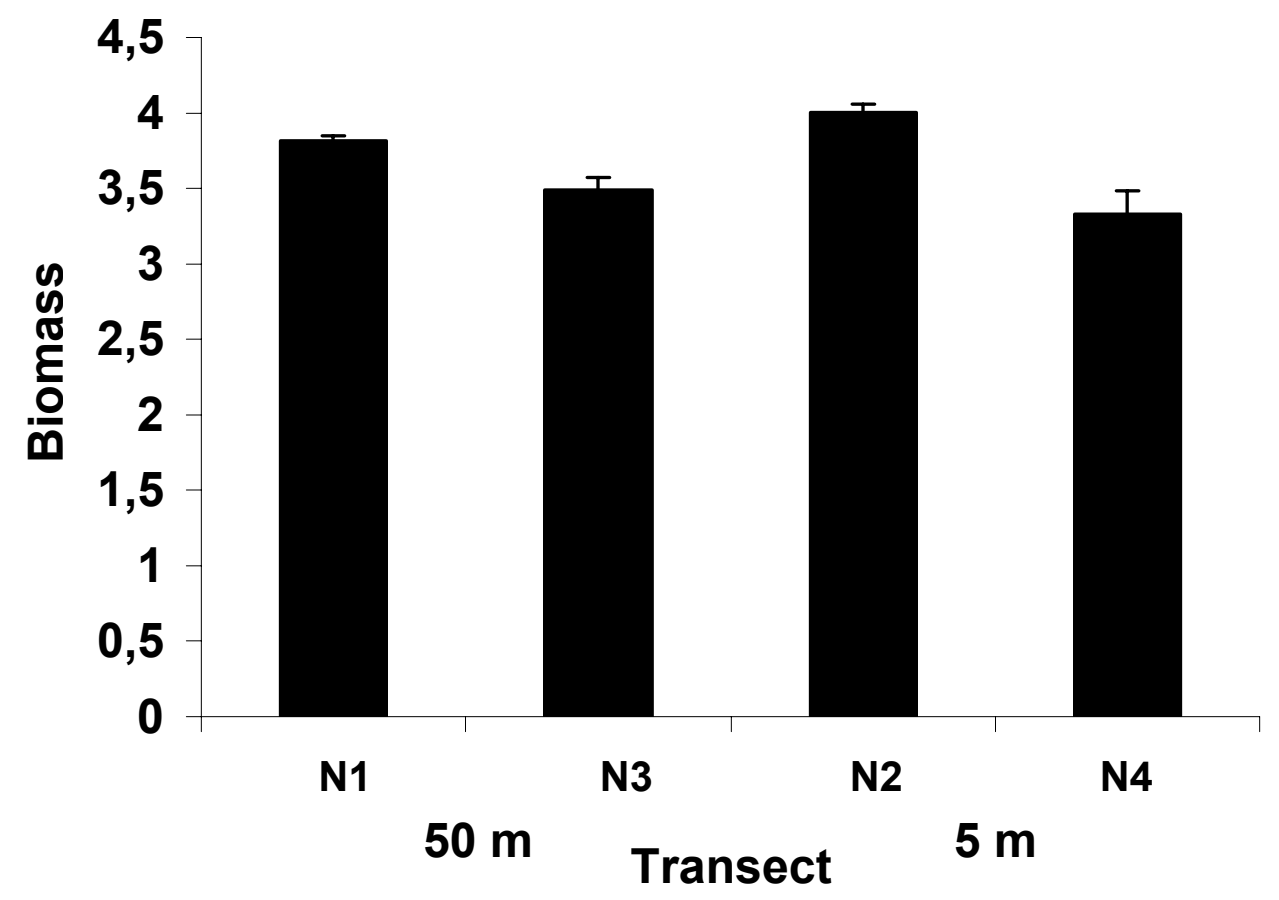


Although the habitat requirements of ginseng may not be as limited as previously thought (McGraw et al. 2003), the higher rate of emergence on north aspects was not completely surprising. The southern aspect study site was dry, dominated by oaks and the leaf litter was very deep. There was slow decomposition of oak leaves in the top $15 \mathrm{~cm}$ of litter, and the shoots of the seeds that emerged were etiolated and thin when they did emerge through the litter.

Nearly all of the seeds that were dispersed greater than $2 \mathrm{~m}$ from the transects on the north and south aspects were found in caches, some of which had as many as 50 seeds and 35 seedlings. This observation strongly suggested rodent dispersal. Dispersal greater than $2 \mathrm{~m}$ was only observed on the shorter (i.e., $5 \mathrm{~m}$ ) transects. The density of the planting design may have resulted in a resource 'advertisement' to small mammals. Evidence of rodent dispersal (e.g., berries with tooth marks, and berries dispersed away from adult reproductive plants) were observed previously in multiple ginseng populations (Van der Voort pers. obs. 1998-2000, Furedi pers. obs. 2000-2004). 'Washing' of seeds occurred on two of the study transects; one transect ran across a spring seep and the other was located in an area that experienced heavy spring rains one season.

Seedling survival might be expected to be higher in the range center of a species than at the margin. Variability in seedling survival rates was found in this experiment as in previous work. The rates of emergence observed here were lower than what Lewis and Zenger (1982) found in Missouri, but much higher than the rates documented by Charron and Gagnon (1991) in southern Québec (the northern extension of the range of ginseng). The higher rate of new seedlings to 1-leaf genets than 1-leaf to 1-leaf genets found in this study may be explained by a severe drought year in 1999. Ginseng seeds and seedlings are moisture sensitive. 
The change in the root:shoot ratio was greater between the youngest seedlings and the two older cohorts, suggesting that the allocation patterns during establishment were different among the transects. The greater allocation to shoot development in the first year could be due to lower light levels. By the second year, the root:shoot ratio had increased for most of the seedlings. The larger biomass of seedlings on two of the transects suggested that the microsite quality in those transects was more conducive to early growth and establishment for ginseng. We know that nutrient availability varies considerably across environments. Understanding the details of that variability will allow us to better understand the requirements for seed emergence and early growth in American ginseng. The effects of density on seed emergence and seedling survival need to be explored further. Nearly 2.5 times as many seeds emerged on the $50 \mathrm{~m}$ transects, but survival was ca. 2.5. times higher on the shorter transects.

Seeds are hard to follow in wild plant populations making parameter estimation difficult for seed bank and emergence elements in demographic models. This study documented long-term viability of ginseng seeds and secondary dispersal. Microsite quality appears to be important in early seedling growth and survival for $P$. quinquefolius. Results of this research suggested the importance of further exploring spatially-explicit and density-dependent demographic models in order to improve our understanding of the dynamics of American ginseng in the wild. 


\section{Literature Cited}

Anderson, R.C., J.S. Fralish, J.E. Armstrong, and P.K. Benjamin. 1993. The ecology and biology of Panax quinquefolium L. (Araliaceae) in Illinois. Am. Midl. Nat. 129:357-372.

Bannerman, J.E. 1998. Goldenseal in world trade: pressures and potentials. HerbalGram, 41:51-52.

Baskin, C.C. and J.M. Baskin. 1998. Seeds. Ecology, biogeography, and evolution of dormancy and germination. Academic Press, New York. 666 pp.

Bodmer, R.E. 1995. Managing Amazonian wildlife: biological correlates of game choice by detribalized hunters. Ecol. Applic., 5:872-877.

Carpenter W.G. and G. Cottam. 1982. Growth and reproduction of American ginseng (Panax quinquefolius) in Wisconsin, USA. Can. J. Bot. 60:2692-2696.

Caughley, G. 1994. Directions in conservation biology. Journal of Animal Ecology 63:215-244.

Charron D. and D. Gagnon. 1991. The demography of northern populations of Panax quinquefolium (American ginseng). J. Ecol. 79:431-445.

Freese, C.H. 1998. Wild species as commodities. Managing markets and ecosystems for sustainability. Island Press, Washington, DC.

Furedi, M.A. 2004. Effects of herbivory by white-tailed deer (Odocoileus virginianus Zimm) on the demography and conservation biology of American ginseng (Panax quinquefolius L.). Ph.D. thesis. Morgantown, WV. USA. pp. 163. 
and J.B. McGraw. 2004. White-tailed deer: dispersers or predators of American ginseng seeds? Am. Midl. Nat. 152:268-279.

Hackney, E.E. and J.B. McGraw. 2001. Experimental demonstration of an Allee effect in American ginseng. Cons. Biol. 15(1):129-136.

Harding, A.R. 1936. Ginseng and other medicinal plants. A book of valuable information for growers as well as collector of medicinal roots, barks, leaves, etc. A.R.Harding Pub. Co. Columbus, Ohio. 171 pp.

Harper, J.L. 1977. Population biology of plants. Academic Press, New York. $892 \mathrm{pp}$.

Hu, S.Y., L. Rüdenberg, and P.D. Tredici. 1980. Studies of American ginseng. Rhodora 82:627-636.

Lewis, W.H. 1984. Population structure and environmental corollaries of Panax quinquefolium (Araliaceae) in Delaware County, New York. Rhodora, 86:431437.

, 1988. Regrowth of a decimated population of Panax quinquefolium in a Missouri climax forest. Rhodora, 90:1-5.

Lewis, W. and V.E. Zenger. 1982. Population dynamics of the American ginseng Panax quinquefolium (Araliaceae). Am. J. Bot., 69:1483-1490.

Mangel , M., R.J. Hofman, E.A. Norse, and J.R. Twiss, Jr. 1993. Sustainability and ecological research. Ecological Applications 3(4):573-575. 
Maxwell, H. 1898. The history of Randolph county, West Virginia. From its earliest settlement to the present. The Acme Publishing Company, Morgantown, W. Va. $531 \mathrm{pp}$.

S.M. Sanders and M.E. Van der Voort. 2003. Distribution and abundance of Hydrastis canadensis L. (Ranunculaceae) and Panax quinquefolius L. (Araliaceae) in the central Appalachian region. J. Torr. Bot. Soc. 130(2):62-69.

and MA Furedi. 2005. Deer browsing and population viability of a forest understory plant. Science 307:920-922.

Millspaugh, C.F. 1974. American medicinal plants. Dover Publications. New York, New York. 806 p. First published in 1892 as Medicinal plants. John C. Yorston and Company, Philadelphia.

Nantel, P, D. Gagnon and A. Nault. 1996. Population viability analysis of American ginseng and wild leek harvested in stochastic environments. Cons. Biol. 10(2):608-621.

Robbins, C.S. 2000. Comparative analysis of management regimes and medicinal plant trade monitoring mechanisms for American ginseng and goldenseal. Cons. Biol., 14:1422-1434.

SAS, 1994. JMP v. 3.2. Statistical Analysis Systems, Inc., Cary, NC.

SAS, 1998. StatView. Statistical Analysis Systems, Inc., Cary, NC.

Schlessman, M.A. 1985. Floral biology of American ginseng (Panax quinquefolium). Bull Torr. Bot. Club 112:129-133. 
Van der Voort, M.E. 1998. An inventory of wild-harvested plants in the Otter Creek wilderness area of the Monogahela National Forest, West Virginia. M.S. Thesis. $77 \mathrm{pp}$.

B. Bailey, J.B. McGraw and D.E. Samuel. 2003. Recovery of populations of goldenseal (Hydrastis canadensis L.) and American ginseng (Panax quinquefolius L.) following harvest. Am. Mid. Nat. 149:282-292. 


\section{Chapter 5}

Effects of harvester behavior on population growth rate affects sustainability of ginseng trade 


\begin{abstract}
When long-term, intense levels of harvest nearly extirpated Chinese ginseng (Panax ginseng) in the early $18^{\text {th }}$ century, commercial harvest of American ginseng ( $P$. quinquefolius) began and large quantities of the roots were exported to East Asia. Annual export figures have fallen over the past 200 years, but demand for wild American ginseng has not abated. Persistent harvest of long-lived, slow-maturing species can have negative impacts on population growth rates, yet those closest to wild resources are often in a position to be the best stewards of that resource. This study explored the consequences of alternative harvester behaviors on the population dynamics of American ginseng. Drawing on known behaviors, I developed three harvester 'types' and ran demographic simulations on wild ginseng populations, partitioning the sources of differences in population growth rates using a life table response experiment (LTRE). The simulations showed that ignoring size class limits and harvest season onset dates dramatically affected population growth rates. Existing laws in many states are not adequate to protect wild ginseng populations. A stewardship-oriented harvester, who delays harvest onset by two weeks, selflimits harvest intensity and plants ginseng seeds at the time of harvest can reverse declining population growth rates.
\end{abstract}


Introduction

Ginseng has been used in traditional medicine for several thousand years (Robbins, 1998). Long-term, intense levels of harvest nearly extirpated Chinese ginseng (Panax ginseng, also described as Asiatic, Oriental or Korean ginseng) in the early part of the $18^{\text {th }}$ century (Millspaugh, 1974). A Jesuit missionary hypothesized that if ginseng were to be found in North America, it was likely to be in Canada where environmental conditions resembled those for Chinese ginseng (Kimmens, 1975). His premise proved to be correct and American ginseng (Panax quinquefolius L.) was found growing in Canadian hardwoods (Kimmens, 1975). Word of the American species spread quickly to China and export began almost immediately. Large quantities of ginseng were dug in North America in the early 1700 s and shipped directly to East Asia for further processing and sale (Carlson, 1986). Anecdotal reports indicate that within 20-30 years the plant became increasingly difficult to find, although it was not extirpated from the wild (Millspaugh, 1974, Kimmens, 1975). Harvest and export quickly ended in the province of Québec (Evans, 1985; Gagnon pers. comm.), and annual harvest figures dropped in the central portion of its range (central Appalachia). Nonetheless, over $60,000 \mathrm{~kg}$ continue to be harvested annually and sold for export (Prescott-Allen and Prescott-Allen, 1986; Robbins, 2000).

P. quinquefolius was placed on Appendix II of the CITES (Convention on International Trade in Endangered Species of Wild Fauna and Flora) list in 1973. The listing prompted the US government to create a management program with range states to ensure that federal responsibilities under CITES were satisfied (Robbins, 2000). Before export of an Appendix II species, federal authorities must determine that removal of that species will not be detrimental to its survival in the wild. In the case of $P$. quinquefolius, all states requesting export permission must file, on an annual basis, records of the previous year's harvest by weight and by collection location. The US Fish and Wildlife Service (USFWS), Office of Scientific Authority, then annually determines whether or not continued 
harvest of the species is detrimental to long-term survival in the wild (Robbins, 2000).

Collection of $P$. quinquefolius requires informal or formal permitting (unless the digging is done on one's property) and must be harvested in season. Opening dates vary among states and range from 1 August to 15 September (McGraw et al., 2005). Digging on national forest land requires a permit, as does harvest on state lands where permitted (harvest is usually restricted, Robbins, 2000). When collecting on private lands, written permission from the owner is necessary.

While the CITES requirements have institutionalized a framework within which states compile and submit data to USFWS managers for review, the program has struggled with multiple problems since its inception (Robbins, 2000). For example, the states receive no funding from the federal government to carry out any of the required work. Because responsibility for record keeping, submission of data to USFWS and management of wild ginseng populations does not lie with the same agencies among states, regional coordination can be complicated (Robbins, 2000). Until recently (Gagnon, 1999) there was no unifying monitoring protocol among states so data was often not comparable. Even with the design of a monitoring protocol, however, many states simply cannot or will not participate due to a lack of funding.

Managing an economically valuable species which is uncommon and widely-dispersed across a geographic range is difficult. State boundaries are meaningless to species distribution but the different regulations among states further complicate any monitoring efforts. Unifying harvest practices that enhance populations of American ginseng is important if wild collection is to continue. 
In the course of long-term demographic research on $P$. quinquefolius populations in the range center over the past decade, multiple types of harvesting behavior have been documented. Plants have been harvested both in and out of season (Furedi, 2004; McGraw and Furedi, 2005; Van der Voort, Chapter 5), and removal of plants of illegal size/age has been documented (Furedi, pers. comm. 2000-04; McGraw, pers. comm. 2004; McGraw and Furedi, 2005). Through observation and personal interviews (Bailey, 1999), harvest of ginseng from areas that are both legal and illegal for collection of wild plants has also been documented.

Demographic research on ginseng in southern Québec (the northern margin for the species) indicated that populations there are increasing at an average rate of approximately $3 \%$ per year (Charron and Gagnon, 1991). When harvest was included in the demographic model under varying environmental conditions, the finite rate of increase $(\lambda)$ declined with increasing rates of harvest and the minimum viable population size necessary to rebuild harvested populations was estimated at 170 plants (Nantel et al., 1996). Recent demographic studies of $P$. quinquefolius in the range center indicate that high densities of white-tailed deer (Odocoileus virginianus Zimm.) are negatively impacting long-term survival of American ginseng (McGraw and Furedi, 2005). McGraw and Furedi's (2005) estimate of minimum viable population size (under ambient white-tailed deer densities) was 800 plants. No studies have been carried out on the impacts of human harvest on $P$. quinquefolius demography in the range center.

The primary objectives of this study were to explore the potential consequences of alternative harvester behaviors on the population dynamics of $P$. quinquefolius, and to partition the sources of differences in population growth rates between the different harvesting behaviors using life table response experiments (LTREs). I asked three questions: (1) What are the consequences of ignoring size class limits and harvest season onset dates for population growth 
rate? (2) Is harvester behavior that fully complies with existing laws for several important harvesting states (West Virginia, Kentucky, Tennessee and Virginia) adequate to sustain populations in the long term? (3) What, if any, advantage is gained by population stewards who self-limit harvest intensity and use what is known about ginseng reproductive ecology to ensure recruitment after harvest? My null hypotheses were that any harvest would have a negative effect on population growth and that there would be no dependence of this effect on harvester behavior.

Methods

Study Species

P. quinquefolius is a long-lived, perennial herb native to the rich, moist, deciduous forest of eastern North America (Millspaugh, 1974). It emerges in spring before full canopy leaf emergence. Individuals can live for three or more decades (Charron and Gagnon, 1991; McGraw, 2001). Ginseng progresses through a series of growth stages where leaf number is closely associated with size (Carpenter and Cottam, 1982; Charron and Gagnon, 1991; Anderson et al., 1993). A single trifoliate leaf emerges at germination (Anderson et al., 1984). Plants can retain a single leaf (with 3-5 leaflets) for multiple years (Furedi, McGraw, Van der Voort, pers. obs.). Two-leaf plants often flower, but rarely produce seeds (Anderson et al., 1984; Charron and Gagnon, 1991). The 2-leaf stage is typically followed by a reproductive adult period ( 3 or more leaves) which can begin as early as age 7 or 8 (Carpenter and Cottam, 1982; Charron and Gagnon, 1991), but may be much later. P. quinquefolius proliferates primarily through sexual reproduction (Schlessmann, 1987), although asexual reproduction occurs rarely (Lewis and Zenger, 1982; Anderson et al., 1993; Van der Voort et al., 2003). One- to 3-seeded berries ripen from August-September and require warm and cold stratification over a period of 18-20 months, as seed 
embryos are immature at the time of dispersal (Hu et al., 1980; Baskin and Baskin, 1998).

Although populations were once reported to be much larger (Maxwell, 1898; Kimmens, 1975) the majority of populations have fewer than two hundred individuals (Carpenter and Cottam, 1982; Lewis, 1984; Schlessman, 1985; Lewis, 1988; Charron and Gagnon, 1991; Van der Voort, 1998; McGraw and Furedi, 2005). The underground structures, the root and rhizome, are of primary interest to the harvester (and the consumer). Therefore, harvest kills the plant, although if the plant is reproductive, harvesters may facilitate reproduction by planting the seeds. Leaves are used for teas and other concoctions, but hold no value on the international market.

Study Sites

Six study populations were located in north central West Virginia in second-growth mixed mesophytic hardwoods, all of which were logged by the early part of the $20^{\text {th }}$ century. All study populations were randomly located by systematic searching (see McGraw et al., 2003 for discussion of sampling this widespread but scarce understory herb). When found, individuals were marked with unique, underground tags and followed for 3 years. Aspect (4 populations were located on north-facing aspects, one on east-facing and one south-facing), slope (moderate to steep, ca. 30 to 60 , two sites had unstable soils) and elevation (ranged from 475-810 m) varied among populations. Detailed maps of each population were made to assist future relocation.

\section{Annual Censuses}

All individuals were censused at least twice annually from 10 June to 8 July and then again (for reproductive data) from 11 August to 26 August in 1998, 1999 and 2000. Leaf and leaflet counts were made for each individual. The 
dimensions (length and width) of the longest leaflet of each leaf of the plant was measured. Reproductive status was recorded, including the number of buds and/or flowers present. Any signs of herbivory, disease or other unusual characteristics were noted. As with many plants, $P$. quinquefolius seed production is concentrated during a single period of the year resulting in a birthpulse population (Caswell, 2001). At the August census, berries were ripe or ripening but not yet dispersed, and seed number could therefore be determined accurately.

Population Projection Matrix Models

Matrix population models project numerical change over time. They provide a theoretical basis for population management, and because most management problems involve vital rates, demographic models are essential tools in conservation and population management (Caswell, 2001). Matrix population models have been used to design management and conservation programs for species as varied as loggerhead sea turtles (Crouse et al., 1987), Furbish's lousewort (Menges, 1990), Florida manatees (Marmontel et al., 1997) and California condors (Meretsky et al., 2000), to mention just a few.

A projection matrix model specifies a matrix of transition probabilities between different classes (Table 5.1), from time $t$ to $t+1$, with the transition probabilities representing observed values of survival, growth, stasis, regression in size, fertility and recruitment (Bierzychudek, 1999). This population projection equation is:

$$
n(t+1)=A n(t)
$$

where $\boldsymbol{n}$ is a column vector whose values represent the numbers of individuals in each class, and $\mathbf{A}$ is a square, non-negative matrix. Each element, $a_{i j}$, gives the 
Table 5.1. Transition probability matrix (A) for Panax quinquefolius. Each element $a_{i j}$ represents the number of size $i$ individuals in year 2 per size $j$ individual in year 1 . Classes are defined as: $1=$ seed, $2=$ seedlings and 1 -leaf combined, 3=2-leaf, 4=small adults (3-leaf plants with leaf area $<250 \mathrm{~cm}^{2}$ ) and $5=$ large adults (3-leaf plants with leaf area $>250 \mathrm{~cm}^{2}$ and all 4-leaf plants). 


\section{FROM stage class}

$\begin{array}{lcccccc} & & 1 & 2 & 3 & 4 & 5 \\ & 1 & a_{11} & 0 & a_{13} & a_{14} & a_{15} \\ & 2 & a_{21} & a_{22} & a_{23} & 0 & 0 \\ \begin{array}{l}\text { TO } \\ \text { clase }\end{array} & 3 & 0 & a_{32} & a_{33} & a_{34} & a_{35} \\ & 4 & 0 & 0 & a_{43} & a_{44} & a_{45} \\ & 5 & 0 & 0 & a_{53} & a_{54} & a_{55}\end{array}$


number of size $i$ individuals in year 2 per size $j$ individual in year 1 (Table 5.1). The dominant eigenvalue of $A$ gives the finite rate of increase $(\lambda)$ of the population. When $\lambda=1$, the population is stable in the long-term. When $\lambda<1$, the population is declining when the stable stage distribution (SSD) is reached and when $\lambda>1$ the population is increasing (at SSD).

Model Parameterization and Model Development

In plants, size is often a better indicator of individual fates than age (Werner, 1975; Harper, 1977). Although leaf number was used in past ecological studies of $P$. quinquefolius (Carpenter and Cottam, 1982; Charron and Gagnon, 1991; Anderson et al., 1993) as a simple and convenient method of data collection, leaf area may be a more accurate parameter because it is assumed to be proportional to photosynthetic capacity. P. quinquefolius individuals with greater leaf area may reach reproductive maturity earlier and produce more seeds than smaller individuals of the same age. Leaf area has been used in other demographic models to better capture real size differences among individuals and their vital rates (Werner, 1975; Werner and Caswell, 1977, McGraw and Antonovics, 1983; McGraw, 1989). Recent demographic research on $P$. quinquefolius using a combination of leaf area and leaf number provided more accurate estimates for the vital rates and the impact of plant size on vital rates in the central Appalachians (Furedi, 2004; McGraw and Furedi, 2005.). Leaf area was used to divide the 3-leaf plants into small and large adults. The decision to divide only 3-leaf plants was based on the significantly lower rate of reproduction in 2-leaf plants ( $G=567.973, P=0.0001)$ and the high variability in size and seed set within the 3-leaf class. Four-leaf plants produced significantly more seeds than 3-leaf plants and were categorized as large adults (ANOVA, $F$ ratio $=139.1842, \mathrm{P}=0.0001)$.

Leaf length and width measurements were used to calculate leaf area based on the following multiple regression equation $\left(r^{2}=0.95, N=102\right)$ : 
$L A=4.03(L L)+5.17(L W)+1.38\left(L L^{*} L W\right)$.

The equation was derived from leaflet lengths and widths, with leaf areas measured independently using a portable Li-Cor Model Li-3000A leaf area meter $(n=102)$. All leaf area data for 3-leaf plants used in demographic studies from 1998-2003 were pooled (Furedi, 2004; Van der Voort, unpublished data 2004). The mean of the annual median leaf area was $252.45 \mathrm{~cm}^{2}( \pm 4.49)$. The value $250 \mathrm{~cm}^{2}$ was chosen as the cutoff between small and large adults as it was within the $95 \%$ C.I. of the true mean. Small adults were defined as having $<250 \mathrm{~cm}^{2}$ of leaf area. Large adults had a leaf area $\geq 250 \mathrm{~cm}^{2}$. The leaf area of all 4-leaf plants was $>250 \mathrm{~cm}^{2}$.

Kalisz (1991) and Kalisz and McPeek (1992) demonstrated the importance of quantifying the effects of seed bank dynamics, including aging of seeds, in demographic models. A large seed germination and survival study (Van der Voort, Chapter 3 ) indicated that $P$. quinquefolius does possess a seed bank with seeds remaining viable for at least 5 years, as suggested by Lewis (1988). To estimate seed survival $\left(a_{11}\right)$ and germination rates $\left(a_{21}\right)$ required for parameter estimation of the seed class in the demographic model for $P$. quinquefolius, McGraw and Furedi (2005) used seed cage data collected from the 6 populations used for this study. The seed cages were embedded at the field sites in 2002, and checked for viability in Spring 2003 and 2004. The 2003 data were used to estimate the proportion of seeds remaining viable in the seed bank from August to May ( $p$ ). The 2004 data were used to estimate the proportion of seeds remaining in the seed bank $(v)$ and the proportion of seeds dying. For more detail on methodology, see McGraw and Furedi (2005). 
The fertility estimates for reproductive classes $\left(a_{1 j}\right)$ were calculated as follows:

$$
a_{1 j}=\frac{p S_{j}}{n_{j}},
$$

where $S_{j}$ is the total number of seeds produced by class $j$ in year $1, n_{j}$ is the number of individuals in class $j$ in year 1 , and $p$ is the proportion of seeds remaining viable in the soil from August until May as determined from the seed cage study (2003 data). A delayed dormancy of at least 18 months was assumed and seeds produced in August did not germinate until one year after their first spring. The number of seeds germinating $\left(s_{g}\right)$ was calculated as follows:

$$
S_{g}=\frac{R}{0.90},
$$

where $R$ is the number of new seedling recruits found in a population in year 2 within $2 \mathrm{~m}$ of adult $P$. quinquefolius plants, and 0.90 is a correction factor used to adjust for uncounted seedlings beyond the $2 \mathrm{~m}$ search radius (90\% of seedlings move less than $2 \mathrm{~m}$ after gravity dispersal; Van der Voort, Chapter 3). The number of seeds remaining dormant $\left(s_{d}\right)$ was needed to estimate $a_{11}$ (seeds remaining seeds from y 1 to y 2 ), and was calculated as follows:

$$
S_{d}=\operatorname{vpS}_{o}-S_{g} \text {, }
$$

where $S_{0}$ is the actual number of seeds produced in the August prior to $y 1$ of the interval under consideration and $v$ is the proportion of seeds remaining viable in the soil for 12 months as determined from the seed cage study (2004 data). Seed numbers from 1997 were needed to calculate $S_{0}$ for the first transition (1998-1999). A mean 1997 seed number was calculated by averaging seed counts from all 3 years of this study (i.e., 1998, 1999 and 2000). The elements $a_{11}$ and $a_{21}$ are therefore calculated as follows: 


$$
\begin{aligned}
& a_{11}=\frac{v p S_{0} S_{g}}{p S_{0}} \\
& a_{21}=\frac{(R / .90)}{p S_{0}} .
\end{aligned}
$$

The formulas for $a_{11}, a_{21}$ and fertilities $\left(a_{1 j}\right)$ used here are taken directly from McGraw and Furedi (2005).

The effect of environmental variation on seed viability in the seed cage experiments is relevant to a time period after this study was conducted. However, I assumed that the variation was representative of environmental differences in 1998-2000 as well.

Once censuses were completed, every individual was assigned to a size/stage class. The five classes in the matrix model were defined as follows: seeds (class 1 ), seedlings (1-leaf plants; class 2), 2-leaf plants (class 3 ), small adults (class 4 ), and large adults (class 5). Due to the low number of new seedlings, seedlings and 1-leaf plants were combined into a single class to ensure adequate parameterization. Assumptions were necessary when data were missing on individuals during the annual census periods (i.e., due to browse, harvest or some other factor). If a plant was recorded as missing for 2 years in a row, its fate was considered death in the first year it was missing. Harvest is fully destructive to an individual; a plant was considered dead if harvested. When a plant was present in years 1 and 3 , but missing in year 2, class assignments were dictated by status in the first year. The number of individuals following this pattern varied among populations, but ranged from 0 $12 \%$, with a mean of approximately $5 \%$ per population. 
Individuals present in the first two years of the study but missing in the third, were assigned to classes based on the probability of survival or death calculated from known fates of other individuals. The number of individuals that needed assignments also varied among populations in this category. Values ranged from $14-51 \%$, with a mean of about $28 \%$. The probability of surviving increased with size, however, large adults were 1.5 times more likely to need probability assignments. A population missing one half of the individuals for the year 3 census was browsed heavily by white-tailed deer (O. virginianus) early in the season. Furedi (2004) found that deer generally focused their browsing on larger $P$. quinquefolius which may explain the need for more probability assignments in this class. For adequate estimation, probability assignments were based on a mean of the 6 study populations.

Although not all transitions were possible for all individuals, plants could transition in more than one way depending on class. For example, a small adult could remain in the same class from one year to the next (stasis, $a_{i j}$, where $i=j$ ), regress in size $\left(a_{i j}\right.$, where $\left.i<j\right)$, grow $\left(a_{i j}\right.$, where $\left.i>j\right)$, or die. A one year time step from June to June was used to calculate the vital rates and for projecting the future size and structure of the populations.

Harvesting Simulations

Estimating a rate of harvest for $P$. quinquefolius for use in harvest simulations is complicated by several factors. Personal interviews with harvesters (Bailey, 1999) indicated that harvest practices varied widely in regard to size and number of plants taken, time of harvest events, and the fate of seeds present in a population at the time of harvest. Quantifying the variability is especially difficult with a species like $P$. quinquefolius as harvesting is typically a solitary activity (or small unit of related individuals), veiled in secrecy (Bailey, 1999). 
To estimate the rate of harvesting, I drew on several sources. The mean rate of harvest observed among all six populations in this study was about $3 \%$. McGraw et al. (2003) estimated an annual rate of harvest in West Virginia of ca. $5 \%$ by extrapolating multiple estimates of $P$. quinquefolius densities from three census methods covering a wide range of aspects, elevations, management regimes and forest cover types. These low overall figures include a mixture of populations that are harvested and those that are not (probably a majority). Mooney (pers. comm., 2004) conducted a harvesting experiment whereby novice "harvesters" (i.e., people who could identify P. quinquefolius but who were not familiar with the experimental site) were presented with an area known to contain P. quinquefolius and asked to flag all plants of legally harvestable size (i.e., 3-leaf and larger plants). Her estimates of harvest ranged from $16-37 \%$ of the total population. While the presentation of a site known to contain $P$. quinquefolius might bias the harvest rate upward, active harvesters often benefit from "cultural knowledge" passed on from a family member and/or through previous scouting episodes made throughout the year while foraging for other wild harvested products (Bailey, 1999). The experimental study population was unusually large $(n=391)$ and widely dispersed in space. Population size of $P$. quinquefolius is not well known across the state. The median population size was 5 individuals in a previous study of 43 populations containing a total of 961 plants (Van der Voort, 1998 and unpubl. data). The majority of the populations (i.e., 65\%) were < 10 genets. McGraw and Furedi (2005) found a median of 93 individuals in 36 populations studied in an eight-state region near the range center of ginseng from 2000-2004; 53\% had < 100 genets. A harvester encountering a small population could easily remove as much as $90 \%$ of all aboveground plant material at a site (i.e., taking all 2-leaf and larger plants). I set the harvest rate for this set of experiments at $25 \%$ as a compromise figure from the various estimates of harvest. This rate is undoubtedly within the range of actual rates experienced by those populations encountered by harvesters, without being extremely high or low. 
Browsing by white-tailed deer in ginseng populations influenced the availability of plants for harvest (Furedi 2004). Intensive, repeated censusing of all P. quinquefolius individuals in study populations by Furedi (2004) provided a mean rate of browse across 4 years at different dates throughout the growing season. The mean browse rate (adjusted for date) was applied to the harvester models to adjust numbers of available plants. While the browse censuses were conducted from 2000-2004, I assumed that the variation was representative of differences in 1998-2000.

The timing of harvest also impacts demographic rates due to differences in seed ripening and seed germinability (McGraw et al., 2005). Nearly all $P$. quinquefolius seeds in West Virginia were green (98\%) at the onset of the harvest season (15 August). Green seeds germinate at a significantly lower rate than red seeds at this time (McGraw et al,. 2005). Further, an experimental study showed that seeds planted $2 \mathrm{~cm}$ deep germinated at a rate 8-fold higher than those scattered on the surface (McGraw, unpublished data, 2002). Adjustments for germination in relation to date of harvest were applied to the harvester type models.

The range of harvesting behaviors and extent of harvest vary across a spectrum. To explore the impact that this variability could have on population vital rates, I analyzed the effect of three classes of harvester behaviors that incorporated timing and extent of harvest and alternate fates for harvested seeds (from both red and green berries). 
Construction of Harvester Models

The Non-compliant Harvester

The non-compliant harvest date was set at 15 June. Bailey's (1999) harvester interviews documented that non-compliant harvest occurred any time plants were found. In my simulations, non-compliant harvesters removed $25 \%$ all 3-leaf and larger plants, and consistent with their willingness to disregard harvest season, they harvested $25 \%$ of all 2-leaf plants (an illegal size). This behavior has been observed in many monitored populations and is corroborated by dealers who frequently find small pre-adult roots in batches they buy from harvesters (McGraw, pers. obs., 2004). There was no browse adjustment for the non-compliant harvester as harvest onset coincided with the first demographic censuses, leaving all known plants in the population available to the harvester. Seed production of all harvested plants was set to zero, as fruits are not present in mid-June.

The Compliant Harvester

Compliant behavior was characterized by harvesting as soon as harvest season began on 15 August. The compliant harvester took $25 \%$ of the available 3-leaf and larger plants, and any berries on these plants were scattered on the surface of the leaf litter. To adjust for the mean rate of browsed plants at the onset of compliant harvesting, $9 \%$ of all small and large adults were randomly removed from the available plants for harvest. These individuals remained in the matrix for all calculations, however, fertilities were reduced to zero. Furedi and McGraw (2004) found that white-tailed deer generally browsed larger $P$. quinquefolius, fertility of all reproductive classes were reduced by browsing and regression to smaller classes and reduced bud set occurred with repeated browsing events on the same individuals (Furedi, 2004). Further, Furedi and McGraw (2004) documented seasonal elimination of reproductive potential (both 
for individuals and whole populations) in populations where complete browse occurred. I extrapolated the germination of green seeds based on a previous experiment where green and red seeds were planted at 3 different dates (McGraw unpublished data). An adjustment was made to the germination rate in the matrix model based on the fraction of seeds that were harvested on that date. Germination was adjusted downward for the compliant harvester by multiplying $a_{21}$ by 0.8955 .

\section{The Steward}

I asked whether there are optimal harvester behaviors that could positively influence population growth rate and created the steward harvester model to examine this question. The steward delayed harvest by 2 weeks to allow berry ripening (McGraw et al., 2005), harvested 25\% of the 3-leaf and larger plants in the population only if they were fruit-bearing (i.e., the steward only took plants with berries), and always planted the berries (regardless of color) at a depth of 2 $\mathrm{cm}$. Plants unavailable for harvest due to browse was set at $15 \%$. Small and large adults were randomly removed for the analysis as outlined above for the compliant harvester. Germination of seeds for the steward was adjusted upward by multiplying $a_{21}$ by 2.6825 , taking into account the higher number of ripe seeds at the later harvest date and the increased germination due to seed burial at depth of $2 \mathrm{~cm}$.

Table 5.2 summarizes the harvester types. The non-compliant and steward harvesters are viewed as being near the opposite ends of a spectrum of behaviors that exist, with compliant probably representing the middle of the spectrum. Undoubtedly there could be more extreme non-compliant individuals (e.g., harvesting earlier or more intensely), and stewards could be more extreme as well (e.g., harvesting fewer plants, while planting many more seeds). 
Table 5.2. Description of three harvester types with explanation of harvest intensity and adjustments for deer browse and seed germination dependent on berry color, time of harvest and seed fate. See text. 


\begin{tabular}{|c|c|c|c|}
\hline & Non-compliant & Compliant & Steward \\
\hline Season & $\begin{array}{l}\text { Ignores harvest } \\
\text { season (harvests } 15 \\
\text { June) }\end{array}$ & $\begin{array}{l}\text { Harvests in-season } \\
\text { (15 August) }\end{array}$ & $\begin{array}{l}\text { Delays harvest until } \\
\text { greater berry } \\
\text { ripening } \\
\text { (1 September) }\end{array}$ \\
\hline Stage & $\begin{array}{l}\text { Harvests } 2 \text {-leaf, } \\
\text { small adults and } \\
\text { large adults }\end{array}$ & $\begin{array}{l}\text { Harvests only small } \\
\text { and large adult } \\
\text { plants. Berry color } \\
\text { does not matter }\end{array}$ & $\begin{array}{l}\text { Harvests only small } \\
\text { and large plants with } \\
\text { berries. Berry color } \\
\text { does not matter }\end{array}$ \\
\hline Intensity & $\begin{array}{l}\text { Takes } 25 \% \text { of the } 2- \\
\text { leaf, small adults } \\
\text { and large adults }\end{array}$ & $\begin{array}{l}\text { Takes } 25 \% \text { of small } \\
\text { and large adults }\end{array}$ & $\begin{array}{l}\text { Takes } 25 \% \text { of small } \\
\text { and large adult } \\
\text { plants in the } \\
\text { population only if } \\
\text { berries are present }\end{array}$ \\
\hline Seed fate & $\begin{array}{l}\text { N/A. Berries not } \\
\text { present }\end{array}$ & $\begin{array}{l}\text { Berries planted by } \\
\text { scattering }\end{array}$ & $\begin{array}{l}\text { All berries (i.e., red } \\
\text { and green) planted } \\
\text { at a depth of } 2 \mathrm{~cm}\end{array}$ \\
\hline $\begin{array}{l}\text { Seed } \\
\text { adjustment }\end{array}$ & $\mathrm{N} / \mathrm{A}$ & $\begin{array}{l}a_{21} \text { is adjusted } \\
\text { downward by: } \\
a_{21} \times 0.88955\end{array}$ & $\begin{array}{l}\mathrm{a}_{21} \text { is adjusted } \\
\text { upward by: } \mathrm{a}_{21} \mathrm{x} \\
2.6825\end{array}$ \\
\hline $\begin{array}{l}\text { Browse } \\
\text { adjustment }\end{array}$ & $\mathrm{N} / \mathrm{A}$ & $\begin{array}{l}9 \% \text { of small and } \\
\text { large adults are } \\
\text { browsed }\end{array}$ & $\begin{array}{l}15 \% \text { of small and } \\
\text { large adults are } \\
\text { browsed }\end{array}$ \\
\hline
\end{tabular}


Data Analysis

All six populations were pooled and an average matrix was estimated for year 1 of the data set. Fewer plant fates in year 1 were estimated by probability assignments $(\cong 5 \%)$, therefore giving increased confidence in the parameters of the model for that year. To quantify the contribution of each of the estimated vital rates (i.e., the $a_{i j} s$ ) in the transition matrix to the variability in $\lambda$, life table response experiments (LTREs) were used (Caswell, 1989). Elasticities and sensitivities calculated from matrix projections predict the results of perturbations of the vital rates before they happen, but they do not tell us anything about which vital rates are actually responsible for an observed change in $\lambda$ (Caswell, 1989). The decomposition analysis of an LTRE does so by combining the actual change in the $a_{i j}$ 's with sensitivity analysis $\left(s_{i j}=\delta \lambda / \delta a_{i j}\right)$. LTREs can be used for multiple comparisons of different "environmental conditions" (Knight, 2004); in this case, different types of harvesting behavior.

An 'ambient' matrix was created from the estimated average matrix by removing harvest altogether. Harvested plants were reassigned fates according to their class affiliation in the year of harvest. In other words, if a large adult was harvested, it was reassigned to the large class (i.e., class 5 ) for the creation of the 'ambient' matrix. This followed the protocol for fate assignments described earlier. The majority of the harvested plants were in the large adult class and seed production of the harvested individuals was high. I changed fates to survived rather than removing the observations altogether so that I did not inadvertently eliminate large and/or fecund individuals from the population. In Comparison Set I, each of the harvester types was compared to the 'ambient' matrix. In Comparison Set II, three additional comparisons were made: compliant-non-compliant, steward-non-compliant and steward-compliant, for a total of 6 LTREs. 
The different harvesting type matrices were created by applying the rates of harvest, browse and germination adjustments outlined above to the data set 10 separate times to create 10 different matrices for each scenario. The mean matrix was determined to produce the non-compliant, compliant and steward scenario matrices respectively. Each model can be summarized:

$$
\lambda_{\text {Scenario A }}-\lambda_{\text {Scenario B }} \cong \sum\left(a_{i j \text { Scenario A }}-a_{i j \text { Scenario }}\right) s_{i j}
$$

The summed terms give an indication of the relative contribution of each parameter. The $s_{i j}$ 's were the sensitivities of the average matrix created using the 2 matrices being compared (e.g., $\lambda_{\text {Scenario } \mathrm{A}}+\lambda_{\text {Scenario } \mathrm{B}} / 2$ for the generic example above).

MATLAB (Mathworks, Version 4.0) was used for all calculations for the demographic analyses including estimation of standard errors, which were calculated using jackknifing.

Results

Effects of harvester type on demography

As expected, mortality of large and small adults varied greatly among simulations. In the absence of harvesting (i.e., 'ambient'), large adult mortality was very low (2\% per year; Fig. 5.1 ). Mortality of class 5 plants was highest in the non-compliant simulation ( $27 \%)$, followed by compliant $(25 \%)$ and then steward (17\%; Fig. 5.1). Class 3 (2-leaf) plants, were only removed in the noncompliant simulation. Mortality in this class was $30 \%$ for the non-compliant simulation and $7 \%$ in the other three simulations. Stasis and growth of small adults was also altered by harvesting (Fig. 5.1). Fertility was also greatly reduced in the presence of harvesting (Fig. 5.1). The non-compliant simulation had the largest reduction ( $25 \%$ lower than 'ambient'). There were also very large 
differences in the rate of germination among the harvester classes (Fig. 5.1). These will be discussed in detail in the LTRE analysis.

Effects of harvester type on population growth rate

Estimates of population growth rates $(\lambda)$ in the four scenarios varied (Fig. 5.2). The non-compliant harvester population was estimated to be declining by $15 \%$ per year $(\lambda=0.8522, \pm 0.0229$ ), while the compliant harvester population was estimated to be declining by $8 \%$ per year $(\lambda=0.9236, \pm 0.0199)$. This same population under the steward simulation was estimated to be increasing by $4 \%$ per year $(\lambda=1.0412, \pm 0.0195)$. In the absence of harvest (i.e., 'ambient'), the population was also increasing by ca. $4 \%(\lambda=1.0389, \pm 0.0173$; Fig. 5.2$)$.

Elasticity analysis of the four populations indicated that small changes in the proportion of plants remaining in the same class (i.e., stasis across classes) had the greatest relative effect on population growth rate (Table 5.3). Stasis of large plants $\left(a_{55}\right)$ had the highest elasticity for three of the four simulations (all but non-compliant, where stasis of 2-leaf plants, $a_{33}$, was higher). Survival in the seed bank class $\left(a_{11}\right)$ had a substantial effect on population growth rate in all but the 'ambient' matrices. Small changes in the proportion of germinating seeds $\left(a_{21}\right)$ also affected $\lambda$ in all simulations.

\section{LTRE analysis}

Depending on the comparison, varying numbers of the 17 vital rates were affected by harvesting. Only those parameters that had substantial differences in the vital rates and the sensitivity of $\lambda$ to changes in those vital rates will be discussed. All comparisons are listed in Tables 5.4 and 5.5. 
Fig. 5.1. Life cycle diagram of Panax quinquefolius showing the five classes (seeds, seedlings and 1-leaf plants, 2-leaf plants, small adults and large adults) and all possible transitions between classes when (a) all plants were included in the calculation of a mean ambient matrix (i.e., no harvesting), when (b) the noncompliant harvester treatments were applied, when (c) the compliant harvester treatments were applied and (d) when the steward harvester treatments were applied. The probabilities of transitioning from one class to another $\left(a_{i j}\right)$ are indicated by the numbers above each arrow. 

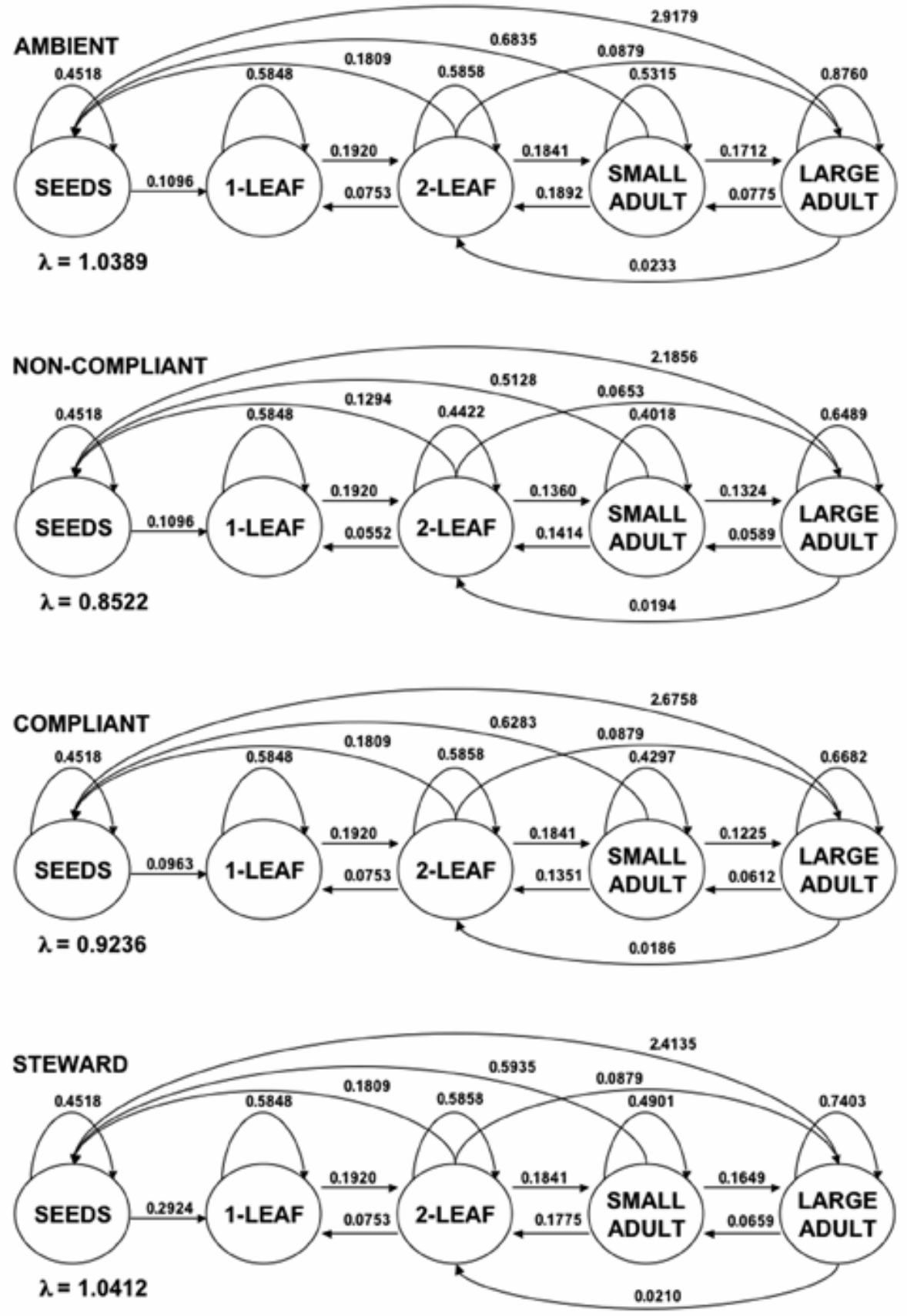
Fig. 5.2. The population growth rate (and 95\% confidence intervals from the mean se of 10 jackknifed mean matrices for each harvest type) of a single population of Panax quinquefolius under four varying conditions of harvest. When $\lambda=1$, the population is stable, when $\lambda>1$, the population is increasing and when $\lambda<1$, the population is declining. 


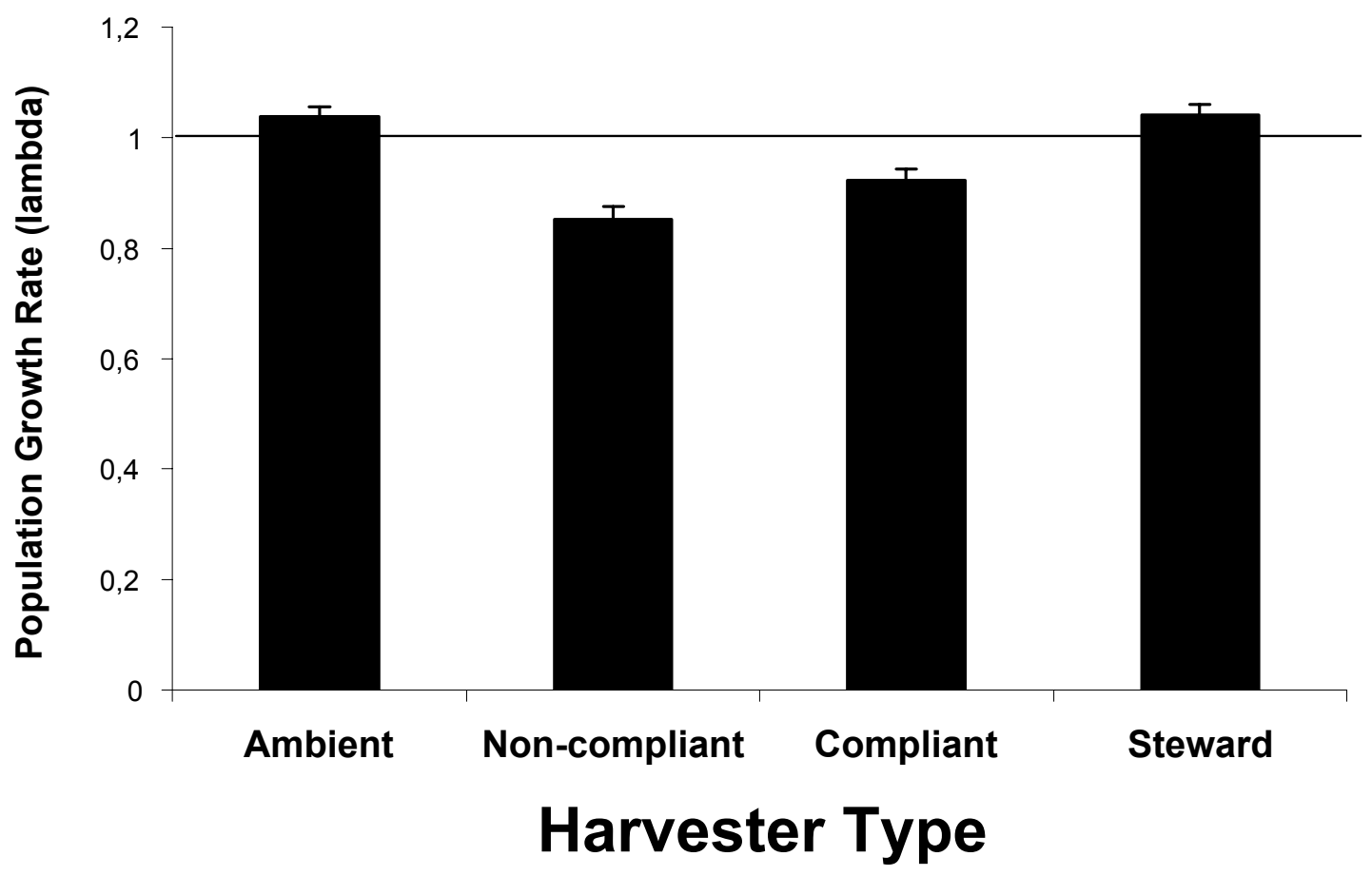


Table 5.3. Elasticities $\left(e_{i j} s\right)$ corresponding to the mean matrices for harvester type under four varying conditions of harvesting: ambient (no harvest), noncompliant, compliant and steward. Elasticity values reflect the proportional effect of small changes in each $a_{i j}$ on $\lambda$. The matrix elements having the greatest effect on population growth rate are in bold. 


\begin{tabular}{|c|c|c|c|c|c|}
\hline \multirow[b]{2}{*}{ Size at time $t+1$} & \multicolumn{5}{|c|}{ Size at time $t$} \\
\hline & Class 1 & Class 2 & Class 3 & Class 4 & Class 5 \\
\hline \multicolumn{6}{|l|}{ Ambient } \\
\hline Class 1 & 0.0425 & - & 0.0027 & 0.0053 & 0.0469 \\
\hline Class 2 & 0.0549 & 0.0783 & 0.0059 & - & - \\
\hline Class 3 & - & 0.0608 & 0.1087 & 0.0186 & 0.0047 \\
\hline Class 4 & - & - & 0.0409 & 0.0625 & 0.0188 \\
\hline Class 5 & - & - & 0.0347 & 0.0358 & 0.3780 \\
\hline \multicolumn{6}{|l|}{ Non-compliant } \\
\hline Class 1 & 0.0810 & - & 0.0060 & 0.0089 & 0.0569 \\
\hline Class 2 & 0.0718 & 0.1773 & 0.0093 & - & - \\
\hline Class 3 & - & 0.0811 & 0.1037 & 0.0125 & 0.0026 \\
\hline Class 4 & - & - & 0.0413 & 0.0459 & 0.0101 \\
\hline Class 5 & - & - & 0.0395 & 0.0301 & 0.2222 \\
\hline \multicolumn{6}{|l|}{ Compliant } \\
\hline Class 1 & 0.0680 & - & 0.0066 & 0.0101 & 0.0543 \\
\hline Class 2 & 0.0710 & 0.1457 & 0.0135 & - & - \\
\hline Class 3 & - & 0.0844 & 0.1847 & 0.0188 & 0.0033 \\
\hline Class 4 & - & - & 0.0456 & 0.0470 & 0.0084 \\
\hline Class 5 & - & - & 0.0408 & 0.0251 & 0.1726 \\
\hline \multicolumn{6}{|l|}{ Steward } \\
\hline Class 1 & 0.0653 & - & 0.0094 & 0.0121 & 0.0636 \\
\hline Class 2 & 0.0851 & 0.1192 & 0.0079 & - & - \\
\hline Class 3 & - & 0.0930 & 0.1454 & 0.0174 & 0.0026 \\
\hline Class 4 & - & - & 0.0523 & 0.0550 & 0.0095 \\
\hline Class 5 & - & - & 0.0435 & 0.0322 & 0.1865 \\
\hline
\end{tabular}


Table 5.4. Comparison Set I. Life table response experiment (LTRE) for three harvester type comparisons to the mean ambient matrix (no harvesting) for Panax quinquefolius. 


\begin{tabular}{llllllllll}
\hline Comparison: & \multicolumn{3}{l}{ Non-compliant-Ambient } & \multicolumn{3}{l}{ Compliant-Ambient } & \multicolumn{4}{l}{ Steward-Ambient } \\
\hline Parameter & $\Delta a_{i j}$ & $s_{i j}$ & $\Delta \lambda$ & $\Delta a_{i j}$ & $s_{i j}$ & $\Delta \lambda$ & $\Delta a_{i j}$ & $s_{i j}$ & $\Delta \lambda$ \\
\hline$a_{11}$ & 0 & 0.1231 & 0 & 0 & 0.1205 & 0 & 0 & 0.1296 & 0 \\
$a_{21}$ & 0 & 0.5504 & 0 & -0.0133 & 0.6130 & -0.0082 & $\mathbf{0 . 1 8 2 8}$ & $\mathbf{0 . 3 8 0 8}$ & $\mathbf{0 . 0 6 9 6}$ \\
$a_{22}$ & 0 & 0.1887 & 0 & 0 & 0.1846 & 0 & 0 & 0.1834 & 0 \\
$a_{32}$ & 0 & 0.3509 & 0 & 0 & 0.3757 & 0 & 0 & 0.4369 & 0 \\
$a_{13}$ & -0.0515 & 0.0242 & -0.0012 & 0 & 0.0236 & 0 & 0 & 0.0332 & 0 \\
$a_{23}$ & -0.0201 & 0.1080 & -0.0022 & 0 & 0.1200 & 0 & 0 & 0.0976 & 0 \\
$a_{33}$ & $\mathbf{- 0 . 1 4 3 6}$ & $\mathbf{0 . 2 0 0 8}$ & $\mathbf{- 0 . 0 2 8 8}$ & 0 & 0.2442 & 0 & 0 & 0.2326 & 0 \\
$a_{43}$ & $\mathbf{- 0 . 0 4 8 1}$ & $\mathbf{0 . 2 4 8 0}$ & $\mathbf{- 0 . 0 1 1 9}$ & 0 & 0.2391 & 0 & 0 & 0.2732 & 0 \\
$a_{53}$ & $\mathbf{- 0 . 0 2 2 6}$ & $\mathbf{0 . 4 6 2 2}$ & $\mathbf{- 0 . 0 1 0 4}$ & 0 & 0.4308 & 0 & 0 & 0.4839 & 0 \\
$a_{14}$ & -0.1707 & 0.0110 & -0.0019 & -0.0552 & 0.0113 & -0.0006 & -0.0900 & 0.0146 & -0.0013 \\
$a_{34}$ & -0.0478 & 0.0910 & -0.0043 & -0.0541 & 0.1175 & -0.0064 & -0.0117 & 0.1023 & -0.0012 \\
$a_{44}$ & $\mathbf{- 0 . 1 2 9 7}$ & $\mathbf{0 . 1 1 2 4}$ & $\mathbf{- 0 . 0 1 4 6}$ & $\mathbf{- 0 . 1 0 1 8}$ & $\mathbf{0 . 1 1 5 0}$ & $\mathbf{- 0 . 0 1 1 7}$ & -0.0414 & 0.1201 & -0.0050 \\
$a_{54}$ & -0.0388 & 0.2095 & -0.0081 & $\mathbf{- 0 . 0 4 8 7}$ & $\mathbf{0 . 2 0 7 3}$ & $\mathbf{- 0 . 0 1 0 1}$ & -0.0063 & 0.2127 & -0.0013 \\
$a_{15}$ & $\mathbf{- 0 . 7 3 2 3}$ & $\mathbf{0 . 0 1 9 6}$ & $\mathbf{- 0 . 0 1 4 4}$ & -0.2421 & 0.0184 & -0.0045 & $\mathbf{- 0 . 5 0 4 4}$ & $\mathbf{0 . 0 2 3 0}$ & $\mathbf{- 0 . 0 1 1 6}$ \\
$a_{35}$ & -0.0039 & 0.1629 & -0.0006 & -0.0047 & 0.1903 & -0.0009 & -0.0023 & 0.1607 & -0.0004 \\
$a_{45}$ & -0.0186 & 0.2011 & -0.0037 & -0.0163 & 0.1863 & -0.0030 & -0.0116 & 0.1887 & -0.0022 \\
$a_{55}$ & $\mathbf{0 . 2 2 7 1}$ & $\mathbf{0 . 3 7 4 9}$ & $\mathbf{- 0 . 0 8 5 1}$ & $\mathbf{- 0 . 2 0 7 8}$ & $\mathbf{0 . 3 3 5 7}$ & $\mathbf{- 0 . 0 6 9 8}$ & $\mathbf{- 0 . 1 3 5 7}$ & $\mathbf{0 . 3 3 4 3}$ & $\mathbf{- 0 . 0 4 5 4}$
\end{tabular}


Table 5.5. Comparison Set II. Life table response experiment (LTRE) with results for a pairwise comparison of three harvester types of Panax quinquefolius. 


\begin{tabular}{lllllllllll}
\hline Comparison: & \multicolumn{3}{l}{ Compliant-Non-compliant } & \multicolumn{3}{l}{ Steward-Non-compliant } & \multicolumn{4}{l}{ Steward-Compliant } \\
\hline Parameter & $\Delta a_{i j}$ & $s_{i j}$ & $\Delta \lambda$ & $\Delta a_{i j}$ & $s_{i j}$ & $\Delta \lambda$ & $\Delta a_{i j}$ & $s_{i j}$ & $\Delta \lambda$ \\
\hline$a_{11}$ & 0 & 0.1472 & 0 & 0 & 0.1538 & 0 & 0 & 0.1488 & 0 \\
$a_{21}$ & -0.0133 & 0.6226 & -0.0083 & $\mathbf{0 . 1 8 2 8}$ & $\mathbf{0 . 3 8 1 7}$ & $\mathbf{0 . 0 6 9 8}$ & $\mathbf{0 . 1 9 6 1}$ & $\mathbf{0 . 4 1 2 6}$ & $\mathbf{0 . 0 8 0 9}$ \\
$a_{22}$ & 0 & 0.2451 & 0 & 0 & 0.2315 & 0 & 0 & 0.2213 & 0 \\
$a_{32}$ & 0 & 0.3862 & 0 & 0 & 0.4410 & 0 & 0 & 0.4680 & 0 \\
$a_{13}$ & 0.0515 & 0.0364 & 0.0019 & 0.0515 & 0.0491 & 0.0025 & 0 & 0.0463 & 0 \\
$a_{23}$ & 0.0201 & 0.1540 & 0.0031 & 0.0201 & 0.1217 & 0.0024 & 0 & 0.1284 & 0 \\
$a_{33}$ & $\mathbf{0 . 1 4 3 6}$ & $\mathbf{0 . 2 4 2 5}$ & $\mathbf{0 . 0 3 4 8}$ & $\mathbf{0 . 1 4 3 6}$ & $\mathbf{0 . 2 3 1 9}$ & $\mathbf{0 . 0 3 3 3}$ & 0 & 0.2714 & 0 \\
$a_{43}$ & $\mathbf{0 . 0 4 8 1}$ & $\mathbf{0 . 2 4 2 4}$ & $\mathbf{0 . 0 1 1 7}$ & $\mathbf{0 . 0 4 8 1}$ & $\mathbf{0 . 2 8 2 6}$ & $\mathbf{0 . 0 1 3 6}$ & 0 & 0.2656 & 0 \\
$a_{53}$ & $\mathbf{0 . 0 2 2 6}$ & $\mathbf{0 . 4 7 0 6}$ & $\mathbf{0 . 0 1 0 6}$ & $\mathbf{0 . 0 2 2 6}$ & $\mathbf{0 . 5 2 7 9}$ & $\mathbf{0 . 0 1 1 9}$ & 0 & 0.4889 & 0 \\
$a_{14}$ & 0.1155 & 0.0150 & 0.0017 & 0.0807 & 0.0187 & 0.0015 & -0.0348 & 0.0189 & -0.0007 \\
$a_{34}$ & -0.0063 & 0.0998 & -0.0006 & 0.0361 & 0.0885 & 0.0032 & 0.0424 & 0.1108 & 0.0047 \\
$a_{44}$ & 0.0279 & 0.0997 & 0.0028 & 0.0883 & 0.1078 & 0.0095 & 0.0604 & 0.1084 & 0.0065 \\
$a_{54}$ & -0.0099 & 0.1936 & -0.0019 & 0.0325 & 0.2015 & 0.0065 & 0.0424 & 0.1995 & 0.0085 \\
$a_{15}$ & $\mathbf{0 . 4 9 0 2}$ & $\mathbf{0 . 0 2 0 5}$ & $\mathbf{0 . 0 1 0 0}$ & 0.2279 & 0.0256 & 0.0058 & -0.2623 & 0.0237 & -0.0062 \\
$a_{35}$ & -0.0008 & 0.1368 & -0.0001 & 0.0016 & 0.1208 & 0.0002 & 0.0024 & 0.1388 & 0.0003 \\
$a_{45}$ & 0.0023 & 0.1367 & 0.0003 & 0.0070 & 0.1472 & 0.0010 & 0.0047 & 0.1358 & 0.0006 \\
$a_{55}$ & 0.0193 & 0.2655 & 0.0051 & $\mathbf{0 . 0 9 1 4}$ & $\mathbf{0 . 2 7 5 0}$ & $\mathbf{0 . 0 2 5 1}$ & $\mathbf{0 . 0 7 2 1}$ & $\mathbf{0 . 2 5 0 1}$ & $\mathbf{0 . 0 1 8 0}$
\end{tabular}


Comparison Set I.

In the first set of comparisons, all three harvester types were compared to the 'ambient' (no harvest) matrix.

Thirteen of 17 vital rates differed between the non-compliant and 'ambient' matrices (Table 5.4). Change in the rates of stasis of large and small adults and 2-leaf plants accounted for the 3 highest contributions to the $\lambda$ difference between the two matrices. Lower stasis of large adults $\left(a_{55}\right)$ in the non-compliant matrix accounted for nearly half of the reduction in $\lambda$ seen in the non-compliant simulations. The illegal harvest of 2-leaf plants was second in importance, accounting for $16 \%$ of the reduction. The change in all fates of 2 -leaf plants accounted for $28 \%$ of the reduction in $\lambda$. Even though population growth rate had a relatively low sensitivity to the fertility of large adults, the change in the vital rate $\left(a_{15}\right)$ was very large (the highest change in $\Delta a_{i j}$ among all six comparisons). The lower fertility of large adults in the non-compliant matrix accounted for $8 \%$ of the reduction in $\lambda$.

Change in rates of stasis of large and small adults accounted for the two highest contributions to the difference between the compliant and 'ambient' matrices (Table 5.4). Lower stasis of large adults $\left(a_{55}\right)$ accounted for over half $(61 \%)$ of the reduction in $\lambda$ in the compliant simulations. Less stasis of small adults $\left(a_{44}\right)$ accounted for $10 \%$ of the reduction while less growth of small adults into the large adult $\left(a_{54}\right)$ class accounted for $9 \%$ of the reduction in $\lambda$. Despite the fact that the population growth rate was most sensitive to germination of seeds, $\lambda$ was little affected by it because $\Delta a_{21}$ was very small between the compliant and 'ambient' matrices.

The effects of increased germination (due to seed planting in the steward simulations) in the steward-'ambient' simulations contributed $58 \%$ to the increase in $\lambda$, despite all the other changes between the matrices being negative (due to 
harvest. Table 5.4). Even with the lower rate (38\%) of stasis of large adults $\left(a_{55}\right)$ and a $10 \%$ reduction in fertilities of large adults $\left(a_{15}\right)$ in the steward matrix, $\lambda$ was slightly higher than that of the 'ambient' matrix.

Comparison Set II.

The compliant $(\lambda=0.9236)$-non-compliant $(\lambda=0.8522)$ comparison was of particular interest because it quantified the positive effect of existing regulations, or conversely, the negative effect of breaking those laws. The top three contributors to the lower $\lambda$ in compliant $v s$. non-compliant simulations were differences in fates of 2-leaf plants (Table 5.5). These changes were present due to the illegal harvest of 2-leaf plants in the non-compliant regime. The change in all fates of 2 -leaf plants accounted for $81 \%$ of the reduction in $\lambda$ in the non-compliant matrix. The lower fertility of large adults in the non-compliant matrix accounted for $15 \%$ of the reduction in $\lambda$. The largest change in a vital rate was in the fertility of large adults $\left(a_{15}\right)$. Although $\lambda$ had a low sensitivity to this parameter, the large $\Delta a_{15}$ resulted in an impact on $\lambda$. Even though population growth rate was most sensitive to the germination of seeds, the difference between the matrices in $a_{21}$ was very small and therefore the impact on projected population growth was small as well.

Fourteen of 17 vital rates differed in the steward vs. non-compliant comparison, all of which positively contributed to the difference in the projected high rate of growth for the steward matrix (Table 5.5). The greatest change was in the parameter $a_{21}$, germinating seeds, and population growth rate was very sensitive to this vital rate. The increased germination of seeds in the steward matrix $(37 \%)$ accounted for over one third of the increase in $\lambda$. Similar to the previous comparison (compliant-non-compliant) the stasis of 2-leaf plants contributed substantially to the difference in the projected population growth rate of the steward (18\%). The change in fates of all 2-leaf plants accounted for $31 \%$ of the increase in $\lambda$. 
In the steward-compliant comparison, fewer changes were observed between the matrices that contribute to the difference in the estimated population growth of the two harvester types (Table 5.5). The increased rate of germination $\left(a_{21}\right)$ accounted for nearly three quarters $(72 \%)$ of the increase in $\lambda$. The $\Delta a_{21}$ in this matrix combined with the high sensitivity of the population growth rate to the transition, resulted in the highest contribution (i.e., $\Delta \lambda$ ) of the comparisons in Comparison Set II.

Discussion

In the first set of comparisons (three harvester types compared to the 'ambient,' no-harvest matrix), neither the non-compliant nor the compliant harvester had an opportunity to compensate for the loss of seeds due to harvesting. The non-compliant harvester eliminated all reproductive potential from the individuals that were taken in June. Total seed loss from a population was also potentially higher for the non-compliant model because the number of plants harvested in June was greater (i.e., no browse adjustment was made for the non-compliant harvester). The compliant harvester reduced germination of all seeds present at the time of harvest because germination rates are lower on 15 August than 1 September (McGraw et al., 2005), and seeds were not buried.

The consequences of ignoring size class limits and harvest season onset date for population dynamics of $P$. quinquefolius are large, suggesting that these regulations, if followed, would partially protect the resource. Wild ginseng populations in the non-compliant model were expected to decline at an average rate of approximately $15 \%$ per year when the stable stage distribution (SSD) is reached, a rate that would rapidly drive a population to extinction. The noncompliant harvester removed 2-leaf plants (class 3 ). All of the LTRE comparisons with the non-compliant harvester indicated that stasis and growth of class 3 individuals contributed substantially to the difference in the projected 
population growth rates among populations. Initially, increasing the proportion of 2-leaf plants remaining 2-leaf plants and growing into larger stages would have the largest effect on $\lambda$.

Compliance with current federal and state regulations, if it is only marginal compliance as with my compliant harvester scenario, does not appear to be adequate to ensure the sustainability of harvest of $P$. quinquefolius. The compliant model simulations showed that such populations were expected to decline at an average rate of approximately $8 \%$ per year (at SSD). In contrast, under the steward model wild ginseng populations were expected to increase at an average rate of approximately $4 \%$ per year when the stable stage distribution was reached. The steward behavior results in a $12 \%$ difference in the projected population growth rate between the two models. The $\Delta \lambda$ between the two matrices is not trivial, particularly when much of the difference can be explained by the increase in a single parameter, $a_{21}$ (germination of seeds). Results of these experiments suggest that stewardship behavior could dramatically impact population growth rates of wild $P$. quinquefolius. Seed planting at a depth of 2 $\mathrm{cm}$, combined with a later harvest season, could cause declining ginseng populations to increase. Wild ginseng populations are widely dispersed geographically; many populations will not experience harvest in a given year. Drawing on wildlife models where no-take limits are imposed regionally in areas with especially high rates of harvest (to provide rest time for population recovery), ginseng harvest could be closed on a countywide basis for set time periods (Bailey, 1999).

Suggested changes in best harvest practices for ginseng diggers will not be effective unless dissemination of supporting materials explaining the purpose of the changes is widespread. While ginseng harvest seasons were devised to ensure berry ripening, there is no clear geographic pattern to the season onset dates (McGraw et al., 2005). However, the recent amendment by the West Virginia legislature which reset harvest onset to the $1^{\text {st }}$ of September is 
encouraging and may foment more widespread unification. Appropriate educational materials and workshops combined with effective dissemination outlets (e.g., hunting and outdoor magazines, materials circulated with hunting licenses and regulations, workshops conducted through state extension agencies, etc.) would provide a good venue for harvest regulation changes.

Non-compliant harvesters exist in reality and they can "break the rules" more dramatically than defined in the model. For example, all individuals in populations may be removed (Bailey, pers. comm., 1995-98), and digging may occur earlier than 15 June in some areas (Furedi, pers. obs., 2000-2003). Diggers whom I would characterize as stewards, sometimes remove fewer large adults than prescribed in the model (Bailey, pers. comm., 1995-99). The variability in harvester types devised for this study falls within the realm of possible behaviors for diggers. Unfortunately, the frequency of harvesters along the behavioral continuum is unknown, suggesting an important gap in our understanding of the harvest dynamics. My results strongly suggest that only by having a predominance of 'stewards' will ginseng be sustainably harvested. Regulation changes, e.g. harvest season changes that align seasons with seed ripening phenology (McGraw et al., 2005) could go a long way toward making 'compliant' harvesters into better stewards. However, it is difficult to force compliant harvesters to plant seeds in an optimal manner on a site, which the LTRE analysis shows is an important component of the 'steward' strategy. Therefore any move toward improved sustainability of harvest must include a strong educational component that shows how stewardship is in the best longterm interest of each harvester. 
Acknowledgments

The authors express appreciation to B. Bailey, H. and G. Clowes, M. Deinlein, M. A. Furedi, E. Hackney, R. Kenyon, R. Landenberger, C. Packert, J.Portman, S. Sanders and M. Spencer for their help in the field, and B. Bailey and E. Mooney for sharing data on harvesting behavior, M. Dufour for her generous computer help, and M.A. Furedi for help with refining model parameterization. This research was supported in part by National Science Foundation grant DEB0212411 and USDOI/U.S. Geological Survey-Biological Resources Division, grant 1434-HQ-97-RU-01563 to J.B. McGraw. 


\section{Literature Cited}

Anderson, R.C., J.S. Fralish, J.E. Armstrong and P.K. Benjamin. 1984. Biology of ginseng (Panax quinquefolium) in Illinois. Department of Conservation, Division of Forest Resources and Natural Heritage. Springfield, Illinois.

Anderson, R.C., J.S. Fralish, J.E. Armstrong, and P.K. Benjamin. 1993. The ecology and biology of Panax quinquefolium L. (Araliaceae) in Illinois. American Midland Naturalist 129, 357--372.

Bailey, B. 1999. Social and economic impacts of wild harvested products. Ph.D. Dissertation. West Virginia University, Morgantown.

Baskin, C.C. and J.M. and Baskin. 1998. Seeds. Ecology, biogeography, and evolution of dormancy and germination. Academic Press, San Diego, California.

Bierzychudek, P. 1999. Looking backwards: assessing the projections of a transition matrix model. Ecological Applications 9(4), 1278--1287.

Carlson, A.W. 1986. Ginseng-America's botanical drug connection to the Orient. Economic Botany 40, 233--249.

Carpenter W.G. and G. Cottam. 1982. Growth and reproduction of American ginseng (Panax quinquefolius) in Wisconsin, USA. Canadian Journal of Botany 60, 2692--2696.

Caswell, H. 1989. The analysis of life table response experiments. I. Decomposition of effects on population growth rate. Ecological Modeling 46, 221--237. 
Caswell, H. 2001. Matrix population biology, $2^{\text {nd }}$ edition. Sinauer Assoc., Inc., Sunderland, Massachusetts.

Charron D. and D. Gagnon. 1991. The demography of northern populations of Panax quinquefolium (American ginseng). Journal of Ecology 79, 431--445.

Crouse, D.T., L.B. Crowder and H. Caswell. 1987. A stage-based population model for loggerhead sea turtles and implications for conservation. Ecology 68(5), 1412--1423.

Evans, B. 1985. Ginseng, root of Chinese-Canadian relations. Canadian Historical Review 66, 1--26.

Furedi, M.A. 2004. Effects of herbivory by white-tailed deer (Odocoileus virginianus Zimm) on the demography and conservation biology of American ginseng (Panax quinquefolius L.). Ph.D. thesis, West Virginia University, Morgantown.

and J.B. McGraw. 2004. White-tailed deer: dispersers or predators of American ginseng seeds? American Midland Naturalist 152, 268--279

Gagnon, D. 1999. An analysis of the sustainability of American ginseng harvesting from the wild: the problem and possible solutions. Final report to the Office of Scientific Authority of the U.S. Fish and Wildlife Service. Arlington, Virginia.

Harper, J.L. 1977. Population biology of plants. Academic Press, New York.

Hu, S.Y., L. Rüdenberg, and P.D. Tredici. 1980. Studies of American ginseng. Rhodora 82, 627--636. 
Kalisz, S. 1991. Experimental determination of seed bank age structure in the winter annual Collinsia verna. Ecology 72(2), 575--585

Kalisz, S. and M.A. McPeek. 1992. Demography of an age-structured annual: resampled projection matrices, elasticity analyses, and seed bank effects. Ecology 73, 1082--1093.

Kimmens, A.C., ed. 1975. Tales of the ginseng. William Morrow and Company, Inc., New York.

Knight, T.M. 2004. The effects of herbivory and pollen limitation on a declining population of Trillium grandiflorum. Ecological Applications 14, 915--928.

Lewis, W. and V.E. Zenger. 1982. Population dynamics of the American ginseng Panax quinquefolium (Araliaceae). American Journal of Botany 69, 1483--1490.

Lewis, W.H. 1984. Population structure and environmental corollaries of Panax quinquefolium (Araliaceae) in Delaware County, New York. Rhodora 86, 431-437.

, 1988. Regrowth of a decimated population of Panax quinquefolium in a Missouri climax forest. Rhodora 90, 1--5.

Marmontel, M., S.R. Humphrey and T.J. O'Shea. 1997. Population viability analysis of the Florida manatee (Trichechus manatus latirostris), 1976-1991. Conservation Biology 11(2), 467--481.

MATLAB. 1993. MATLAB, Version 4.0. Mathworks, Natick, Massachusetts. 
Maxwell, H. 1898. The history of Randolph county. From its earliest settlement to the present. The Acme Publishing Company, Morgantown, WV.

McGraw, J.B. and J. Antonovics. 1983. Experimental ecology of Dryas octopetala ecotypes. II. A demographic model of growth, branching and fecundity. Journal of Ecology 71, 899--912.

. 1989. Effects of age and size on life histories and population growth of Rhododendron maximum shoots. American Journal of Botany 76, 113--123.

, 2001. Evidence for decline in stature of American ginseng plants from herbarium specimens. Biological Conservation 98, 25--32.

S.M. Sanders and M.E. Van der Voort. 2003. Distribution and abundance of Hydrastis canadensis L. (Ranunculaceae) and Panax quinquefolius L. (Araliaceae) in the central Appalachian region. Journal of the Torrey Botanical Society 130(2), 62--69.

and M.A. Furedi. 2005. Deer browsing and population viability of a forest understory plant. Science 307, 920--922.

—_ K. Maiers, C. Carroll, G. Kauffman, A. Lubbers, J. Wolf, R.C. Anderson, M.R. Anderson, B. Wilcox, D. Drees, M.E. Van der Voort, M.A. Albrecht, A. Nault, H. MacCulloch and A. Gibbs. 2005. Berry ripening and harvest season in wild American ginseng. Northeastern Naturalist 12(2), 141-152.

Menges, E.S. 1990. Population viability analysis for an endangered plant. Conservation Biology 4, 52--62. 
Meretsky, V.J., N.F.R.Snyder, S.R.Beissinger, D.A.Clendenen and J.W. Wiley. 2000. Demography of the California condor: implications for reestablishment. Conservation Biology 14(4), 957--967.

Millspaugh, C.F. 1974. American medicinal plants. Dover Publications, New York. First published in 1892 as Medicinal plants: an illustrated and descriptive guide to the American plants used as homoeopathic remedies. John C. Yorston and Company, Philadelphia.

Nantel, P., D. Gagnon and A. Nault. 1996. Population viability analysis of American ginseng and wild leek harvested in stochastic environments. Conservation Biology 10(2), 608--621.

Prescott-Allen, C. and R. Prescott-Allen 1986. The first resource: wild species in the North American economy. Yale University Press, New Haven, Connecticut.

Robbins, C. S. 1998. American ginseng: the root of North America's medicinal herb trade. TRAFFIC North America. Washington, DC.

2000. Comparative analysis of management regimes and medicinal plant trade monitoring mechanisms for American ginseng and goldenseal. Conservation Biology 14, 1422--1434.

Schlessman, M.A. 1985. Floral biology of American ginseng (Panax quinquefolium). Bulletin of the Torrey Botanical Club 112, 129--133. . 1987. Gender modification in North American ginsengs. Dichotomous sex choice versus adjustment. BioScience 37(7), 469--475. 
Van der Voort, M.E. 1998. An inventory of wild-harvested plants in the Otter Creek Wilderness Area of the Monongahela National Forest, West Virginia. M.Sc. Thesis, West Virginia University, Morgantown.

B. Bailey, J.B. McGraw and D.E. Samuel. 2003. Recovery of populations of goldenseal (Hydrastis canadensis L.) and American ginseng (Panax quinquefolius L.) following harvest. American Midland Naturalist 149, 282--292.

Werner, P.A. 1975. Predictions of fate from rosette size in teasel (Dipsacus fullonum L.). Oecologia 20, 197--201.

and $\mathrm{H}$. Caswell. 1977. Population growth rates and age versus stagedistribution models for teasel (Dipsacus sylvestris Huds.). Ecology 58, 1103-1111. 


\section{CHAPTER 6}

General Conclusions

By the early part of the $18^{\text {th }}$ century, Panax ginseng (Chinese ginseng) was nearly impossible to locate in the wild (Millspaugh, 1974; Kimmens, 1975). Persistent, intense levels of harvest almost extirpated the species. A growing body of work on American ginseng (Panax quinquefolius), suggests that it may well be moving in the same direction (Charron and Gagnon, 1991; Nantel et al., 1996; McGraw et al., 2003; McGraw and Furedi, 2005). In this study, $P$. quinquefolius populations were estimated to be decreasing at a rate of ca. $7 \%$ per year in the range center (Chapter 2), a growth rate that is clearly unsustainable. In contrast, populations at the northern margin were expected to increase by ca. $3 \%$ per year. The differences in population growth rates documented here between West Virginia and Québec were substantial. It is critical that similar long-term demographic studies are conducted in the central Appalachians in order to test whether the results of this study are an anomaly or a reflection of a wider trend in the range center. Concomitant research at the southern extension and northern margin of ginseng's range should also be conducted to eliminate any time bias in data collection.

This research supports Lewis' (1988) earlier work that indicated that ginseng population recovery following harvest is possible if seeds are present in the soil at the time of harvest (Chapter 3 ). Numerical recovery following the complete harvest of a ginseng population was rapid and the presence of viable seeds in the soil conveyed some resilience to a harvest event. The size structure of the harvested population was slow to recover, however; even 10 years postharvest, only ca. $40 \%$ of the preharvest reproductive, large adults were present. For a species that is slow to mature, the complete removal of all genets in a population severely impact the rate of seed production and demographic structure of the recovering population. Further, the recovery documented here was from an established population with a majority of older genets with high 
fertilities; numerous seeds were present in the soil. Fertilities in the study populations are low (Chapters 2 and 5); Furedi (2004) and McGraw and Furedi (2005) also documented low fertilities in these and other populations in the range center.

The viability of planting ginseng rhizomes to aide in population recovery was documented in Chapter 3 (i.e., the recovery following harvest chapter) the possibility of which should be explored further. Rhizome planting would be more difficult to implement than seed planting for a few reasons. There is no current precedent for it, although occasional reference to this practice can be found (Hufford, 1999). Also, many end-users of ginseng feel that the efficacy of the root is lost if the neck, or rhizome, is removed (Kephart, 1926). However, as wild harvested resources become more scarce, consumers have been forced to accept changes in availability.

With the documentation of a seed bank in $P$. quinquefolius (Chapter 4), we are able to incorporate more accurate estimates in our demographic models for this transition element. This study also suggested that density and microsite are important to seed emergence and survival. It is conceivable that wild $P$. quinquefolius populations may require supplemental seed planting. Such conservation action is expensive, both in terms of time and money and should only be implemented when we refine our understanding of these early processes in ginseng's life cycle.

The evident reliance of $P$. quinquefolius on seeds for population recovery (Lewis 1988; Van der Voort et al. 2003; Chapter 4) points to the importance of several things. Firstly, because the timing of harvest clearly impacts seed fates, present state regulations for harvest onset dates must be reviewed. The majority of harvest season onset dates do not correspond well with ginseng phenology (McGraw et al., 2005), so even those harvesters who are following current laws and who may be planting seeds at the time of harvest will not promote the rates 
of germination that could be obtained with a short delay in onset of harvesting. Secondly, harvester behavior clearly impacts population dynamics (Chapter 5). This research points out the potential positive effects of seed planting at a depth of $2 \mathrm{~cm}$ (as opposed to broadcast over the forest floor).

The high rates of deer browsing of American ginseng and the resulting negative impacts on population growth rates documented by McGraw and Furedi (2005) add another aspect to the impacts of human harvest on ginseng. The combination of persistent annual removal of plants and repeated browse on wild populations may be more downward pressure on $P$. quinquefolius than it can bear. Models incorporating both kinds of population pressure will aide in future conservation planning. Increases in deer densities throughout North America are likely to change the population dynamics of ginseng at the northern margin (Gagnon and Huot pers. comm., 2005); this should be tested directly.

Freese (1998) indicated that it is not the question 'should we' better manage what is already going on in wild harvest, but rather, 'how can we' better manage. 'Sanging,' collection of ginseng from the wild, has been a common practice throughout the Appalachians for hundreds of years (Kephart 1926) and remains an important piece of the social fabric of many families in West Virginia (Bailey 1999). Community participation in the design of management programs is not essential (i.e., the federal government can easily close ginseng harvest and/or alter harvest season onset dates unilaterally if continued collection is shown to be detrimental to wild populations).

Ginseng harvest has continued for hundreds of years, but we don't know if declining populations in West Virginia are reflective of widespread decline throughout the range. Maintaining a sustainable harvest may require a multifaceted approach. Deer herds clearly need to be managed differently (and reduced) in certain parts of ginseng's range. Managers may need to look to wildlife management models and close harvest regionally for set periods to allow 
population recovery of ginseng (Bailey 1999). Finally, due to the scattered nature of individual populations in the wild and the impossibility of protecting adequate land areas for population recovery, harnessing the aide of ginseng diggers may be one of the most effective ways to improve the chances of longterm survival of ginseng. This will not be easy; ginseng collection is often a solitary activity and much secrecy surrounds the event. However, if harvesters participate in the design of a program, it is more likely that an effective management program will be developed (Freese, 1998). 


\section{Literature Cited}

Bailey, B. 1999. Social and economic impacts of wild harvested products.

Ph.D. Dissertation. Morgantown, West Virginia. $111 \mathrm{p}$.

Charron D. and D. Gagnon. 1991. The demography of northern populations of Panax quinquefolium (American ginseng). J. Ecol. 79:431-445.

Freese, C.H. 1998. Wild species as commodities. Island Press, Washington, DC, USA. 319pp

Furedi, M.A. 2004. Effects of herbivory by white-tailed deer (Odocoileus virginianus Zimm.) on the demography and conservation biology of American ginseng (Panax quinquefolius L.). Ph.D. dissertation, Department of Biology, West Virginia University, Morgantown, WV.

Hufford, M. 1999. American ginseng and the idea of the commons. In: Tending the commons. Folklife and landscape in southern West Virginia. Library of Congress (web address:

Http://memory.loc.gov/ammem/cmnshtml/cmnshome.html)

Kephart, H. 1926. Our southern highlanders: a narrative of adventure in the southern Appalachians and a study of life among the mountaineers. $4^{\text {th }}$ printing. The MacMillan Company, New York. 469 pp.

Kimmens, A.C. [ed.]. 1975. Tales of the ginseng. William Morrow and Company, Inc. New York.

Lewis, W.H. 1988. Regrowth of a decimated population of Panax quinquefolium in a Missouri climax forest. Rhodora 90(861):1-5. 
McGraw, J.B., S.M. Sanders and M.E. Van der Voort. 2003. Distribution and abundance of Hydrastis canadensis L. (Ranunculaceae) and Panax quinquefolius L. (Araliaceae) in the central Appalachian region. J. Torr. Bot. Soc. 130(2):62-69.

,and M.A. Furedi. 2005. Deer browsing and population viability of a forest understory plant. Science 307: 920-922.

K. Maiers, C. Carroll, G. Kauffman, A. Lubbers, J. Wolf, R.C. Anderson, M.R. Anderson, B. Wilcox, D. Drees, M.E. Van der Voort, M.A. Albrecht, A. Nault, H. MacCulloch and A. Gibbs. 2005. Berry ripening and harvest season in wild American ginseng. Northeastern Naturalist 12(2), 141-152.

Millspaugh, C.F. 1974. American medicinal plants. Dover Publications, New York, USA 806pp. First published in 1892 as Medicinal plants: an illustrated and descriptive guide to the American plants used as homoeopathic remedies. John C. Yorston and Company, Philadelphia.

Nantel, P., D. Gagnon and A. Nault. 1996. Population viability analysis of American ginseng and wild leek harvested in stochastic environments. Cons. Biol. 10(2): 608-621.

Van der Voort, M.E., B. Bailey, J.B. McGraw and D.E. Samuel. 2003. Recovery of populations of goldenseal (Hydrastis canadensis L.) and American ginseng (Panax quinquefolius L.) following harvest. Am. Mid. Nat. 149:282-292. 


\author{
Martha Ellen Van der Voort \\ 419 rue Fraser, \#4 \\ Québec (Québec) G1S 1R3 \\ Canada \\ 418.681.4603 \\ Martha.VanderVoort@mail.wvu.edu
}

\title{
EDUCATION:
}

Denison University, Granville, Ohio. BA, Biology, 1980.

West Virginia University, Morgantown, WV. MS, Wildlife and Fisheries Resources, 1998.

West Virginia University, Morgantown, WV. Ph.D., Biology, 2005.

1994-98: West Virginia University, Morgantown, WV. Masters research: Commenced baseline ecological research for the state of West Virginia on a suite of economically and socially important wild-harvested plant species.

1996-2005: Department of Biology. Research focus: Plant population biology and ecological research on Panax quinquefolius L. (American ginseng).

\section{EXPERIENCE:}

1992-1994: Smithsonian Institution, Migratory Bird Center, National Zoo, Washington, DC. Conservation Biologist.

Consultant to the Migratory Bird Center contracted to prepare a review of middle elevation regions of the Atlantic slope of Mexico and Central America, with an analysis of land use patterns, resident and migrant birds restricted to the zone and an evaluation of the status of existing conservation units in the region. Research included a focus on land under coffee cultivation and the effects of different coffee growing regimes on migratory bird populations specifically, and, biological diversity in general.

1990-1991: International Council for Bird Preservation (ICBP), Washington, DC. Panamerican Program Officer. Coordinated ICBP's program in Latin America from a one person office in Washington, DC.

Designed long range plan to stabilize and significantly enlarge the Panamerican office of ICBP and developed an institutional support proposal for this expansion. The staff increased by three people at the time of my departure. 
As the liaison officer for the ICBP Board of Directors based in the western hemisphere and headquarters in Cambridge, U.K., coordinated program planning and grant review for projects throughout Latin America and the Caribbean on education and training pro

Coordinated the publication and design of a bilingual newsletter with a distribution of approximately 2,000.

Coordinated, at the national level, the U.S. non governmental organization community participating in the "Partners in Flight" program, a U.S. federal, state and private initiative for the conservation of migratory birds.

1989: $\quad$ Smithsonian Institution, National Zoo, Washington, DC. Research Associate.

Conducted field research on the effects of hurricane Gilbert on migrant bird populations in Yucatan, Mexico. Data reduction and analysis completed in Washington, DC.

1982-1988: World Wildlife Fund, US (WWF), Washington, DC. Program Officer, Asia.

1985-88: $\quad$ One of two people to develop new Asia program with activities in Bhutan, Burma, China, Indonesia, Malaysia, Nepal, Philippines and Thailand. Responsibilities included the development of a long range planning document for the initiation of a conservation program in Asia, review of proposals from governments, non-governmental organizations and universities in Asia for conservation interventions including research, training and institution strengthening. Frequent travel to assist with project design and to review program implementation and evaluate progress on projects related to protected area management, conservation research and training and education.

Recruited and hired Administrative Assistant and, designed and coordinated the implementation of master filing system and other office administration.

1982-84: Research Assistant to Vice President for Science, Thomas E. Lovejoy.

Provided editing support for scientific manuscripts on Amazon ecology, minimum critical area requirements for species diversity protection, and endangered species conservation.

Coordinated external scientific committee involved in grant review of migratory bird research.

Provided administrative support to Vice President's office. 
1981-1982: Smithsonian Institution, National Zoo. Washington, DC. Research Assistant to Eugene S. Morton

Conducted research in animal vocalization/communication and, on long term population studies of migrant birds. Worked at field and laboratory sites in Washington, DC, Front Royal, Virginia and Veracruz and Yucatan, Mexico.

1980-1981: University of Minnesota. High Island, Michigan. Field Assistant to Francesca J. Cuthbert.

Conducted research on common tern reproductive biology and assisted in development of management plan for this endangered species.

1980-1981: National Audubon Society. Tavernier, Florida. Field Research Technician to George VN Powell.

Conducted research on heron ecology in Florida Bay and Everglades National Park.

AWARDS: American Women in Science-West Virginia Chapter, Career Enhancement Award, \$1,000.00. Granted Spring 1996.

PROFESSIONAL AFFILIATIONS:

Ecological Society of America

Society for Conservation Biology

West Virginia Native Plant Society

\section{PUBLICATIONS:}

McGraw, J.B., M.A. Furedi, K. Maiers, C. Carroll, G. Kauffman, A. Lubbers, J. Wolf, R. C. Anderson, M.R. Anderson, B. Wilcox, D. Drees, M.E. Van der Voort, M.A. Albrecht, A. Nault, H. MacCulloch and A. Gibbs. 2005. Berry ripening and harvest season in wild American ginseng. Northeastern Naturalist 12(2):141152.

McGraw, J.B., S.M. Sanders, and M.E. Van der Voort. 2003. Distribution and abundance of Hydrastis canadensis L. (Ranunculaceae) and Panax quinquefolius L. (Araliaceae) in the central Appalachian region. J. Torr. Bot. Soc. 130(2):62-69.

Van der Voort, M.E., B. Bailey, D.E. Samuel and J.B. McGraw. 2003. Recovery of Populations of Goldenseal (Hydrastis canadensis L.) and American Ginseng (Panax quinquefolius L.) Following Harvest. Am. Mid. Nat. 149:282-292. 
Van der Voort, M.E. 1998. An inventory of wild-harvested plants in the Otter Creek Wilderness Area of the Monongahela National Forest, West Virginia. M.S. Thesis, Morgantown, WV. $77 \mathrm{pp}$.

Perfecto, I. , R. A. Rice, R. Greenberg, and M.E. Van der Voort. 1996. Shade coffee: a disappearing refuge for biodiversity. BioScience 46:598-608.

Morton, E.S., M.E. Van der Voort and R. Greenberg. 1993. How a warbler chooses its habitat: field support for laboratory experiments. Anim. Behav. 46:47-53.

Morton, E.S., S.L. Gish, and M.E. Van der Voort. 1986. On the learning of degraded and undegraded songs of the Carolina wren. Anim. Behav.(34):815820.

Lynch, J.F., E.S. Morton, and M.E. Van der Voort. 1986. Habitat segregation between the sexes of wintering hooded warblers (Wilsonia citrina). Auk 102(4):714-721.

Lovejoy, T.E., J.M. Rankin, R.O. Bierregaard, Jr., K.S. Brown, Jr., L.H. Emmons, and M.E. Van der Voort. 1984. Ecosystem decay of Amazon forest remnants, p. 295-325. In Matthew H. Nitecki [ed.] Extinctions. Univ. of Chicago Press, Chicago, Illinois.

\section{PROFESSIONAL PRESENTATIONS:}

Furedi, M., M.E. Van der Voort, S.M. Spencer, and J.B. McGraw. 2002. Browsing effects on growth and reproduction in a natural population of American ginseng. ESA Meeting $\left(87^{\text {th }}\right)$, Tuscon, AZ

Van der Voort, M.E., B. Bailey, J. B. McGraw and D.E. Samuel. Population recovery of goldenseal (Hydrastis canadensis L.) and American ginseng (Panax quinquefolius L.) following human harvest. Bulletin of the Ecological Society of America Abstracts, p. 205. Spokane, WA, August 1999.

Van der Voort, M.E., B. Bailey and J.B. Mcgraw. Population recovery of goldenseal following harvest. Ecological Society of America meeting, Baltimore, MD, 1998.

Van der Voort, M.E. and B Bailey: "The basics before the business: Social and ecological characteristics of the goldenseal harvest in West Virginia, USA" and Bailey, B. and M.E. Van der Voort, "Trade in the shade: An overview of wildharvested products and foragers in Central Appalachia." Forum '97, New Linkages in Conservation and Development, Istanbul, Turkey, 1997. 
Van der Voort, M.E., B. Bailey and J.B. Mcgraw. Are wild goldenseal populations resilient to harvest? Society for Conservation Biology meeting, Victoria, BC, 1997.

Van der Voort, M.E., D.E. Samuel and J.B. McGraw. The importance of biological inventory for valuable wild-harvested species such as American ginseng. The Sixth International Symposium on Society and Resource Management: Social Behavior, Natural Resources and the Environment. The Pennsylvania State University, University Park, PA, May 1996.

Van der Voort, M.E., E. S. Morton and J.F. Lynch. Horizontal habitat separation in wintering male and female hooded warblers (Wilsonia citrina)," American Ornithologists Union annual meeting, Chicago, IL, 1982

Other Presentations:

An ecological study of Panax quinquefolius in central Appalachia: seedling growth, harvest impacts and geographic variation in demography. Université Laval, Département de Biologie, Québec City, Québec.

Must one travel the high or low road? What about the middle? From motor boat to knee pads: How birds led me to plants. Expanding Your Horizons Workshop. Orono, ME, 1998.

Crazy for Caffeine: Are migratory birds coffee drinkers? University of Maine, Wildlife Ecology Seminar Series, Orono, ME, 1998.

Habitat associations of American ginseng (Panax quinquefolius L.). Ginseng Workshop, Morgantown, WV, 1997 